\title{
A Critical Analysis of Civil Service Reform Program in Ethiopia
}

\author{
Meskerem Legesse Fetiya Ahmed Selamawit Wudneh \\ Addis Ababa University, College of Business and Economics, Department of Public Administration and \\ Development Management, Ethiopia
}

\begin{abstract}
The purpose of this study is to critically analyze the civil service program of Ethiopia with special emphasis on challenges and major achievements. In order to gather relevant data Secondary data were used as a main source of data. The secondary data includes; report, manuals, internal publications, journals and books. Studies conducted in CSRP indicated that some of the reform successes registered in some selected organizations was attributed to the competence and dedication of their leadership. However, many of the organization leaders in the civil service were believed to have blurred view about the mission and goal of CSRP. The study recommended that Ministry of Civil Service should make the reform internally identified and home grown to take the advantage from the implementation of the program.
\end{abstract}

Keywords: Civil Service, Civil Service reform

DOI: 10.7176/PPAR/9-1-01

\section{INTRODUCTION}

To increase efficiency and effectiveness of government institutions in Ethiopia and to create conducive environment for investment and economic growth, the public sector has gone through a series of reform processes. In recognition of the multifaceted problems facing, the Government of Ethiopia launched fourteen national capacity building reform programs (NCBRP). From fourteen NCBRP six of them directly involved in public sector which has got attention to rapidly scale up under a consolidated five year federal program called public sector capacity building program / PSCAP/. These are; (i) Civil Service Reform Program (CSRP); (ii) District Level Decentralization Program (DLDP); (iii) Urban Management \& Development Programme (UMCBP); (iv)Tax System Reform Program (TSRP); (v) Justice System Reform Programme (JSRP); (vi) Information and Communication Technology (ICT) (CSRP ,2004).

The Civil Service Reform Program is a subset of a broader program of political, economic and administrative reforms intended to build national capacity for the realization of socio-economic development goals and objectives. Overall, it focuses on improving the scale, efficiency and responsiveness of public service delivery at the federal, regional and local level; to empower citizens to participate more effectively in shaping their own development; as well as to promote good governance and accountability (ibid).

Civil Service is the operational arm of the government charged with the implementation and administration of public policy (Atkilt 1996), must keep pace with the changing times in order to meet the aspirations of the people. The purpose of reform is to reorient the Civil Services into a dynamic, efficient and accountable apparatus for public service delivery built on the ethos and values of integrity, impartiality and neutrality. Thus, the impetus of Civil Service reform is to raise the quality of public services delivered to the citizens and enhance the capacity to carry out core government functions, thereby, leading to sustainable development. Hence, the government of Ethiopia through its Public Service Reform Programme continues to improve and modernize its systems to support the development of the country and provide timely and high quality services to all customers. The latest development in this process is the introduction of the civil service reform.

To this effect, Ethiopian Government has taken the initiative to build the capacity in all the regional states of the country:

$\checkmark$ To shake off basic weaknesses ingrained in the existing Civil Service inherited from the past regime

$\checkmark$ To build the capacity of the Civil Service so that it will execute the policies and programs of the government successfully

$\checkmark$ To facilitate the Civil Service to provide efficient and fair services to the public

$\checkmark$ To enhance transparency and accountability in the Civil Service

$\checkmark \quad$ To build a Civil Service that stands for gender and ethnic equality and rights

$\checkmark$ To build a Civil Service that is ethically sound and free of corruption, nepotism, and favoritism

Generally, the study critically analyzes the Civil Service Reform Program of Ethiopia with special emphasis on Challenges and Achievements.

\section{Justification of the Paper}

It is apparent that efficient and effective civil service sector that plays a major role for the development of a nation in all dimensions. In other words, civil servants are an engine who mobilizes resources of a country to the direction of functional activities. However, this sector cannot play its decisive role in traditional and back ward 
management systems unless it is updated and reformed to the changing circumstances. In most developing countries including Ethiopia, traditional management techniques play immense ingredient that influence working cultures almost in all sectors.

The Civil Service Sector in Ethiopia has been bewildered in a number of problems and challenges over the past years. Many scholars have raised different issues that might have attributes to the root problems in the Ethiopian Civil Service Sector. Government has also undertaken several measures to this end despite the implementation and design of programmes as well as the inception and selection of programmes have been arguably too restrictive.

The Ethiopian Civil Service Reform Programme is one effort by the government implemented to alleviate some of the problems associated with low level of service delivery in the Ethiopian Civil Service which is characterized by high inefficiency and ineffectiveness. The rationale behind this study is to show case the historical back ground of civil service sector in Ethiopia, discuss on the theoretical background, present overview of the current Civil Service Reform including the major challenges and problems faced to come to a reasonable conclusion up on which recommendations are made. In addition to this, the study critically analyses the procedures that a concerned body follow while developing a certain programme.

Accordingly, this study is meant to address the following questions through the literature and critical analysis:

1) Why the Civil Reform Program is designed and who is responsible for implementing the Program?

2) What are the causes behind the design of the Program and how the program contributed to the modernization of the civil service in Ethiopia?

3) What are the achievement and challenges of implementing Civil Service Reform Program of Ethiopia?

4) Does the Civil Service Reform Program of Ethiopia achieve the gap for which it has been designed?

\section{Objective of the study}

\subsection{General Objective}

The general objective of the study is to critically analyze the civil service Reform Program of Ethiopia.

\subsection{Specific Objective}

The study has also the following specific objectives:

1) To identify the reason and responsible body for the implementation of the Civil Service Reform Program in Ethiopia

2) To identify the rationales behind inauguration and contribution of the Program to the modernization of civil service in Ethiopia

3) To critically analyze the achievements and challenges of the civil service reform program in Ethiopia

4) To analyze whether the civil service reform program positively contributed towards filling the public sector gap

\section{Methodology of the Paper}

The paper is descriptive type of study which contains qualitative type of data. Secondary data is used as a main source of data; Report, manuals, internal publications, journals and books are used to assess theoretical and practical aspect of civil service reform in Ethiopia. Finally descriptive analysis is made by considering both theoretical and empirical literature for having critical analysis and extensive study on civil service reform program in Ethiopia.

\section{Result and Discussion}

\subsection{Critical Analysis of the Civil Service Reform in Ethiopia}

\subsubsection{Main Features of civil services reform before and After Implementation}

The Task Force which was constituted to investigate the existing gaps and problems in the public sector came up with certain report which indicated the following findings:

$\checkmark$ Management concentrates on the administration and control of inputs and activities rather than achievement of government policy objectives;

$\checkmark$ Management systems are outdated and unable to respond to the changing environment in which the Civil Service operates;

$\checkmark$ The public's perception of the bureaucracy was one of a hindrance than a facilitator and called for changes in rules, regulations and practices which were inherited from the past;

$\checkmark \quad$ The Civil Service was under-resourced in terms of manpower and budget. Recurrent budget on Civil Service and the number of civil servants per 10,000 population was among the lowest in the world;

$\checkmark$ The entrenched organizational culture is such that concentration of powers at the higher level of the Civil Service hierarchy poses serious problems of delegation; 
$\checkmark$ Staffs are under-paid and under-rewarded and hence the system does not attract and retain skilled manpower. Conversely, it has given rise to corruption and unethical practices.

The above bullet points serve as the basis for evaluating the performance of the programme notwithstanding the concern of the process through which these findings sprang up. This also pegs the question as to how these findings comprehend the overall all panorama of the civil service saga in this country covering all the possible challenges and problems to be addressed through informed policy adoption, programme design and implementation.

The first finding emphasizes on the concentration of the bureaucracy in the administration and control of inputs and activities rather than achievement of government policy objectives. Business Process Re-engineering (BPR), Result Oriented Performance Appraisal and other recent developments, notably, the adoption of the Balanced Score Card (BSC) and KAIZEN (Continuous Improvement) scheme were the efforts exerted through the program to align public discourse and implementation with national goals; albeit the existence of reservations from different scholars on their impact.

The noble intention of having free and neutral civil service where the civil servants serve the people rather than ruling parties without tampering the political will and leverage is seriously impeded by high politicization and patronage systems. Recent, practices show that civil servants are being appraised not only in terms of their contribution to the achievement of corporate goals but also to their political views.

Another finding indicated that the management systems are outdated and unable to respond to the changing environment in which the Civil Service operates. Institutionalization of strategic plans in the public sector and the implementation of the Business Process Re-engineering has created a space for improving the management system by creating means for transparency and accountability. As such the civil service before the programme was limited in differentiation and has a centralized outlook. This was resolved in the current decentralized arena as the contemporary system allows for the existence of management at different levels including ministerial offices, directorates, departments, units and teams.

The third finding that the public's perception of the bureaucracy was one of a hindrance than a facilitator and called for changes in rules, regulations and practices which were inherited from the past is something that calls for systematic intervention. The program does so by providing certain changes in policies, regulations, guidelines and the likes however fails to change the attitude of the public perceiving the bureaucracy as a fence hindering them to get their rightful services. Highly corrupt and inefficient officials and technocrats make the provision of descent services impossible as they hustle to satisfy their greed than the interest of the general public.

The findings of the task force also concluded that the Civil Service was under-resourced in terms of manpower and budget. Recurrent budget on Civil Service and the number of civil servants per 10,000 populations was among the lowest in the world. Current government figures show that there is a tremendous increment in the number of public servants. The civil service structure, however, is literally a transit place for professionals to get employment elsewhere which provide better payment. This is because the current civil service pay scale is very low compared to the living standard in the country. As a result, the civil service is a place for incompetent and ineffective personnel making it very difficult to achieve corporate goals.

Concentration of power at the top is one of the finding among study results on the former civil service. This type of centralized civil service system is resolved by decentralization of power at all level. As a result this brings improvement in the process and delivery of services by empowering the lower unit of the system, reducing stapes and procedures of service delivery and rapid decision making.

Concerning the last finding of the study which is under-payment and under-rewarded Staffs, the system does not attract and retain skilled manpower. Conversely, it has given rise to corruption and unethical practices. One of the effort made to overcome this problem is salary increment even if it doesn't solve the problem. Many authors agreed up on remuneration of civil servants is very much below the minimum standard of living in the cities and is lower than what they could earn in other sectors. It is significantly lower than the non-government sector resulting in an irreversible brain drain. Another challenge that arises from this is the fact that there is no differentiation between the core civil service and public service employees such as teachers, health workers and agricultural extension workers; making the civil service unmanageable. Under such conditions corruption get the great place to spread throughout the public sector and manipulate public resources.

\subsubsection{Major Achievements of the Civil Service Reform in Ethiopia}

The following are some of the major achievements of civil services reform in Ethiopia which include:

\section{The Institutionalization of Strategic Plans in Public Sector Institutions}

Public sector institutions have started to align their visions and missions with the national vision and to design their annual operational plans with the view to contribute their respective share to the attainment of institutional and national vision. As a result, the concept and application of strategic thinking, priority setting and rational resource allocation are taking stronghold in the public service. 


\section{The Initiation of Business Process Reengineering (BPR) in the Public Sector}

In an effort to bring about dramatic changes in operational efficiency and effectiveness and increased customer needs satisfaction, civil service wide BPR initiatives were launched in 2005. Although a majority of the BPR exercises are still in progress, anecdotal evidence and a few research and survey results strongly indicate that the number of institutions where dramatic changes in performance are taking place is growing. A sampling of a few cases would suffice to demonstrate the case. According to a recent study commissioned by the World Bank the Federal Investment Agency (FIA) has drastically reduced the cycle time of its major operations, providing a more conducive environment for foreign and domestic trade and investment.

Finalization and Roll-out of A Results-Oriented Performance Appraisal System (ROPAS)

One of the most important goals of the civil service reform is to establish a results-oriented performance management culture. Over the past years various performance management models were reviewed for adoption and some were even pilot-tested. Currently, the performance management system based on Balanced Scorecard is adopted and being pilot-tested in selected federal institutions before civil service wide roll-out.

\section{Completion of Roll-out of New and Improved Financial Management Systems}

Roll-out of budgeting, accounts, cash and asset management, internal audit systems and procurement to the emerging regions excepting Somali Regional State, were successfully undertaken. After much delay in consultancy procurement the reform work on Integrated Financial Management System (IFMIS) is now underway. The EMC sub-programme has resulted in significance improvement in the use of double-entry accounting, ICT assisted accounting, regularity of reconciliation of fiscal and bank records, reducing of accounts backlog and the state of internal and external auditing of the books (The World Bank, 2006).

Continued Measures Taken to Improve Accountability and Transparency

Comprehensive external audit operational manuals and standards pertaining to financial, performance, control and fraud audit fulfilling international standards and practices were developed and implemented. Ethiopian Code of Ethics for Professional Accountants was issued in 2005 by the Office of the Auditor General (OFAG) although oversight of adherence to the code is constrained because of shortage of staff. The Federal Ethics and Anti-Corruption Commission (FEACC) in addition to its continuous conduct of popularization and sensitization programmes through the media, has as of recent months intensified its crack-down on offenders and has filed lawsuits against 405 public officials and managed to have over 100 of them sentenced to do time in jail ranging between 18 years and eight months. Regional EACC's are also taking tougher measures against corruption.

\subsubsection{Challenges of Civil Service Reform in Ethiopia}

In spite of the significant growth of the concept the civil service not all organizations embarking on civil service reform projects achieve their intended results. Civil Service rules by themselves will not lead to good governance if they are not backed by political will and the preparedness of government to impose total adherence to these rules to promote public good.

There are multiple challenges in every reform. However, to be successful in any reform process the organization should identify challenge and forward appropriate solution. Paulos in his study (2001), has identified the major challenges that faced during the process in the civil service reform. As he suggested possible solutions and achievements are not achieved without any challenge in CSR. Further, he argues that Organizational leaders, steering teams, redesign teams and change agents have passed through many challenges at different times and in different processes of the CSR. These are:

\section{Misconceptions about civil service program or attitudinal problem:}

Misconceptions and attitudinal problems include: not understanding civil service reform in its entire sense and attempts to restructure departments; weakness or unwillingness to sense and internalize the need for change; complacence with the status quo; relating civil service only with downsizing and turning once back to the concepts and empirical evidences. According to him, the framework of the civil service reform emphasized that the need for more attitudinal changes rather than reinforcing or strengthening the existing organizations, structures and methods. He argues that in Ethiopia the civil servant seems pessimistic about the whole reform process. In order to tackle these problems there should be necessary motivating measures such as competitive salary and benefit schemes for the civil service that hardly exist. If these preconditions are not fulfilled for the civil servant, one may wonder how the reform measures, especially in service delivery and ethics are going to be implemented. Ataklit(1996), in his finding, he mentioned that the objective of the civil service reform is not layoffs but to deliver public service in the right manner. In cases where the capabilities of some public servants do not fit the requirements of the new jobs, the government has promised to pay their salary until another job is found for them (with or without retraining); or until they find other jobs by themselves, or until they are trained and organized to start their own business (with financial accommodation by the government). For the aged civil servants, retirement is another option.

\section{Absence consolidated bureaucratic structure with competent personnel:}

According to Ataklit(1996), there is a serious problem or shortage of a professionally recruited and trained staff. The administrative performances in delivering public services are very poor which resulted from absence of 
well-developed administrative system. But the whole civil service forced to move blindly from one to another end. To alleviate, he proposes that before implementing the whole concepts or elements of NPM there should be essential background work in capacity building and in other areas of administration.

Limited Commitment among Some Organizational Leaders (at early stages):

Lack of such commitments and poor communication has been revealed through: lack of adequate knowledge on the concepts of business process re-engineering (BPR); putting the change agenda aside or giving it as an assignment to others; not cooperating with the assigned change agents (consultants); not assigning the best people for reengineering teams; inadequate follow up and weak support. To overcome these obstacles, the leadership at Ministry of Capacity Building has made discussions with the top leadership of such organizations and reached at consensus. Such measure has improved the problem of what in most circumstances happen in public institutions.

\section{Poor Communication:}

The BPR framework requires communication with employees, customers and stakeholders throughout the various phases of the project cycle. Due to lack of formal communication (especially in the middle of the project), however, confusion and rumors among employees have been common in many public institutions.

\subsubsection{Problems and Challenges of Ethiopian CSRP Implementation}

A number of problems and challenges have been encountered during CSRP implementation among which the following are the major ones:

\# Sustaining top leadership's commitment and ownership of the CSRP process.

* The delay in design and application of the Institutional Transformation Model and the resulting duplication of work that followed in BPR undertakings.

* Shortage of competent and committed professionals that could provide technical support to federal and regional civil service institutions.

* The delay in the completion of some critical reform studies which could support the speedy implementation of CSRP because of delays in consultancy procurement and lack of proper follow-up.

* The inability to adequately and effectively popularize the positive gains of the reform and countering covert and overt resistances to change because of serious constraints in information, education and communications (IEC) capacity and capability.

* Absence of accountability framework whereby institutional leadership could be held responsible rewarded for good performance and penalized for poor performance.

\section{Conclusion}

From the commencement of the implementation of civil service reform program in Ethiopia, the public service delivery reform objectives wanted to achieve efficiency and effectiveness, render better quality services and be accountable for its failure, produce committed citizen and to bring attitudinal change. The implementation of the civil service reform program covers a lot of things that will change public institutions in the provision of services. After the implementation of the service delivery reform changes have come in Ethiopia. Delay in service delivery has been reduced to certain extent and customers' satisfaction has improved. It is also important to note that changes in public service lack sustainability. This is because of the problem faced while implementing the program.

The civil services reform implementation in Ethiopian has faced different challenges at the beginning awareness creation is not well done by the responsible body which create confusion and misunderstanding about the reform. Not only this but also different challenges has become a bottleneck for successful implementation of the reform like Challenges related with the attitude of service provider and service seeker, Challenges related with qualification of civil servant, Limited commitment of the civil servants, Absence of well-developed bureaucracy and problems related with tools of implementation, Poor communication, Resistance to Change and etc.

Studies conducted in CSRP indicated that some of the reform successes registered in some selected organizations was attributed to the competence and dedication of their leadership. However, many of the organization leaders in the civil service were believed to have blurred view about the mission and goal of CSRP. Therefore, Ministry of Civil Service should work hard to take the advantage from the implementation of the program.

Finally it needs to be said that the problems in ministry of civil service require thorough diagnosis and sustained thought about the way to bring about attitudinal changes. The reform measures need to be executed incrementally through identifying priority areas in the light of the capacity to implement the measures.

\section{Recommendation}

In order to alleviate or reduce the problems the following recommendation are forwarded.

* Ministry of Civil Service should be concerned with the general human resource policies and designing 
systems and organizational structure of government offices. This requires enhancing the human resource of the ministry with well qualified and well-paid organizational experts. Because knowledge obtained in academics becomes worthless unless it is supported by favorable working environment.

* Civil servant should be trained on regular basis. Such training should be deliberately planned, made compulsory and geared towards the achievement of specialization and professionalism.

* The appointment into civil service and promotion must be based on merit and qualification instead of political commitment alone and the civil service should be made attractive in all respects, and accorded greater recognition and responsibility.

* Civil servant should be motivated to stimulate them to contribute efforts, because individual productive capacity depends very largely on one's level of psychological satisfaction. This will increase the level of commitment, hard work, creativity and disposition among the civil servants. In addition to this it is important for the administration to strive to improve employees' remuneration and rewards to make them more committed.

* The government should ensure the existence of effective communication and coordination of reform activities. This should start from initiating reform goals and objectives and maintaining them in a sustainable manner both for reformers and those affected by the reform outcomes.

\section{References}

Atkilt, A. (1996), Civil Service Reform and Administrative Modernization, in Merit (A Quarterly Bulletin of the Ethiopian Civil Service Commission).

CSRP (2004), Civil Service Reform program in Ethiopia. Ethiopia: Addis Ababa.

PaulosChanie (2001), "The Challenges of the Civil Service Reform In Ethiopia: Initial Observation", Eastern Africa Social Science Research Review, Vol. XVII No.1.

World Bank, (2006), Civil Service Reform; Strengthening World Bank And IMF Collaboration; Washington: Library Congress Cataloging-In-Publication Data. 


\title{
Performance Evaluation of Public-Private Partnerships in Health Sector of Pakistan
}

\author{
Nasir Abbas \\ Institute of Business Administration, University of the Punjab, Lahore, Pakistan \\ Jafar Hussain \\ Hailey College of Business Administration, University of the Punjab, Lahore, Pakistan \\ Talat Islam \\ Institute of Business Administration, University of the Punjab, Lahore, Pakistan \\ Dr, Zeshan Ahmer \\ Institute of Business Administration, University of the Punjab, Lahore, Pakistan
}

\begin{abstract}
The current study aimed to evaluate the performance of hospitals working under public-private partnership (PPP) using Marshall and Hays model. The model of Marshall and Hays proposed five elements i.e. patient care, doctor's behavior, financial assistance, technical quality and accessibility that influence hospital performance. We adopt this model to explore the hospital's performance working under PPP in Pakistan. Data were collected from 384 patients from the hospitals working under PPP. The findings of the current study show that patient care, and accessibility of healthcare services to the patients positively influence the performance of publicprivate hospitals. The results of the study have significant theoretical and practical implications.
\end{abstract}

Keywords: PFI Model, public private partnership, hospital sector, technical quality

DOI: $10.7176 /$ PPAR/9-1-02

\section{Introduction}

Historically, service delivery for health care systems is controlled by governments as it is considered the prime responsibility of the government in the country. As the population is growing, the government bodies are finding it difficult to provide quality healthcare services to the masses. The cost for the delivery of appropriate health care services is also increasing. Globally, a major portion of the federal budgets are allocated for the betterment of the public health care, yet there are issues with the efficiency of the systems and the patients face problems. The government initiated several programs to improve the delivery of health care service to the general public, such as public-private partnerships. Public-private partnerships are demand-driven, market-based arrangements to satisfy unmet needs (Savas \& Savas, 2000); the arrangements are made between the government and the private sector for the betterment of public services. The funds generate under Public-private partnerships generally provide used for the construction of infrastructure, improvement of technical facilities and healthcare services.

The idea of public-private partnerships has gained popularity around the globe, majorly focusing on transportation sector and health sector. The advantage of this idea was to save investment of state in providing the facilities to the people of the country while the payback period to the investor was spread over a longer period of time. The projects of public-private partnership in healthcare sector had also faced failures. In some cases, the partners faced financial stress causing the finance issues leading to failure. Also, there were reported issues regarding service quality (Barlow, Roehrich, \& Wright, 2013).

In Pakistan, public-private partnership experiments in some sectors in last few years. The sectors participating in public-private partnership mainly include transport, road infrastructure, sports infrastructure, housing projects, wastewater treatment plants, education, and healthcare. International funding agencies are also showing interest to support the projects involving public-private partnerships e.g. Asian Development Bank. Public-private partnerships in health care are managed through the ministry of health both at federal and provincial levels. The nature of collaboration in the healthcare sector is mainly in financing and healthcare provision. The regulatory role lies with the government.

The health infrastructure of public sector institutions is deteriorating and the private sector facilities are out of budget for the common people. In Punjab, the work has started in this dimension since 2008 with the partnerships with the private sector of Turkey and NGO's. The restructuring of health facilities is already taking place within different provinces. The current research tries to evaluate the performance of few selected hospitals being run under public-private partnership using five dimensions chosen from the literature.

The primary aim of the study is to evaluate the performance of hospitals working under the public-private partnership model. The study also aims to evaluate the effect of various factors contributing towards hospital 
performance. In this regard, a model developed by Marshall and Hays (1994) has been adopted to identify the important factors that ascertain a hospital's performance. Five factors have been identified in this model, i.e. patient care, technical quality, financial aspects, doctors' behavior and accessibility.

\section{Literature Review}

Pakistan ranked as emerging economies by IMF in 2016, yet there is lack of basic facilities especially regarding education, transportation, and health. These are emerging issues in all province of Pakistan. Many people are deprived of health and education facilities. This is mainly due to overpopulation, corruption, and missmanagement that is resulted in poor performance of the public sector in the country. There are two classes of people in Pakistan; one is an elite class who enjoys the health facilities of private sector hospitals and another one is middle and lower class who are dependent on public sector health facilities. The public-private partnership is introduced to provide better facilities in the healthcare sector.

The rising demand and increased expenses for health service delivery are stressing health service delivery frameworks around the world. Tending to these difficulties is overwhelmingly an issue for governments, as most health service delivery systems today stay inside the administrative control (Sapri, Hariati, Ting, \& Sipan, 2016). By enlarge, governments' initial step is to consider how public hospitals specifically, are financed and operated, since, in most nations, public hospitals and the individual auxiliary administrations represent the major portion of healthcare spending. Intending to this issue, governments are progressively considering different models of private division support, frequently alluded to as Public-Private Partnerships (PPPs). Such courses of action progressively offer a feasible way to deal with controlling costs, improving service quality and even expanding access to the general public (Kinlaw, 2008).

A Public-Private Partnership (PPP) refers to as a legal contract/agreement between a public organization and a private sector entity in which both parties have settled to work together in initiating a program and that each party has a clearly defined role and say in how the enactment occurs.

(Balgescu and Young, 2005). Under the PPP contracts, both parties share assets for the development of infrastructure and facilities for the benefit of the general public. In addition to the sharing of assets, each party shares the potential threats and rewards associated with the investment in a particular program (Cruz \& Marques, 2013).

Through this plot, the government has endowed the private sector with the obligation of planning, financing, building, and working with public entities. As indicated by Yescombe (2011) private sector organizations have a more noteworthy aptitude for the management of complex ventures, are proficient in conveying them on time and budget. In addition, private entities are capable of maintaining and improving the performance. In this manner, PPP is considered as a compelling way to improve venture profitability through administrative proficiency and creative abilities from business practice.

Every country's approach to PPP to achieve the policy objectives of its government and to enhance the quality of basic services to the general public. PPPs for the betterment of the better health services of the general public can apply to a variety of activities. For instance, major infrastructural changes to providing support services such as lab analysis, up to the management of a hospital or building and maintaining a network of hospitals and clinics. The three most common models for hospital PPPs are PFI (Private Finance Initiative) Model, OS (Organization Social) Model and Concession Model (Kinlaw, 2008). The details of three models are given below:

\section{PFI Model}

PFIs commonly include government giving contracts to private organizations for the development and support of hospitals and related facilities, with installments spreading equitably for a long period of time over 20 to 30 years. The PFI model is perfect for land ventures where the government has ceaselessly underfunded the infrastructure and equipment. PFIs can be a vehicle for government sector to work with the private division in a politically acceptable way. A noteworthy advantage is equitable cost dissemination over a long time period. However, the PFI model is very weak as a means to implement true reform as the emphasis is on new facility development. In PFI model, the service delivery component remains under public control (Kinlaw, 2008).

\section{OS Model}

The OS model is a type of management where infrastructure and facilities (new) are provided by the government, and service delivery, including all work of therapeutic and support staff, is contracted to a nonprofit association. This model has various characteristic qualities including giving full control to the contracted party over managing the workforce and full control over buying (Kinlaw, 2008).

\section{Concession Model}

Concession model is basically a coordination of the two models above, including either development (or redesign), and operation of a medical facility. The key quality of the concession model is that the private supplier's price t commonly satisfies the venture needs. Like the OS Model, the concession model considers full control over staff and full control over buying. However, the concession model is the most politically 
troublesome to execute (Kinlaw, 2008).

With every model of PPPs, there are some key challenges involved. These may include lack of ability of government to enforce contracts with the private sector, a restricted pool of solid bidders as there are only a couple of worldwide hospital management organizations and no availability of local suppliers with operational experience, political risk that another/ new political party may not value working in collaboration with the private sector, funding risk that payments get delayed and cause liquidity issues etc. (Pasha \& Nasar, 2003).

However, PPPs, if implemented by addressing the pre-requisites can yield certain benefits as PPP is an arrangement where both parties-public and private are responsible for designing, financing and managing public facilities for a time period of 20-30 years (Sapri et al., 2016). The ultimate objective is to achieve Value for Money (VFM) that is the combination of costs, benefits, risks, and quality of services provided. VFM is based not only on the minimum purchase price but also on the maximum efficiency and effectiveness of the purchase (Akintoye, Beck, \& Hardcastle, 2008). PPPs also contribute by guaranteeing the sustainability of projects by improving the abilities of local associations, and by expanding the community's approach to the capability and proficiencies of the private sector. Through PPPs, the reach of the health interventions extends to a wide range of population (through national healthcare programs) and project costs are shared through additional contributions of associated partners which generally would be past the reach of implementers (Goel, Galhotra, \& Swami, 2006).

\section{Hypotheses development}

The model is adapted from Marshall and Hays (1994). The dimensions are patient care, technical quality, financial aspects, doctor's behavior and convenience provided to the patient. The dimensions are observed variables while Performance of public-private partnership is evaluated as the latent variable.

Patient care is reflecting the medical care that patient is receiving including minimum waiting time, treating a patient with respect, a thorough examination of the patient and explaining the reasons for any tests or medicines prescribed. Technical quality includes the infrastructure, diagnosis facilities and quality of doctors. Financial aspects refer to whether there is an additional financial burden on the patient or the facilities provided in the hospital are sufficient enough to cover the needs of the patients. Doctor's behavior with the patients is the key to providing quality service to the patients. The last dimension is easy accessibility for the patient to the services offered by the hospital.

The conceptual model is presented in Figure 1.

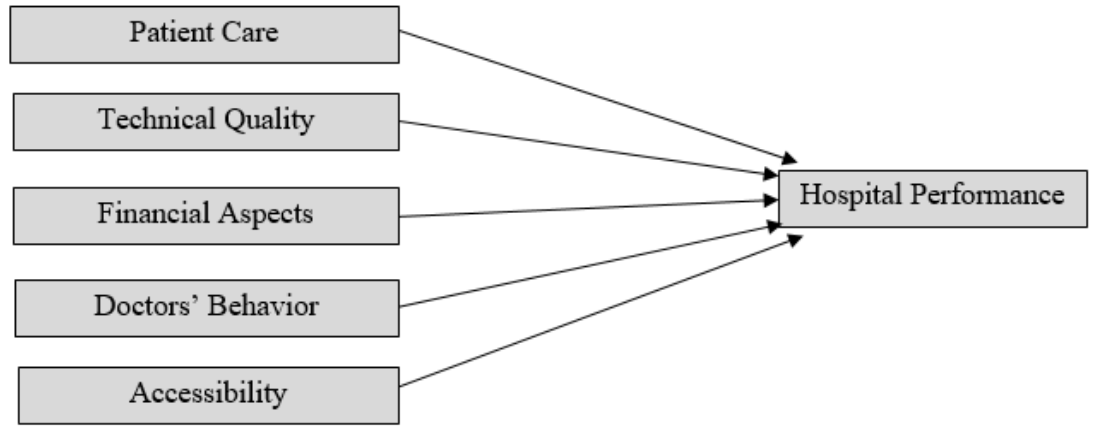

Figure 1. The Conceptual Model

Adopted from Marshall and Hays (1994)

\section{Hypotheses}

The hypotheses for the study are devised as under:

H1: Patient care has a positive and significant impact on hospital performance.

$\mathrm{H} 2$ : Technical quality has a positive and significant impact on hospital performance.

H3: Financial aspects has a positive and significant impact on hospital performance.

H4: Doctors' behavior has a positive and significant impact on hospital performance.

H5: Accessibility has a positive and significant impact on hospital performance.

\section{Methodology}

The population for this study consist of the hospitals working on a public-private partnership in Pakistan. There are over hundred hospitals working under public-private partnership. For this study, a sample of eight hospitals from four provinces of Pakistan was approached for data collection. The provinces include Punjab, Khyber Pakhtun Kha, and Baluchistan. This is a limitation to visit only eight hospitals as the approach to remote areas is difficult and also expenses of data collection will go beyond the resources.

The selected hospitals were visited to gather data. A questionnaire was designed for this study. Patients of 
the hospitals were approached and were requested to fill in the questionnaire voluntarily. As the total population was unknown so the sample size was calculated using the available online free calculator with $95 \%$ level of significance and 5\% margin of error (Hulley, Steven, Browner, Grady, and Newman, 2001). According to the formula, 384 respondents were appropriate for data collection. Therefore, a total of 384 questionnaires were distributed to collect the data. While collecting data, both indoor and outdoor patients were included in the sample. The following Table 1 presents the details of selected hospitals for this study.

Table 1 Hospitals Working under Public-Private Partnership Selected

\begin{tabular}{clll}
\hline Sr. No. & Hospital Name & \multicolumn{1}{c}{ City } & \multicolumn{1}{c}{ Province } \\
\hline 1 & Ayub Hospital & Abbottabad & KPK \\
2 & Civil Hospital & Quetta & Baluchistan \\
3 & District Headquarter Hospital & Sahiwal & Punjab \\
4 & District Headquarter Hospital & Zhob & Baluchistan \\
5 & Jinnah Hospital & Lahore & Punjab \\
6 & Khalifa Gul Nawaz Teaching Hospital & Bannu & KPK \\
7 & Lady Wallington Reading Hospital & Peshawar & KPK \\
8 & District Headquarter Hospital & Khuzdar & Baluchistan \\
\hline
\end{tabular}

The collected data from the above-mentioned hospital was entered into Microsoft Excel for data analysis. This excel file was used to apply statistical tests using SPSS and AMOS. The tests included reliability analysis, descriptive statistics, exploratory data analysis, correlation, and regression.

\section{Data Analysis}

Reliability

Table 2 Reliability

\begin{tabular}{lcc}
\hline Factors & Cronbach's Alpha & Number of Items \\
\hline Patient Care & 0.95 & 4 \\
Technical Quality & 0.55 & 3 \\
Financial Assistance & 0.85 & 3 \\
Doctors' Behaviour & 0.66 & 3 \\
Accessibility & 0.94 & 4 \\
Performance & 0.92 & 2 \\
\hline
\end{tabular}

To check the reliability of questions and scales, Cronbach Alpha text was the results shows the high validity of scales and data except for the factor technical quality (0.55) and Doctor's behavior. For patient care, performance and accessibility the results are highly satisfied with the Alpha value of more than 0.90 .

Descriptive Statistics

Data was collected from 8 different hospitals across Pakistan. 12\% responses were taken from Ayub Hospital, 20\% from Civil Hospital, 9.60\% from District Headquarters Hospital Sahiwal, 20\% from District Headquarters Hospital Zhob, 3.60\% from Jinnah hospital, 12.80\% from Khalifa Gul Nawaz Teaching Hospital, 10.00\% from Lady Wallington reading Hospital and 12\% from District headquarter Hospital Khuzdar.

Responses were taken from eight different cities of Pakistan. 12\% responses were from Abbottabad, 20\% from Quetta, 9.60\% from Sahiwal, 20\% from Zhob, 3.60\% from Lahore, $12.80 \%$ from Bannu, 10\% from Peshawar and $12 \%$ from Khuzdar.

Above demographics are showing that the data were collected from various clusters to have more generalized data and to increase the validity of results. $14 \%$ responses were taken from Punjab, 35\% from Kpk and $50 \%$ from Baluchistan. $49.40 \%$ respondents were male patients and $50.60 \%$ was taken from indoor and outdoor female patients.

$16.20 \%$ patients were under age group from 21 - 25 years, $14.40 \%$ from $26-30$ years of age, and $20.20 \%$ from 31-35 years of age, $23 \%$ from $36-40$ years of age, $12.60 \%$ from $41-45$ years of age, $7.60 \%$ from $46-50$ years of age and $3.80 \%$ from $51-55$ years of age.

It was also kept in mind that the responses should be from various educational stratum. 11\% patients are masters qualify, $17 \%$ are bachelors qualify, $15 \%$ were intermediate qualify, $25.20 \%$ were matriculation qualify and $32.30 \%$ were under matriculation qualify.

Data was taken equally from rural and urban areas; $56.8 \%$ from rural areas and $43.20 \%$ from urban because rural and urban patients have a different perspective of hospital performance.

\section{Correlation}

The coefficient of correlation was calculated which depicts significant relation between independent variables and dependent variable. Results are quite astonishing because it shows negative relations between two independent variables which were proposed positive in the model. Significant correlations between independent variables were also found which a disturbing factor is. The researcher needs to revise the proposed model, should collect the more data or maybe the scales and questions need to be changed. These results are demanding a 
multivariate model.

The coefficient correlation between Patient care and performance is $0.929,0.880$ between Financial assistance and performance, 0.926 between accessibility and performance, -0.861 between technical quality and performance and -0.776 between doctors behavior and performance. These results are against our prepositions. We need to change our data and collect responses again. The other correlations are also showing covariance among independent variables.

\section{Table 3 Correlation Matrix}

\begin{tabular}{|c|c|c|c|c|c|c|}
\hline Sr. No & Constructs & 1 & 2 & 3 & 4 & 5 \\
\hline 1 & Patient Care & 1 & & & & \\
\hline 2 & Technical Quality & $-.891^{* *}$ & 1 & & & \\
\hline 3 & Financial Assistance & $.915^{* *}$ & $-.871^{* *}$ & 1 & & \\
\hline 4 & Doctors Behaviour & $-.788^{* *}$ & $.794^{* *}$ & $-.756^{* *}$ & 1 & \\
\hline 5 & Accessibility & $.939^{* *}$ & $-.896^{* *}$ & $.917^{* *}$ & $-.772^{* *}$ & 1 \\
\hline 6 & Performance & $.929^{* *}$ & $-.861^{* *}$ & $.880^{* *}$ & $-.776^{* *}$ & $.926^{* *}$ \\
\hline
\end{tabular}

**. Correlation is significant at the 0.01 level (2-tailed).

Path analysis diagram was also made via SEM and CFA

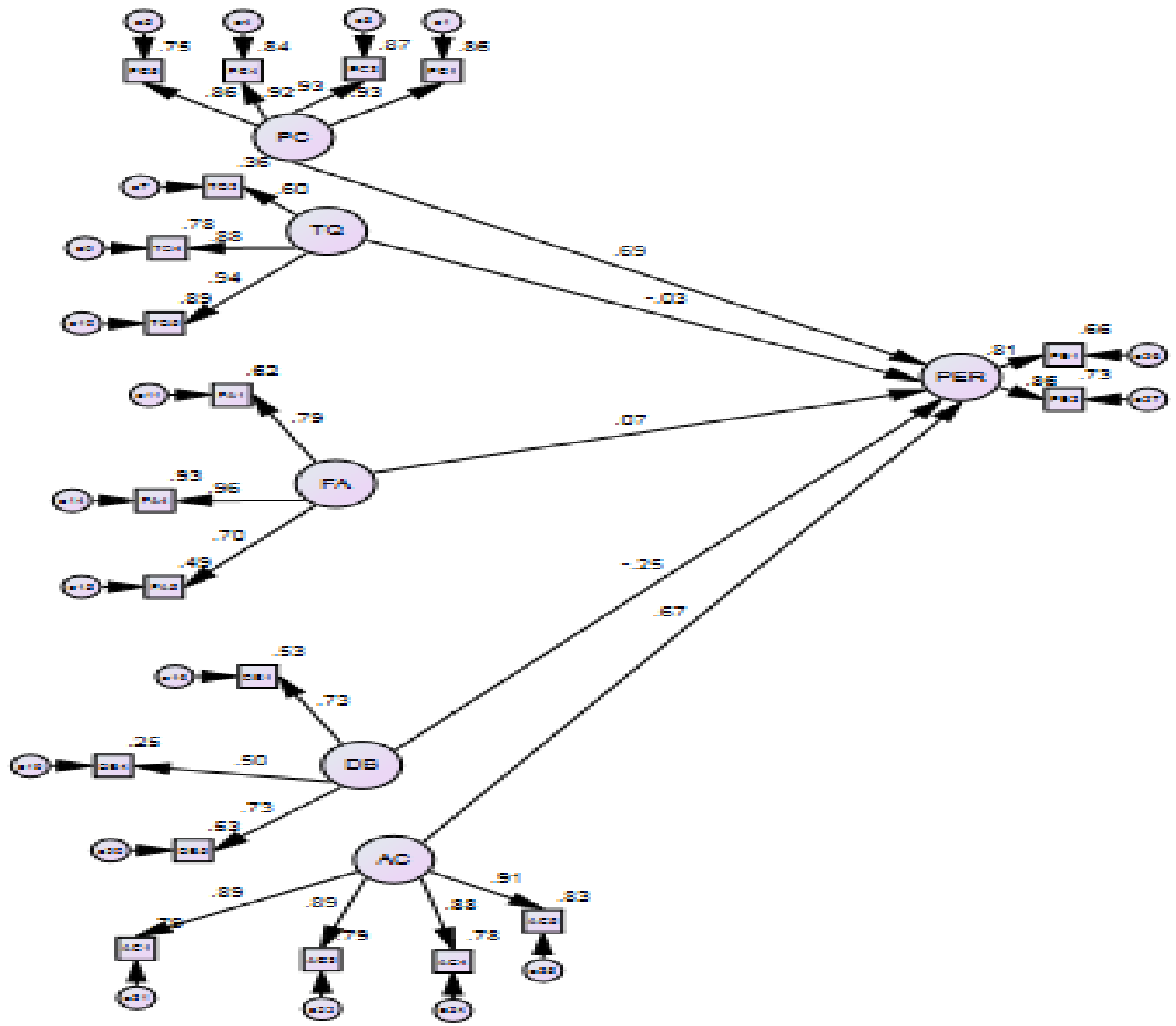

Figure 1-AMOS Results

\section{Model Fit Indicators}

Table 13-Model Fit Indicators

\begin{tabular}{|c|c|c|c|c|}
\hline RMSEA & GFI & CFI & DF & Chi Square \\
\hline 0.246 & 0.512 & 0.623 & 148 & 4618 \\
\hline
\end{tabular}




\section{Regression Estimates}

Table 14-Regression

\begin{tabular}{|ll|c|}
\hline & & Regression Estimate \\
\hline PER <--- & PC & $.69 * * *$ \\
PER <--- & TQ & -.03 \\
PER <--- & FA & .07 \\
PER <--- & DB & $-.25 * * *$ \\
PER <--- & AC & $.67 * * *$ \\
\hline
\end{tabular}

The overall fitness model was analyzed the goodness fit index (GFI), comparative fit index (CFI) and root mean square error of approximation. GFI score is 0.512 which shows the model is a too fit. GFI value more 0.70 is considered as satisfactory. The lowest value is because of negative correlations results of 2 variables. CFI value is 0.623 which says mode is fit.

The RMSEA value should be less than 0.05 (level of significance). Here the RMSEA value is 0.246 which is not acceptable. We need to change the data or apply some tools for data. Confirmatory factor analysis (CFA) was used to explain variables. The value of RMSEA and GFI are not acceptable and has a good fit.

Path analysis diagram was also made via SEM and CFA. Regression estimates for patient care and accessibility are showing significant results and supporting our hypothesis 1 and 5 .

Result for doctors behavior are also significant but shows negative results which are against both alternative and null hypothesis for this variable.

The results for technical quality and financial aspects are not significant overall every analysis is showing a negative result which doesn't support the proposal mode.

\section{Discussion}

The current study aimed to examine the impact of five elements of Marshal and Hays model to the performance of hospitals working under PPP. The findings of the present research reveal that patient care and accessibility of patients to the hospital and its service are detrimental have a positive and significant impact on the performance of hospitals working under PPP whereas doctor's behavior shows the significant but negative impact on hospital performance. Although, the findings of the current research claimed that the availability of financial assistance and high quality of technical service is not sufficient for improving the hospital performance. The results of the present study have significant theoretical and practical implications.

\section{Theoretical Implications}

We adopt Marshal and Hays model to evaluate the performance of hospitals established under public-private partnership. The three elements of Marshal and Hays model (out of five) i.e. patient care and accessibility proved to be the significant predictor for the improvement of hospital performance. The significant impact of Marshal and Hayes model on hospital performance shows that future researchers should identify and examine other factors that lead to improves hospital performance working under PPP.

Moreover, the results of the present research show no significant impact on financial assistance and technical quality on the hospital performance. Although, financial assistance and technical quality are the two most important element of Marshal and Hayes model. So the future researchers should identify the underlying reason for the insignificance of these two elements.

In addition, the findings of the current research show that doctor's behavior indicate the significant but negative impact on hospital performance. Future researchers should examine the underlying factors that why doctor's behavior negatively influence hospital performance.

\section{Practical Implications}

Along with the theoretical implications, the findings of the current study has practical relevance as well. The results of the currents study highlight several points that assist Govt. health ministry and policymakers to make plans for the betterment of health facilities to the public. Based on the outcome of the current study, we make certain suggestions to the concerned departments.

First, Health department and policymakers should offer special training courses and sessions to medical staff to train them for the improvement of patient care. The behavior of doctors with the patients has a positive and highly significant impact on the hospital performance. In Pakistan, doctors faced the issue of work-life balance due to long working hours. Almost, all of the doctors work for more than 100 hours per week as only one doctor is available for a population of 10,000 people. Such type of hectic routine negatively influences the mental and physical health of doctors. Therefore, we suggest policymakers that they should make a plan to increase the number of doctors. As sufficient numbers of doctor to reduce workload.

Moreover, Govt. should make a long-term plan for the delivery of high-quality health services to remote areas. As the accessibility of hospitals to the patients increase the hospital performance. 
Limitations and Future Direction

The findings of the present study have significant theoretical and practical implications. Stil it is not free from limitation. The questionnaire was used to collect the data that give rise to self-reporting bias. Future researchers can eliminate the biasness occur due to self-reporting by collecting data through observations. Secondly, the current study was cross-sectional in nature. So to generalize the findings of the study, future researchers collect the data in different time periods. Moreover, the findings of the current study recommend future researchers to use other research designs as well. For instance, conduct experimental design or collect data through interviews.

\section{References}

Akintoye, A., Beck, M., \& Hardcastle, C. (2008). Public-private partnerships: managing risks and opportunities: John Wiley \& Sons.

Barlow, J., Roehrich, J., \& Wright, S. (2013). Europe sees mixed results from public-private partnerships for building and managing health care facilities and services. Health Affairs, 32(1), 146-154.

Blagescu, M., \& Young, J. (2005). Partnerships and Accountability: Current thinking and approaches among agencies supporting Civil Society Organisations: Overseas Development Institute.

Cruz, C. O., \& Marques, R. C. (2013). Infrastructure public-private partnerships: Springer.

Goel, N., Galhotra, A., \& Swami, H. (2006). Public-Private Partnerships In The Health Sector. The Internet Journal of Health, 6(2), 1-5.

Hulley, S. B., Steven R, C., Browner, W. S., Grady, D. G., \& Newman, T. B. (2001). Designing Clinical Research (Second ed.): Lippincott Williams and Wilkins.

Kinlaw, H. (2008). Public-private investment partnerships in health systems strengthening. Paper presented at the Report on Wilton Park Conference.

Marshall, G. N., \& Hays, R. D. (1994). The patient satisfaction questionnaire short-form (PSQ-18): Rand Santa Monica, CA.

Pasha, H. A., \& Nasar, A. (2003). Public-Private Partnership in the Health Sector: Evidence From A Developing Country.

Sapri, M., Hariati, A., Ting, L. S., \& Sipan, I. (2016). Public-Private Partnership Benefits in Delivering Public Facilities in Malaysia. Paper presented at the MATEC Web of Conferences.

Savas, E. S., \& Savas, E. S. (2000). Privatization and public-private partnerships: Chatham House New York.

Yescombe, E. R. (2011). Public-private partnerships: principles of policy and finance: Butterworth-Heinemann. 


\title{
Administrative and Social Support Services for Students with Disabilities in the Selected Higher Education Institutions of Amhara Regional State-Ethiopia
}

\author{
Getachew Walelign Asres \\ MED in Special Needs Education, Special Needs and Inclusive Education Department, Faculty of Social Science \\ and the Humanity, Debre Tabor University, Ethiopia
}

\begin{abstract}
This study was conducted in universities found in Amhara regional state. There are 7 public universities in the region. One university was selected from each generation. Hence, Gondar was selected from $1^{\text {st }}$ generation, Wollo from $2^{\text {nd }}$ generation and Debre Tabor from the third generation universities. Qualitative case study design was used for this study. The participants of this study were students with disabilities, teacher, students without disabilities, special needs directorates, and library and students service coordinators. Four methods of data collection instruments were used to obtain valid and reliable information from different sources, and for the purpose of triangulation. The result showed that most students with disabilities obtained different administrative and social support services from universities. On the other hand, the findings showed that the actual support services provided for students with disabilities in the sample universities were not in line with its higher education proclamations. It is recommendation that the university should work more on the social accessibility and administrative support services given for students with disabilities.
\end{abstract}

Keywords: Social and administrative assistive services, students with Disability and Higher education institution DOI: $10.7176 /$ PPAR/9-1-03

\section{Introduction}

The higher education expansion and supportive education policy in the present Ethiopian context have opened a window the opportunity to increasing number of citizens with disabilities to benefit from higher education thus taking courageous move to tackle what Fuller et al. (2004) call invincible hurdle of higher education. The quest for equal and fair access is growing voice among students with disabilities, who successfully completed secondary education (Barnes, 2004). As noted in Putnam (2003), although access to persons with disabilities to higher education is slowly gaining momentum from time to time and from place to place, equality with regard to access has remained unattainable in most countries of the world including Ethiopia.

Millions of the people have some type of physical, mental or emotional condition that significantly limits their ability to function successfully in our society. In this case, there is no specific way to support students with special needs; instead, varying approaches of learning can have a better outcome for students with disabilities. Realizing the goal of successful education for students with special educational needs is not the task of the ministries of education and educational institution alone. It requires the co-operation of teachers, families, and the mobilization of the community and voluntary organizations as well as the support of the public-at-large. Therefore, the support services provided for students with disabilities are: academic by teachers, administrative, social, parental and peer (Dash, 2009, Kochung, 2011), If the students have the opportunity to get all the support services by these stakeholders, their academic, and social skills are enhanced.

The word accessibility can have different meanings for different people, for example: financial accessibility of services, Geographical accessibility, linked to the concept of local services, social accessibility in relation to the fight against stigma and psycho-sociological barriers (Handicap, International, 2009). Stinson and Antia (1999) define social accessibility creating conducive environment for students interact with others, make friends and accepted by peers and university communities. That is students with disabilities communicate in ways that are different from those around them and this can slow down their social interaction and development. Barriers that limit a person's full participation include; negative attitude, discriminative policies and practices, and inaccessible environments as a result of these barriers, students with disabilities are being excluded from accessing higher education. In addition, social support services directly related to promoting social initiations, relation and networks, values all students equally; higher expectation and increased inclusion in future environment (Getachew and Belay, 2001).

Administrative support is another important measure implementing for students with disabilities. This includes visiting of supervising students with disabilities; giving feedback to teachers for increasing their efficiency; financial assistance for implementing education for children with disabilities; constructions of resource rooms; maintenance of resource rooms; providing in- service education to teachers and the headmasters; deputing teachers to visit model special needs schools outside the state/ country and monitoring and evaluation of the program (Dash, 2009), For effective implications of students with disabilities, 
administrators are expected to be familiar with the concept, objectives and practices of special needs education in general and disability in particular. Such familiarity will help the administrator in supervision, monitoring, control and for providing leadership (English, 1993). Even when they visit institution, they do not give any specific feed back to the teachers about what they are doing and how they are doing. In such cases, the very purpose of supervision is lost. School expect financial assistance from the government to meet their contingency expenditure for purchase of aids and equipment, and other instructional materials, removal of architectural barriers and other environmental out comes modifications(Kenny, 2004).

Accordingly, very few students with disabilities receive higher education in Ethiopia. As long as, higher education was the preserve of privileged minority, the absence of students with disabilities was little noticed. The main obstacles to learning in Ethiopia are lack of information about diversity, rigid and poor curriculum, inaccessible learning environment, inadequate services, and inadequate assessment procedures, inaccessible building and infrastructure (Jung, 2003; Johnson, 2006). As a result, schools, universities and teachers find it difficult to accommodate students with special educational needs, and compel them to adapt to the school, instead of adapting to the need of the students (MOE, 2006). As many parts of the world including Ethiopia, this is still the case and where institutions of higher education purport to provide equal access, students with disabilities still face discriminatory policies and practices. To alleviate these problems in higher education institutions, the government of Ethiopia incorporated the provision of support services to students with disabilities in the two consecutive proclamations of higher education institutions which is launched in the year 2003 and 2009 respectively. (Getachew and Belay, 2012). These proclamations are

1. The Higher Education Proclamation №.351/2003. In this proclamation, there is a commence to protect the right of person with special needs. In this proclamation Nㅡ. 351/2003 in its 3rd article (special support) sub article one proclaimed

Admission criteria or manner of acceptance set for female students, students with disabilities, students who have been completed with high school education in developing region may be different from others. They shall during their stay in the institution, special support and assistance services from the institutions.

2. The Ethiopian Higher Education Proclamation №. 650/2009 in its article sub article 1-4 proclaimed

Institution shall make to the extent possible their facilities and programs should be amendable to use with relative ease by physically challenged students. In addition, the document described that to the extent situations and resources permits relocate classes, develop alternative testing procedures and provide different educational auxiliary aids in the interest of students with physically challenged. Furthermore, building design, campus physical landscape, computers and other infrastructure of the institution shall take in to account the interest of physically challenged students and students with physically challenges get to the extent necessary and feasible academic assistance including tutorial sessions, exam time extensions and deadline extension.

Even if, the government of Ethiopia launched these two consecutive proclamations to assure the provision of support services for students with disabilities in higher education institution, the development of special needs education is very slow (Yared, 2008). Hence, research plays a pivotal role to examine the administrative and social support services provided for students with disabilities in Ethiopian higher education institutions.

As a result, assessing the administrative and social support services for students with disabilities and its challenges is valuable to design an effective and successful support strategy in order to address the diverse needs of all students with special needs in higher education institution. Despite a number of researches were carried out in relation to assessing the condition of support services in lower grades, scant attention is given on the condition of these assistive services in Ethiopian higher education institutions. Therefore, studying the actual administrative and social assisstive services provided for students with disabilities in universities is worthwhile for realizing their right of students to get support services and equalization between students with and without disabilities that our country is giving top most priority today. This initiated the researcher to conduct research on the area of assessing the administrative and social support services for students with disabilities in the context of higher institutions.

To this end; the researcher formulated the following leading questions:

1. Do students with disabilities have got administrative disability specific support services from higher education institutions?

2. Is the social environment of higher education institutions accessible for students with disabilities?

3. Is the current status of the provision of support services for student with disabilities in higher education institutions in line with its proclamations?

\section{Methods}

\section{Research Design}

The general objective of this study was to assess the administrative and social support services for students with 
disabilities in public higher education institutions. As a result, qualitative case study design was used for this study. Therefore, the study is based on a qualitative design approach which helps in showing the finer details of an issue and is more descriptive in its nature (Mertens 1998). This design is also widely applicable especially on those research that is conducted on special need education (Hartley, 2003). Thus, this research was conducted through in depth examinations of the provision of support services for students with disabilities.

\section{Study Site}

The study was conducted in higher education institutions found in Amhara regional state. There are 7 public universities in the region. These universities are divided as first (Bahir Dar and Gondar), second (Wollo, Debre Markos and Debre Berhan) and third (Debre Tabor and Woldia) generation. Therefore, this research was carried out on the sampled universities of each generation.

\section{Study Population}

This study was focused on all students with sensory (visual and hearing) and physical disabilities who have been attending their education in the selected universities. Therefore, the target population were all these students found in the sample universities (Debre Tabor from $3^{\text {rd }}$ generation, Wollo from $2^{\text {nd }}$ generation and Gondar from the $1^{\text {st }}$ generation).

\section{Inclusion Criteria}

This study includes all regular students with sensory (visual \& hearing) and physical disabilities who have been attending their education in different universities. I.e. the study included only students with visible and/or severe disability and those students who were easily accessible to the researcher

\section{Exclusion Criteria}

This study excluded those students with disabilities who were inaccessible to the researcher (summer, extension and evening students) that were attending their education in the universities. In addition, the study also excluded students with invisible disabilities (learning disability and communication disorder etc...)

\section{Participant of the study}

The participants of this study were students with severe disabilities; students without disabilities and teachers, special needs education directorate, library directorate, student's service coordinators (cafeteria and dormitory).

\section{Sample and Sampling Techniques}

Even if, the government of Ethiopia proclaimed higher education proclamations (i.e. admission criteria or manner of acceptance for students with disabilities, may be different from others) and practiced this proclamation, still the number of students with disabilities received higher institution is very low. Due to this reason, all students with severe disabilities in the selected sample universities and disability category were the informants of the study (interview and FGD). They were selected by using purposive sampling techniques.

Three student's directorate ( 1 from each university) and one (library, cafeteria, and dormitory) coordinator from each university (total of 9 participants) were also be selected as the informants of the study. All these samples were selected by using purposive sampling technique. This is because, the researcher believed that these informants had better information, and exposure about the administration, and social support services for students with disabilities. In addition, teachers of students with disability were also being the participants of the study. They were selected through convenience sampling technique. Whereas, the students' peers were selected by using snowball sampling techniques. Students with disability for FGD were selected using purposive sampling. That is, seven participants from each university who had better information about the support services given for students with special needs were involved in the discussion.

This is because in qualitative case study, it requires all these non-probability sampling techniques. As Gall, Gall and Borg (2007) stated, it is not possible to study everyone at the real life context in qualitative research methods. So, a qualitative study method requires a specific individual or group of individuals to gather detail information from them

\section{Data Gathering Instruments}

To gather authentic, genuine and accurate information about the condition of provision of support services from students with disabilities, their teachers, students without disabilities, special needs education directorate, library and students service coordinators (cafeteria and dormitory), four methods of data collection instruments were used to get rich information and for the purpose of triangulation. These include interview, observation, focus group discussion (FGD) and document review. 


\section{Methods of Data Analysis}

The data collected through different instruments like interview, observation, document review, and FGD were analyzed qualitatively. Qualitative analysis has been applied to the data obtained through all these instruments. Unquestionably, data analysis is the most complex and difficult of all the phases of a qualitative project (Fleury, 1993). Following the data collection through all verified instruments, analysis were made step by step. In order to make appropriate analysis, the collected data was at first presented in meaningful, organized and related manners so that the researcher could easily figure out the findings from each instrument to make the appropriate triangulation. Before the data analysis, the information that were gathered from the above sources were classified and organized by themes. Thus, the researcher were used cross case data analysis method. After these, conclusion were made and possible recommendations were forwarded.

\section{Ethical Consideration}

Disability research more than any other kind of research always requires ethical consideration at the forefront. Accordingly, the investigator has considered a number of measures to make his level best in keeping ethical issues in all stages of the study. Before gathering data from students with disabilities, their students with disabilities, teachers, directorate, the researcher asked permission from the universities and the above informants. Furthermore; the participants were told to them the significance and the purpose of the study.

Regarding the consent, the researcher was informed them that they can withdraw from participating in the research at any time and in any circumstance if they do not feel comfort. Moreover, tape recording was made with their due consent and knowledge. Pseudonyms were used instead of using real names during the data analysis. This is very important to make ethical considerations to gather better information from participants.

\section{Results}

Background Information of Informants

The total number of students with disabilities who have been attending their education in the sampled universities, the background of students with severe disabilities, students without disabilities \& teachers, special needs education directorate, library and students' service coordinators (cafeteria and dormitory) participated in the interview or/ and FGD are presented below

The total number of students with Disabilities attending their education in the sampled Universities

Table 1: The total number of students with disabilities who have been attending their education in the sampled university

\begin{tabular}{|c|c|c|c|c|c|c|c|c|c|c|c|c|c|c|}
\hline \multirow[t]{3}{*}{ No. } & \multirow[t]{3}{*}{ University } & \multirow{3}{*}{$\begin{array}{l}\text { No. } \quad \text { of } \\
\text { students } \\
\text { with } \\
\text { Disabilities }\end{array}$} & \multicolumn{12}{|c|}{ Types of Disability } \\
\hline & & & \multicolumn{3}{|c|}{ Visual } & \multicolumn{3}{|c|}{ Hearing } & \multicolumn{3}{|c|}{ Physical } & \multicolumn{3}{|c|}{ Unidentified } \\
\hline & & & $M$ & $F$ & Total & $M$ & $F$ & Total & $\vec{M}$ & $F$ & Total & $M$ & $F$ & total \\
\hline 1 & $\begin{array}{l}\text { Debre } \\
\text { Tabor }\end{array}$ & 51 & 6 & 2 & 8 & - & 1 & 1 & 14 & 18 & 32 & 3 & 7 & 10 \\
\hline 2 & Gondar & 104 & 16 & 16 & 32 & - & - & - & 45 & 27 & 72 & - & - & - \\
\hline 3 & Wollo & 57 & 8 & 2 & 10 & 1 & 1 & 2 & 28 & 17 & 45 & - & - & - \\
\hline \multicolumn{2}{|c|}{ Total } & 212 & 30 & 20 & 50 & 1 & 2 & 3 & 84 & 62 & 149 & 3 & 7 & 10 \\
\hline
\end{tabular}

As it is depicted from the above table, the total number of students with different disabilities which have been attending their education in the sampled universities were 212. Of these, the larger number (104) constituted Gondar University (GC, Tewodros, Maraki, Fasil and Tseda campuses). These figures include both students with mild and severe disabilities. Among these, students with mild disabilities have been benefited from the preexisting regular educational approaches and the natural environmental conditions without any modification. Due to this reason, the researcher selected those students which have severe disabilities that need educational and environmental modification as an informant of the study (for interview and FGD.

\section{Background of students with disabilities who were participated in the Interview and FGD}

The total number of students with severe disabilities that were participated in interview and FGD from the sampled universities were 29 (9 from DTU, $10 \mathrm{GU}$ and $10 \mathrm{WU}$ ). Of these, the lion share constituted male students (22 in number). These students are placed in different faculties and departments. Furthermore, most students who have been attending their education in the sampled higher education institutions were students with physical disability and follow students with visual impairment. Besides, students with severe hearing impairment did not get the opportunity to enter higher education institutions. In addition, students with visual impairment were interested to attend their higher education in the social science streams, on the other hand, students with physical disabilities were from different departments and faculties. Mild students with disabilities were not included in the interview and FGD. 
Background of Interviewees' Teacher

Teachers who participated in the interview were from the different streams in which students with disabilities were found. In addition, most teachers who have been teaching students with different disabilities have two and above years of experiences. This long teaching experience helps the participants to provide genuine and real information about the conditions of support services in general and students with disabilities in particular. Besides, teachers taught these students in which different disabilities were found at different batches.

\section{Background of Special Needs Directorates}

As tried to obtained information form informants except one, the other informant directorates have 2 and above years of experiences in serving students with and without disabilities in the sampled universities. This long work experience helps the directors to provide reliable, detail and genuine information about the support services rendered for students with disabilities. As it is also indicated from the above table, most participants were females.

\section{The Background information of Library, Cafeteria and Dormitory Coordinators}

All the interviewed informants were taken from the three sampled universities. They had 3 and above years of working experiences in serving students with and without disabilities in different working centers (Library, cafeteria and dormitory) of the sampled universities.

\section{Background of Students without disabilities}

Students without disabilities were selected for interview from different streams in which children with different disabilities were found. These students knew their disabled peers in every aspect of their life and movements. For instance, some of them were support provider with recognized fees by the university, some were note readers and some were also classmates. This close relation that they had helps them to give detail, genuine, valued and reliable information about the administrative and social assistive services for students with disabilities inside and outside the classroom.

\section{Administrative Support Services}

Informants were asked about the administrative support services provided for students with disabilities by higher officials of the university. Almost all respondents agreed that students with disabilities were obtained different supports from administrators. For instance, all disabled and helpless students in all sampled universities have got 100 birr per month for keeping their personal hygiene. Respondents added that these students have been receiving stationary materials, modes for females, sanitation materials, assistive devices (slate, stylus, braille paper, cane, Dictaphone and wheelchair (not all universities)) .Crunch has been also provided for those students with lower limbs are impaired in collaboration with the nearby rehabilitation centers. Furthermore, case 3 during the interview mentioned that in addition to the provision of stationary and assistive devices, the university have been also providing different trainings for students with disabilities like study and life skills, job seeking skills, $\mathrm{CV}$ writing, entrepreneurship and social skills in order to empower students in all aspects of their life.

Special needs education directorate and students with different disabilities during the interview, and FGD disclosed that all students with disabilities have placed classrooms and dormitories in the accessible ground floors of the buildings. This clearly showed that administrators have been giving the greatest emphasis on students with disabilities. In addition to these, the participants described that students with disabilities also have got laundry and photocopy services from the university which was not provided for other students (especially at Gondar University and seldom in Debre Tabor University.). This is also assured by teachers Senit and Gedefaw during the interview. They explained that their department has been providing photocopy services peculiarly for students with disabilities.

Case 1 during the interview mentioned that the university administrators also strongly work with the surrounding community, Ethiopian telecommunication and NGOs like path finder to assist students with disabilities by contributing finance, modes, stationary \& sanitary materials and assistive devices. Students with disabilities also explained that university administrators supported them by providing special room for feeding in the cafeteria and reading room in the library to alleviate the challenges observed in the cafeteria and library service. As they said, the normal feeding rooms in the cafeteria have a slippery character. The nature of this feeding room is not conducive for students with crunch and cane users as well as others whose lower limbs are impaired. 


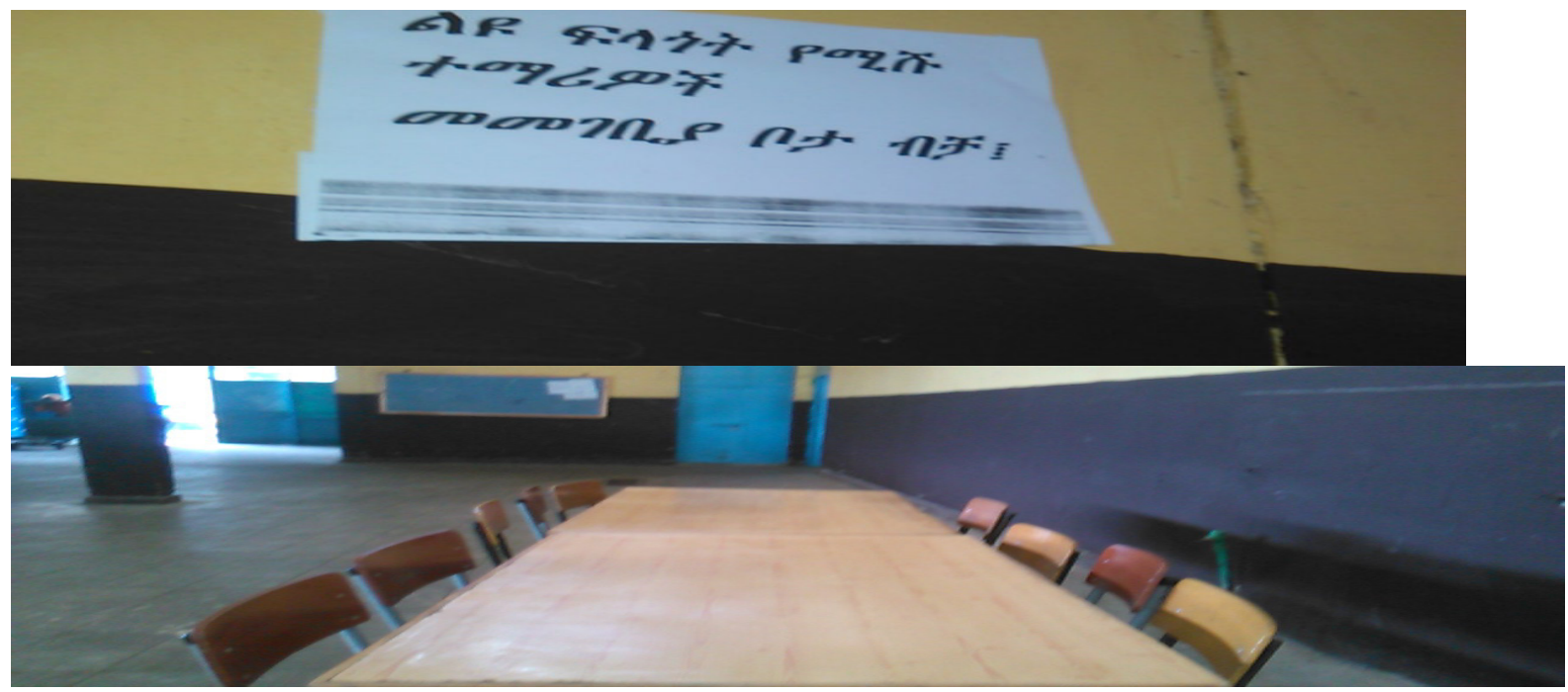

\section{Feeding room for students with disabilities}

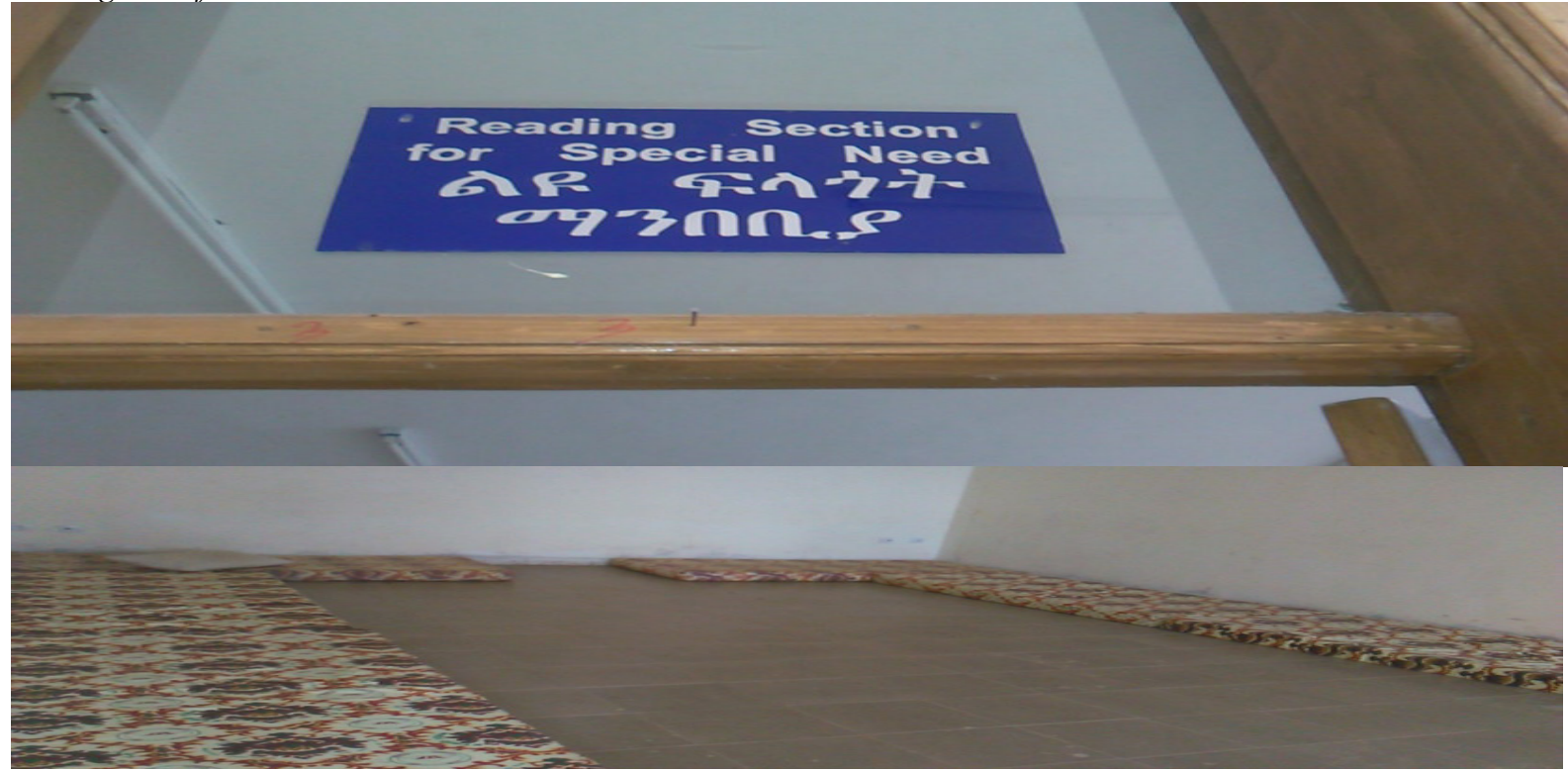

Furthermore, students and directorates repeatedly reported that graduated students with disabilities in all sampled universities have received 'graduation cloth from the university. This kind of special support services were not provided for other students including the poor. The data obtained from all informants also disclosed that the new freshman students with disabilities were allowed to enter in their interested departments. This means, the first department options were kept. They could join to those interested departments which were not given this chance for other freshman students. If the first department option was not even appropriate for them, again they had a chance to change after onwards.

Besides this, case 2 during the interview said:

10 special chairs were ordered to buy among others by considering the special problems of students with disabilities. In addition to this, special foam sponges were bought by the university administrators that used for students with physical disabilities while they read in the library.

This kind of service was not common to all sample universities. In the same vine, one university had assistive computer technology with JAWs software for students with visual impairment in one branch of the library (Wollo University). In addition, the department of special needs education set up resource center which has assistive computer technology with the above software (Gondar University). This resource center has been providing training and internet service for all students with disabilities found in the university. Two universities also established disability service center for the purpose of assisting students with disabilities found in all departments (Wollo and Debre Tabor University.) 


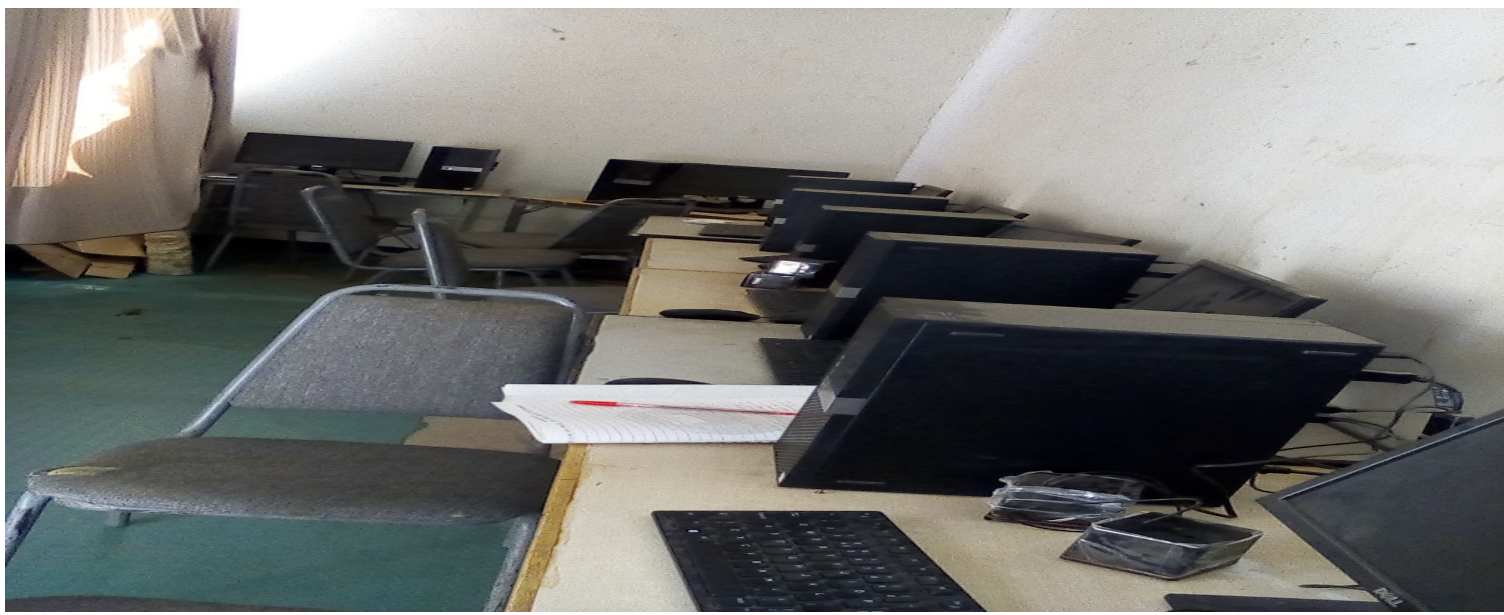

Internet room for students with special need at Wollo University

Regarding the availability of note takers, lab and library assistants, readers, and sign language interpreters, respondent teachers explained that universities did not have specially employed auxiliary aid provider for students with disabilities. Due to having this problem as case 1 described, the university referred deaf students to Addis Ababa University which has a sign language interpreter. Universities did not give due attention to have these professionals who gave support services for students with disabilities due to having low number of students with severe disabilities. To solve the problem of students with blindness and wheelchair users temporally, university administrators assigned their 'normal' peers in order to provide reading, guiding, and pushing wheel chairs services with low fees (Wollo and Gondar Universities). However, students during the interview and FGD reported that these support services are not sufficient.

The researcher also asked the informants about the supervision services provided; giving feedback to teachers and providing in-service teacher training. They responded that the university provided a supervision services to check whether the support services provided were effective or not. That is, whether students with disabilities were placed in the right dormitories and classrooms or not, whether they attended their education regularly or not; if teachers provided tutorial or not; if stationary and assistive services as well as pocket money were provided on time or not. In addition to these, the sampled universities did not provide in service teacher trainings in order to scale up teachers' knowledge and skills about disability education.

\section{Social Support Services}

The researcher asked the informants about the social assistive services provided for students with disabilities. Most participants responded that they took different services in order to create a social accessibility in the university. They further elaborated that the university prepared a well coming ceremony for freshman students for the purpose of valuing and creating a welcoming environment for students with disabilities in all sampled universities. For instance Belaynesh responded:

The university prepared a well coming ceremony for new entrant students. In this ceremony, senior students, special needs coordinator and disability club members gave counseling services and sharing their experiences about the university life. Moreover, in this ceremony, they advised us how to make friends with students with and without disabilities, and how to be effective in academic performances and social interaction. All these advices help me to make new friends and sustaining with them for a long period of time in the life of the university.

Student Sisay also explained as follow

The university was prepared a well coming ceremony for freshman students. This ceremony created a good opportunity for the present good social skills and academic success that I have. However, before the ceremony, my social relation was only limited with my disabled equals. After I entered in the university and participated in this ceremony, I got a good social skills and experiences. Now, I can communicate with the university community without problem.

In addition, most students with disabilities during the interview and FGD disclosed that different efforts were made by the university to create social accessibility for students with disabilities. Similarly, Case 3 during the interview remarked that different trainings such as life and study skills was provided for the purpose of creating a well coming social environment for students with disabilities. As she further explained, most students with disabilities have a problem in accepting their disabilities, giving low values for them and having poor social relations with others. That is why the university gave high intention in providing training for them to alienate these problems. In addition, disability club/ association members also provided advices and counselling services 
in collaboration with the special needs directorate in order to promote the social interactions of students with disabilities with teachers, students with and without disabilities and other staffs of the university.

The data gathered from special needs directorate indicated that library, cafeteria and dormitory workers have been taking training about how to give and improve their services to meet the diverse needs of all students in the university. Its purpose was creating social accessibility for students with disabilities with in these services giving centers. For example, during the interview, Case 1 explained

Some students with disabilities have low social skills. They were seen as facing problems to move in the campus without having guiders. Sometimes, they were absent in the class and exam time. This is because of having low social relations, they faced difficulties to get guiders. To solve this kind of problem, the directorate gives trainings for service giving center workers and assigned 'normal' peers to assist them in their study. This in turn helps them to scale up their social skills.

The researcher inquired students with disabilities about the social interactions that they had with their peers, teachers and administrative staffs (like cafeteria, library, dormitory, lounge etc.). Most participants responded that they had an excellent social relations with their peers and administrative staffs. Opportunities were created by the different levels of university officials to have had a good relations with them. For instance, during interview student Boru explained

The university assigned one 'normal' student as a support provider for assisting me in all aspect of my life. For example, he is a reader, a guider, a counselor and a sanitary. He is my model in every aspect of my life. I have learnt socialization with him. Now, I want to say I have a good social skills. I did not have this skill before the university life. Currently, I communicate simply with my class mates and university community without any difficulties.

Student Kasew mentioned that their normal peers had a positive attitudes towards them. Due to this reason, they could establish a good social relation with students without disabilities. In addition, students with disabilities have learnt different social cues in order to initiate socialization with the university staffs. During the FGD, students reported that they showed different sign and symptoms in order to be accepted by others. For example, show smiling face, talk common agenda, understand others' feelings and ask questions without fear to establish social relations. All these social skills were learnt in different trainings given by the university .However, some students remarked that they could not create social relations with some administrators and teachers. For example, one student during the interview strongly mentioned:

We collected our problems and asked higher administrators of the university to give immediate solutions to our serious problems. Higher officials said that these kind of problems will be solved through time and these kinds are not considered as a problem for us. They further said, you are the lucky person in the university, because at least you have got food. They also said that your equals did not find this opportunity, and they lead their life by begging at the street outside the campus. At this time, we did not feel we are equal with others and after onwards we are not interested to make social relations with them. This kind of sayings affect our psychological feeling.

In the same vein, other student during the interview explained that teachers did not give equal value for all students in the classroom. They assumed that students with disabilities could not do classroom instructions like that of 'normal' peer. They said for instance "Do you have an ability to do this activity" This kind of speech underestimates students with disabilities. Another student during the interview also disclosed that most of the time teachers believed that students with disabilities could not perform their subjects like the 'normal' peers. They considered them as weak, dependent and lazy. He further explained as "this university is not appropriate for you and this course is difficult for 'normal' students and it is even too difficult for you)" All these evidences clearly show teachers do not address diversity and give value for all students in the classroom.

On the other hand, there were some higher officials, and teachers who appreciates, values and address diversity in the university. For instance, Bega during the discussion explained that administrators including the president and vis presidents have a positive attitudes towards students with disabilities. They gave high values and solving their problems immediately. .Besides, there were some teachers who care students with disabilities especially in the usage of classroom language in order not to affect their psychological feeling.

The Assistive Services in Comparison with the Higher Education Proclamations Box 2: The Ethiopian Higher Education Proclamations that address students with Disabilities Proclamation NO. 351/2003, 3rd article (special support) sub article one

$>$ Entry assessment or admission procedure designed for any female, disabled student, a student who has completed high school education in a developing Region or who is native of the nationality of such Region or a student from the nationality whose participation in Higher Education is low shall be different from others. They shall, during their stay in the institution, get special supports; particulars of such support shall be determined by the Ministry.

$>\quad$ Notwithstanding the provisions of Sub-article (1) of this Article education for the dumb and deaf may be 
given in a sign language.

Proclamation NO. 650/2009 in its article sub article 1-4

$>$ Institutions shall make, to the extent possible, their facilities and programs amenable to use with relative ease by physically challenged students.

$>$ Institutions shall, to the extent that situations and resources permit, relocate classes, develop alternative testing procedures, and provide different educational auxiliary aids in the interest of students with physical challenges.

$>$ Building designs, campus, physical landscape, computers and other infrastructures of institutions shall take into account the interests of physically challenged students

$>$ Institutions shall ensure that students with physical challenges get to the extent necessary and feasible academic assistance, including tutorial sessions, exam time extensions and deadline extensions.

$>$ Education for students with complete hearing impairment shall be given in or supplemented by appropriate sign language

Source: Federal Negarit Gazeta of the Federal Democratic Republic of Ethiopia. 9thYear No. 72, Addis Ababa3rdJuly 2003 and 15th year no. 64 Addis Ababa 17th September, 2009

Students with disabilities should have equal opportunities to participate in higher education as well as students without disabilities. These opportunities are mentioned in a number of various international and national legal documents within a growing attention. Hence, The FDRE was launched two higher education proclamations in the year 2003 and 2009. In these proclamations in its article 3(2003 proclamation) and sub article 1-4(2009 proclamation) gave due emphasis on the provision of support services and accessibility for students with disabilities. Thus, in this part, the researcher tried to analyze the actual support services provided for students with disabilities by the university in relation to its consecutive proclamations of the higher education institutions. It analyzes as follows:

1. Entry assessment or admission procedure designed for ......, disabled student, shall be different from others. This sub article of the proclamation has been practicing by all sampled universities. Although the admission criteria/score for disabled students to higher education were different from year after year, they entered higher education with lowered admission score in comparison with students without disabilities.

Table 2: Comparison of university entrance point/ score in Ethiopia (NEAEA) between students with "Normal" and students with disabilities

\begin{tabular}{|c|c|c|c|c|c|c|c|c|c|c|c|c|}
\hline \multirow[t]{4}{*}{ No. } & \multirow[t]{4}{*}{ Year } & \multicolumn{4}{|c|}{ 'Normal'students } & \multicolumn{7}{|c|}{ Students with disabilities } \\
\hline & & \multirow{2}{*}{\multicolumn{2}{|c|}{ Social }} & \multirow{2}{*}{\multicolumn{2}{|c|}{ Natural }} & \multirow{2}{*}{\multicolumn{2}{|c|}{$\begin{array}{l}\text { Hearing } \\
\text { impaired }\end{array}$}} & \multirow[t]{3}{*}{ Blind } & \multicolumn{4}{|c|}{ Pastoral special needs } \\
\hline & & & & & & & & & \multicolumn{2}{|c|}{ Social } & \multicolumn{2}{|c|}{ Natural } \\
\hline & & $\mathrm{M}$ & $\mathrm{F}$ & $\mathrm{M}$ & $\mathrm{F}$ & $\mathrm{M}$ & $\mathrm{F}$ & & $\mathrm{M}$ & $\mathrm{F}$ & $\mathrm{M}$ & $\mathrm{F}$ \\
\hline 1 & 2015 & $280+$ & $270+$ & $315+$ & $300+$ & $300+$ & $300+$ & $270+$ & $270+$ & $270+$ & $300+$ & $300+$ \\
\hline 2 & 2016 & $335+$ & $320+$ & $352+$ & $330+$ & 297 & 275 & $200+$ & - & - & - & - \\
\hline 3 & 2017 & $330+$ & $320+$ & $354+$ & $340+$ & 275 & 275 & $200+$ & $315+$ & $300+$ & $320+$ & $305+$ \\
\hline
\end{tabular}

Ethiopia university entrance point. Sources: https/www.ese tub.com, https/www.esetube/Ethiopia and dire tube

As it is depicted in the above table, the admission score of students with disabilities are lower than when we compared to that of students without disabilities.

In addition in this sub article, the proclamation further stated that students with disabilities shall during their stay in the institution, get special support; particulars of such support shall be determined by the Ministry. In this sub article, the proclamation did not clearly state in detail like what kind of support services shall be provided for students by the institution. Due to this reason, universities have been providing different support services for different categories of disabilities as they could base on their knowledge and interpretation.

2. .... education for the dumb and deaf may be given in a sign language. When we see the actual practice of these sub articles of 2003 and 2009 proclamations, the researcher assured that there is no severely hearing impaired students found in the sampled universities that need sign language experts. Due to having this reality, there were no sign language interpreters employed by the university for this purposes. However, Debre Tabor University referred two deaf students to Addis Ababa University which was admitted to the university in this year, because of unavailable of sign language interpreters in the classroom.

3. .....to the extent possible, their facilities and programs amenable to use with relative ease by physically challenged students. For this sub article, the researcher assured that students with different types of disabilities did not benefit from this sub article of the proclamation. Universities in general and teachers in particular did not amend and modify exam \& class schedules and other programs to students with disabilities. For instance, Neges during the discussion explained as

When class exam and other university programs were scheduled by the university, they considered majority students found in the classroom. No program is modified or accommodated by considering 
students with disabilities. We also did not ask this issue, because we know that the program was not amendable for students with disabilities. Sometimes, when students with disabilities delayed during the exam as a result of their disability, teachers are not happy.

This evidence clearly showed that the programs, and schedules set by the university were not being flexible to satisfy the divers' problems, and needs of students with disabilities in higher education institutions.

4......resources permit, relocate classes, develop alternative testing procedures, and provide different educational auxiliary aids in the interest of students with physical challenges.

The data gathered from different informants clearly showed that students with disabilities were attending their education in a conducive classroom (in terms of location). That is, they have been attending in the ground floors of the buildings. The same is true in their dormitories. This indicated that this part of the sub article is practiced in all sampled universities. However, as data collected from interview and FGD, teachers did not prepare an alternative testing procedures to address the diverse needs of students with disabilities. In addition, the university did not employee professionals (sign and braille language) in providing different educational auxiliary aids in the interest of students with disabilities.

5. Building designs, campus, physical landscape, computers and other infrastructures of institutions shall take into account the interests of physically challenged students

In relation to this sub article, observation, interview and FGD results showed that all buildings in the sampled universities were not constructed by considering students with disabilities. They do not have ramps, bridges and elevators. Ramps were reconstructed currently in a few buildings by the constant suggestions provided by special needs directorate in collaboration with the building design and development directorate of the university. Moreover, the campuses, infrastructure of the university and its land scape were inaccessible for students with disabilities. The natural environment are ups and downs and its roads were not constructed by considering wheelchairs and cane users.

Hence, it is possible to say, this sub article is not practiced in all the sampled universities.

6. ...... students with physical challenges get to the extent necessary, and feasible academic assistance, including tutorial sessions, exam time extensions, and deadline extensions.

As it is described above, students with disabilities have got some academic assistances services from their 'normal' peers. However, except some, most teachers did not provide these services for students with disabilities. That is, they did not give tutorial and adapt their instructions according to the multiple needs of all learners in the classroom. Furthermore, the university teachers did not make any amendment on class, exam and deadline extension to address diversity in the classroom. All these evidences showed that this sub article is not properly implemented.

\section{Discussion}

As it is stated previously, the purpose of this study was to assess the provision of support services for students with disabilities in higher education institutions. There for, the results of the major findings in relation to the research questions, and review of related literature were discussed and interpreted. Hence, the provision of academic, administrative and peers support services; the accessibility of the physical and social environment; the status of support services in relation to the higher education proclamations, and its challenges were discussed in comparison with other research findings.

Review of related literature indicated that differentiation of teaching is basically necessary to help students with disabilities acquire real-life skills and to help them continue their education in harmony with students without disabilities in the same learning environments (Tomlinson, 1999, 2001; Tomlinson, Kaplan, Renzulli, Purcell, Leppien and Burns, 2002). This includes, modifying/ adopting the curriculum to suit to the needs of special needs; flexibility and improving teaching; modifying method of teaching, assessment techniques, activities and schedules. However, the result of this study revealed that most students with disabilities did not obtain a special academic support services from teachers. That is, no adapted curriculum alignment and innovative practices were made; no special tutorial given; no modification was made on the different instructional activities.

The research found out that students with disabilities were obtained different support services from administrators. For instance, all disabled students in all sampled universities have got 100 birrs per month for keeping their personal hygiene. The results also showed that students have been receiving stationary materials, modes for female students, sanitation materials, assistive devices (slate, stylus, braille paper, cane, and crunch), laundry, and photocopy services, Dictaphone and wheelchairs. Supporting this, Bretz, (2000) stated the necessity of ensuring students with disabilities, by means of assistive learning materials as contributory factor to accessibility of education for those enrolled in higher education institutions. The materials include textbooks, modules, digital materials, audio and video materials; Braille texts, computers and accessories and the like materials are supportive to learn alongside their peers at colleges. The finding of the study also identified that universities provided different trainings for students with disabilities like study and life skills, job seeking skills, 
CV writing entrepreneurship and social skills in order to empower students in all aspects of their life. In addition, university administrators supported them by providing special room for feeding in the cafeteria and reading room in the library to alleviate the challenges observed in the cafeteria and library service. Contrary to this, literature showed terribly poor and limited quality of services in the universities covered provided by the administrator (IDEA, 1997; Kenny, 2004)). Higher education accessibility barriers including physical, architectural, service deliveries, provisions of learning materials and equipment, attitudinal and cultural influences.

The finding of the study revealed that universities have special needs coordinator at a directorate level in the organizational structure of the university. Contrary to this finding, HEATH (1999) study showed that the absence of any kind of disability support staff in the Ethiopian institutions, most public and all private institutions reported that they do not have a disability officer/coordinator or advisor. Moreover, all students with disabilities have placed classrooms and dormitories in the first floors of the buildings. Stinson and Antia (1999) explained that disability prevents someone from doing what they want or need to do. It needs to evaluate whether the classroom is effective for wheelchair users or not, as long as has access to the dormitories and the library, as well as to whatever other places and material or equipment that are necessary for students with disabilities to do their job well. Besides, graduate students with disabilities in all sampled universities have received 'graduation cloth' from the university.

However, the administrators did not supply special auxiliary aid provider for students with disabilities like sign and braille language expertise. Literature on this area also identified that most students with disabilities had encountered barriers to their education, including a lack of understanding and cooperation from administrators, faculty, staff and other students; lack of professionals and other accommodations; and inaccessibility of buildings and grounds (English,1993).

With respect to the social accessibility for students with disabilities, the finding indicated that the university prepared a well coming ceremony for freshman students for the purpose of appreciating differences and creating a welcoming environment for students with disabilities in all sampled universities. For instance Belaynesh responded that the university prepared a well coming ceremony for new entrant students. In this ceremony, she has got an opportunity to make friends with her with and without disabilities and to be effective in her academic performances and social interaction. Anderson (1993) arrived essentially as the same conclusion. He described the social support network as important for students with disabilities to successful to academic and social adjustment to university.

The researcher also identified that different trainings such as life and study skills were provided for the purpose of creating a well coming social environment for students with disabilities. Supporting this, Collins (1995) explained that their relationship with the university is not limited to academic education but also to preparation for life beyond the classroom. Building confidence and the necessary social skills of students with disabilities is of equal priority to the necessary academic skills that prepare people to meet future challenges. In addition, disability club/ association members also provided advices and counselling services in collaboration with the special needs directorate in promoting the social interactions of students with disabilities with teachers, students with and without disabilities and other staffs of the university. Emphasizing at this point, Stinson and Antia (1999) described that social accessibility creating conducive environment for students interacts with others, make friends and accepted by peers and university communities.

The data also showed that library, cafeteria and dormitory workers have been taking training at every year for improving their services to meet the diverse needs of all students in the university. Its purpose was creating social accessibility for students with and without disabilities in these service giving centers. In relation to this, Getachew and Belay(2001) noted that the social support services directly related to promoting social initiations, relation and networks, values all students equally; higher expectation and increased inclusion for creating social accessible environment.

Furthermore, their normal peers had a positive attitudes for students with disabilities. Students with disabilities have learnt different social cues in order to initiate socialization with the university staffs. All these social skills were learnt in different trainings given by the university. In relation to this, Stinson and Antia (1999) described that social accessibility is the ability to interact with, make friends with and accepted by peers.

The finding also revealed that there were some higher officials and teachers who appreciates, values and address diversity in the university. For instance, Bega during the discussion explained that administrators including the president and Vis presidents have a positive attitudes towards students with disabilities. They gave high values and solving their problems immediately.

However, some students remarked that they could not create social relations with some administrators and teachers. The result also revealed that teachers did not give equal value for all students in the classroom. Most of the time, teachers believed that students with disabilities could not perform their subjects like that of the 'normal' peers. They considered them as weak, dependent and lazy. This kind of perception leads students with disabilities to be isolated from university staffs and their peers. Previous research findings also advocated this finding, for instance, Tirussew (2005) noted that regarding undermining attitude in the Ethiopian context, 
indicated persons with disabilities are perceived as "weak", "hopeless", “ dependent", and "unable to learn" and "subject of charity". The misconceptions of causal attribution added to the misunderstandings of the capabilities of persons with disabilities have contributed to the low social and economic statues of persons with disabilities.

The research findings also showed that except one, the support services for students with disabilities indicated in the higher education proclamations were not fully implemented in the sample universities. Yared, (2008.) arrived the same conclusion, he explained that some countries in Africa has made progress in introducing disability related legislation, but many of these laws have not yet been implemented. Hence, the first sub- article that is the 'entry assessment or admission procedure designed for disabled student in higher education shall be different from others..... is practiced in all sample universities. Thus, this practice is in line with this sub article. Supporting this, UNESCO (1999) study showed that with regard to admission procedure, the university was following an affirmative action for disabled students in Ethiopia.

\section{Conclusions}

The purpose of this study was to investigate the administrative and social assistive services given for students with disabilities in the selected higher education institutions of Amhara regional state. The data collected through different instruments from various informants were analyzed qualitatively. Based on the findings of the research, the researcher has reached the following conclusions

1. The administrator provided different support services for students with disabilities. That is, they provided financial, stationary materials, modes, sanitation materials, assistive devices, laundry and photocopy and trainings services. However, they did not provide special auxiliary aids for students with disabilities such as sign and braille language professionals.

2. The university took different activities in order to create a social accessibility for students with disabilities by celebrating a well coming ceremony for freshman students, providing trainings for students and staffs, establishing disability club and developing positive attitude to students with disabilities.

3. Except the admission criteria, the support services for students with disabilities indicated in the higher education proclamations were not effectively implemented in the sample universities.

\section{Recommendations}

Based on the findings of the study, the following major recommendations were forwarded:

1. The university should employee special needs education professionals in order to decide the students' eligibility for different supports and related services and provide sign and braille language translations for students with sensory disabilities inside and outside the classroom.

2. The university staffs should know the higher education proclamations set by FDRE and implement its sub articles that give due emphasis on the support services provided for students with disabilities accordingly.

3. The MOE should evaluate and comment the social accessibility of the university for students with disabilities while it is under construction in relation to the building proclamation of Ethiopia.

4. The university should develop specific rules, regulations and guidelines that used to guide the provisions of support services for students with disabilities.

5. Further research needs to be conducted on the provision of support services for each category of students with disability separately in higher education institution in Ethiopia. (i.e. Visual and hearing impairment, physical disability, health impairment, learning and communication disorder.)

\section{References}

Anderson MPI (1993). Social support and barriers to post-secondary education: Experience of students with physical disabilities. Unpublished master's thesis, University of Alberta at Edmonton, Canada

Barnes, C. (2004). Disability: Disability Studies and the Academy. In J. Swain., S. French, C.

Bretz, R., \& Johnson, L. (2000). An innovative pedagogy for teaching and evaluating computer literacy. Information Technology and management,

Collins KD (1995). A model of college adjustment for students with physical disabilities. Unpublished doctoral dissertation, University of Illinois at Urbana-Champaign.

Dash, N. (2009). Support Services for Children with Special Needs in the State of Sikkim Lovely Professional University, Phagwara, Punjab,India. Anuradha Rai, Research Scholar, Deptt of Education, Lovely Professional University, Phagwara, Punjab.

English KM (1993). The role of support services in the integration and retention of college students who are hearing-impaired. Unpublished doctoral dissertation, Claremont Graduate School and San Diego State University

Fuller, M., Healey, M., Bradley, A., Hall, T. (2004). Barriers to Learning: a systematic study the experience of disabled students in one university. Studies in Higher Education,

Gall, M.D., Gall, J.P \& Borg, W. R. (2003). Educational Research an Introduction (7th Ed.). New York: Pearson 
Education, Inc.

Getachew, W and Belay, S. (2012). Special Needs Education (complied). A module for the Course special Needs Education for Linear Program Students. Unpublished.

HEATH (1999). Creating options: A resource on financial aid for students with Disabilities. Washington, DC: George Washington University, Graduate School of Education and Human Development. URL: http://www.heath.gwu.edu/PDFs/2003\%20Finaid\%20Document.pdf (retrieved on 10, January, 2017).

Handicap International. (2009). Accessibility: How to Design and Promote an Environment Accessible to All? Vassel Graphique printing: press

Hatch, T. (1998). How comprehensive can Comprehensive Reform be? Phi Delta Kappan. 79. 518-522

Individuals with Disabilities Education Act (IDEA), (1997). Retrieved on November, 2017,

Johnson

Johnson, A. L. (2006). Students with disabilities in postsecondary education: Barriers to Success and implication to professionals. Vistas Online. Retrieved August 31, 2017, From http://counselingoutfitters.com/vistas2006

Jung, K. E. (2003). Chronic illness and academic accommodation: meeting disabled "Unique needs" and preserving the institutional order of the university. Journal of Sociology and Social Welfare, 30(1),

Kenny, M. (2004). Postsecondary students with disabilities and perception of faculty members. The Journal for Vocational Special Needs Education

Kochung, E. (2011). Role of Higher Education in Promoting Inclusive Education: Kenyan Perspective

Mendez, G. (1998). The Effect of Teachers' Perceived Self- efficacy, Beliefs and Subsequent Behaviors and Support for Research Based Effective Teaching Behaviors on their Attitude toward Children with Special Needs: Implications for Inclusive Education. Dissertation Abstract International. URL: www.lib.umi.com/dissertations/search.

Misrak Tarekegn (2006), Challenges and opportunities of access and mobility in Addis Ababa; the case of people, with motor and visual impairments, Publisher Addis Ababa University School of Graduate Studies http://www.rrtc.hawaii.edu/products/phases/phase2_02.asp?studyNumber

MOE (2006). Special Needs Education Program Strategy: Emphasizing Inclusive Education to Meet the UPEC and EFA Goals. National Report. Addis Ababa.

President Obama. (2014). Supporting Individuals with Disabilities. The President's fiscal year 2014 budget request in education Report. Washington` DC.

Putnam, M., Geenen, S., Powers, L., Saxton, M., Finney, S., \& Dautel, P. (2003). Health and

Wellness: People with disabilities discuss barriers and facilitators to wellbeing. Journal of

Stinson, M. and Anita, S. (1999). Considerations in Educating Deaf and Hard of Hearing Students in Inclusive Settings. Journal of the Deaf Students and deaf Education, 4, 163-175

Tirussew, Tefera..(2005).Disability In Ethiopia: Issues, Insights and Implications. Addis Ababa: Addis Ababa University Press.

Tirussew Teferra (1994). Psychosocial and Educational Problems of Students with Disabilities in Addis

Ababa University. Ethiopian Journal of Health Development Vo.8, No.1, 1994.

Tomlinson, C. A. (1999). The differentiated classroom: Responding to the needs of all learners. Ascd. Retrieved September 24, 2017 from http://classroom.leanderisd.org/users/3748/docs/what_is_differentiation.pdf

Tomlinson, C. A., Kaplan, S. N., Renzulli, J. S., Purcell, J., Leppien, J.,\& Burns, D. (2002). The parallel

Curriculum: A design to develop high potential and challenge high-ability learners. Thousand Oaks

The Federal Democratic Republic of Ethiopia. (2009). Federal Negarit Gazeta. Higher Education Proclamation NO. 650/2009. . 15 th Year No. 64 Addis Ababa 17th September, 2009

The Federal Democratic Republic of Ethiopia. (2009). Federal Negarit Gazeta. Ethiopian Building Proclamation No. 624/2009. 15th Year No. 31 Addis Ababa 6th May, 2009

The Federal Democratic Republic of Ethiopia. (2003). Federal Negarit Gazeta. Higher Education Proclamation no. 351/2003. $9^{\text {th }}$ year no. 72, Addis Ababa-3 ${ }^{\text {rd }}$ July, 2003.

United Nations. (2006). Convention on the Rights of Persons with Disabilities -New York: United Nations. URL: http://www.un.org/disabilities/convention/conventionfull.shtml [11 Jan. 2018]

UN. (1983). World Program of Action Concerning Disabled Person. New York.

UNESCO (1999). Provision for Students with Disabilities in Higher Education. The UNESCO Section for Special Education. 


\title{
Assessing Indonesian Local Government eGovernment- eService Quality: Dimensions and Alternative Model of eService Quality from Banyuwangi's SIPO (Online Permit Registration System)
}

\author{
Rachmat Hidayat ${ }^{1)}$, Tree Setiawan Pamungkas ${ }^{2)}$ \\ 1. Lecturer of Postgraduate Administrative Study Dept, University of Jember, J1 Kalimantan Kampus \\ Bumi Tegalboto, Jember 68121, Indonesia \\ 2. Lecturer of Public Administration Dept, University of Jember, J1 Kalimantan Kampus Bumi \\ Tegalboto, Jember 68121, Indonesia \\ *E-mail of the corresponding author: rachmat.hidayat@unej.ac.id
}

\begin{abstract}
A decentralized mode of local government in Indonesia has subsequently leads to a local initiative for the improvement of local government public service delivery. The regency of Banyuwangi launch an eService Online Permit Registration System (SIPO), which covers 45 type of mostly local business licenses. This paper sought to asses local government eService Quality in the context of one local government in Indonesia, especially in the regency of Banyuwangi in the eastern part of Java. The quantitative approach is used in this research, as well as the application of Structural Equation Modelling for integrating the analysis among three important dimensions of eService: Organization, Information and the service quality. The study finding proposes an alternative model for assessing eService at local government which highlight the important of content management, the stable of eService operating system, and the organizational efficiency as the backbone of eService based at local government level.
\end{abstract}

Keywords: eService model, Decentralization, East Java

DOI: $10.7176 / P P A R / 9-1-04$

\section{Background of the Study}

Information technology not only offers low costs to obtain information and reservations that can be made online, but also provides a means of communication among tourism suppliers, intermediaries, and endconsumers (Kim, 2004). With the current developments and a decentralized mode of government, almost all organizations adopt information technology, not only to reduce costs and efficiency, but also as a means to provide services to ensure customers' satisfaction. To provide maximum benefit from adopting technology by companies and governments and provide satisfying services, and open business opportunities, providing adequate information and communication technology infrastructure is requirement that must be met by the company.

Limi (2008) states that infrastructure is one of the most important supporting factors in economic development. Platforms embedded in information technology, such as personal computers, mobiles, internet, databases and others, have major contributions in organization. According to Piatkowski (2003), there are three contributions provided by information technology platforms that pose an impact on organizational performance, namely (1) providing business feasibility, (2) providing more accurate, reliable, up to date information to the company, and (3) providing solutions to classic problems faced by companies in business activities. The use of e-mail, social network media makes one easily follow the development of the information needed.

Indonesian political devolution of decentralization has shifted the role of innovation for Indonesian local government at local level (Hidayat,2017). Further, Information technology development in the field of services carried out by Banyuwangi Regency has been carried out in various fields. One of the developments of information technology-based services is the Online Permit Registration System (SIPO). SIPO is a system developed by the Agency of One Door Investment Services and Integrated Services of Banyuwangi Regency. SIPO can be used for the registration process of 45 licensing services in Banyuwangi Regency.

A previous research (Parasuraman et al., 2000) shows that the implementation of online public services is influenced by the quality of the system and also the quality of information including 10 (ten) dimensions of quality (reliability, responsiveness, competence, access, courtesy, communication, credibility, security, understanding and tangible). Several other studies have also found that an online public service is influenced by service quality and information quality (Aladwani, 2002; Cai, 2003; Barnes, 2002; Jun 2004; Li, 2002; Loiacono, 
2002; Parasuraman, 2005; Sohn, 2008; Yang, 2004).

\section{Dimensions of Service, Information, and Organization Quality of eService}

Service quality is generally related to the quality of service content and service delivery (Tan, Benbasad and Cafetely, 2013). Furthermore, Hien (2014) points out that the quality of services is related to the measurement of how well the services provided are able to meet users' needs and desires. In the development of further services, Parasuraman et al. (2000) state that the quality of online services is to extent to which a web site facilitates efficient and effective shopping, purchasing, and delivery.

In terms of the development of online public services, the emergence of self-service technology (SST) has come under the spotlight. SST refers to interface technology that allows service users to independently carry out services, rather than involving service personnel (Meuter, 2000). SST offers several advantages, comprising of reduced service costs, easy access to information, alternative support methods, and better service. Given the importance of self-service technology (SST), there are 3 (three) key dimensions need investigation with respect to Quality Service perspective.

- Reliability: service providers are able to provide accurate and reliable services

- Communication: care for customers and ease of access to services can be informed to service users through various channels

- Responsiveness: agency is willing to help service users get services quickly and efficiently.

In relation to the variable quality of e-Government information services, there are 2 (two) key words, namely conveying information to the public and increasing government transparency (Ma et al., 2005). The aim of the egovernment system is to provide useful and vital information, which is also credible and accessible, in timely manner (Baker, 2009). User assessment of information provided by the government is concerned with how useful information provided by the government is (Wu, Liu, Wang and Wang, 2013). In this study, ease of use, content, level of security, and trust in information become key dimensions. Organizational variables are deemed essential in a system. In the context of public services, organizations are related to organizational management and support. They are also related to the internal process of an organization to provide services to users (Hien, 201). In this study there are 2 (two) main dimensions namely system efficiency and system stability in the process of public service. The following figure is the modeling applied in this study. This research model places 8 (eight) dimensions and 3 (three) main variables, which involve quality service, information service perspective, organization service perspective on eService in Banyuwangi regency.

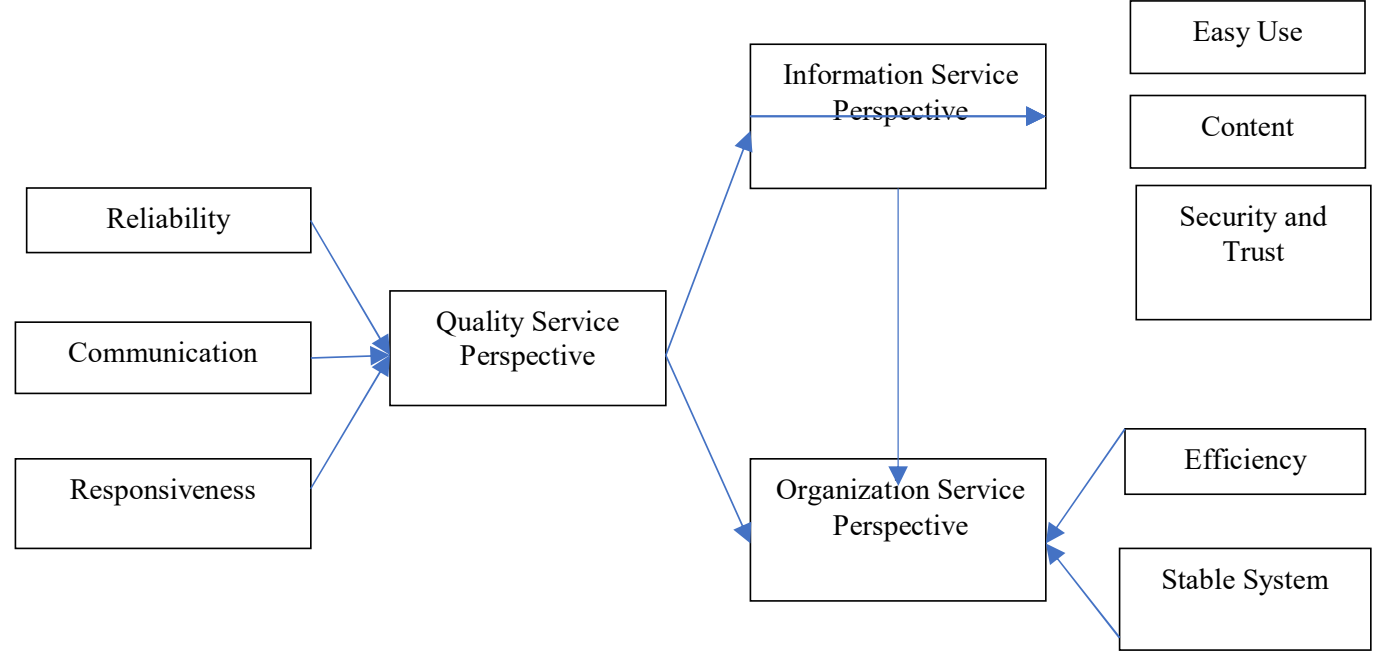

Figure 1. Research Model of eService SIPO in Banyuwangi Regency 


\section{Analysis of the Model}

This study aims to identify quality service perspective, information service perspective, and organization service perspective on the implementation of online licensing services (SIPO) in Banyuwangi regency. To identify some of these variables, quantitative approach is at work. Variables of identification are investigated questionnaires distributed to users of online services in Banyuwangi regency. The Likert scale is used in each question, where a scale of 1 indicates very strong disagreement, while a scale of 5 indicates very strong agreement. To test the hypothesis, CFA (Confirmatory Factor Analysis) technique is used, which is coupled with path analysis, a part of SEM (Structural Equation Modeling). Data analysis deploys Lisrel and SmartPLS software.

\section{The SIPO eService user in Banyuwangi}

This study involved the people of Banyuwangi as research respondents. The respondents were users of the Online Permit Registration System (SIPO) developed by the One-Door Investment Services and Integrated Services of Banyuwangi Regency. Data collection was carried out for 2 (two) months from August to September 2018. Respondents could be categorized into several groups based on age, gender, education, employment and income. Based on the age group of respondents, the respondents were categorized into 5 (five) intervals namely age $<20$ years, age 20-29 years, age 30-39 years, age 40-49 years and also age $>50$ years. Specifically, the age category of respondents is presented in the following table.

Table 1. Respondent Category based on Age Group

\begin{tabular}{|l|r|r|}
\hline \multicolumn{1}{|c|}{ Category } & Frequency & \multicolumn{1}{|c|}{ Percent } \\
\hline$<20$ years & 2 & 2,777778 \\
\hline 20 - 29 years & 24 & 33,33333 \\
\hline $30-39$ years & 19 & 26,38889 \\
\hline $40-49$ years & 18 & 25 \\
\hline$>50$ years & 9 & 12,5 \\
\hline Total & 72 & 100 \\
\hline
\end{tabular}

Most of the respondents in this study are at the age of 20-29 years with a total of 24 people. In the age group of 30-39 years, 19 people are involved. In the third place is the age group 40-49 years with a total of 18 people. The fourth age group $>50$ years involves a total of 9 people. The highest group, aged $<20$ years with a total of 2 people. The results clearly indicate that most applicants are in productive age. Furthermore, based on gender category, respondents are categorized into 2 (two) genders or gender groups, namely men and women. The results of the study showed that some respondents were men with a total of $55.56 \%$. Distribution of respondents based on gender categories is presented in the following table:

Table 2. Respondent Category based on Gender

\begin{tabular}{|c|c|c|}
\hline Gender & Frequency & Percentage \\
\hline Male & 40 & 55,55556 \\
\hline Female & 32 & 44,44444 \\
\hline Total & 72 & 100 \\
\hline
\end{tabular}

Based on the education level, the respondents are categorized into primary education, secondary education, and tertiary education. Judging from the education level group, the majority of respondents are college graduates, which reaches $47.22 \%$ of the entire group. This is followed by secondary education with a total of $44.44 \%$. In the third position, respondents with primary education reach $8.33 \%$ of the total population. As such, it can be seen that the majority of respondents have secondary education and tertiary education. Grouping of respondents' level of education can be seen in the following table: 
Table 3. Respondent Category based on Education Level

\begin{tabular}{|l|r|r|}
\hline \multicolumn{1}{|c|}{ Education Level } & Frequency & Percentage \\
\hline Primary Education & 6 & 8,333333 \\
\hline Secondary Education & 32 & 44,44444 \\
\hline Tertiary Education & 34 & 47,22222 \\
\hline Total & 72 & 100 \\
\hline
\end{tabular}

Based on professions, the respondents can be categorized into 7 (seven) groups, namely civil servants, entrepreneurs, traders, private employees, farmers, employees at informal, and other Sectors. The research results evince that the majority of respondents are in 4 (four) professions, namely private employees with a total of $29.17 \%$, entrepreneurs with a total of $22.22 \%$, traders with a total of $18.06 \%$, and other jobs with a total of $15.27 \%$. By contrast, those working as civil servant contribute only $8.33 \%$. Informal sector workers comprise of $4.17 \%$ of total population. The group working as farmers accounts for $2.78 \%$ of total respondents. Respondents based on their professions are categorized in the following table.

Table 4. Respondent Category based on Based on Profession

\begin{tabular}{|l|c|c|}
\hline \multicolumn{1}{|c|}{ Professions } & Frequency & Percentage \\
\hline Civil servants & 6 & 8,333333 \\
\hline Entrepreneurs & 16 & 22,22222 \\
\hline Traders & 13 & 18,05556 \\
\hline Private employees & 21 & 29,16667 \\
\hline Farmers & 2 & 2,777778 \\
\hline Employees at informal sector & 3 & 4,166667 \\
\hline Others & 11 & 15,27778 \\
\hline Total & 72 & 100 \\
\hline
\end{tabular}

Based on income, the respondents can be grouped into several income levels, ranging from Rp 500.000$\mathrm{Rp}$ 1.000.000, Rp 1.000.000-Rp 1.500.000, Rp 1.500.000-Rp 2.000.000, and over Rp 2.000.000. From the research results, most respondents with income $>2$ million account for $47.2 \%$ of total sample. Those with income ranging from 1.5 million - 2 million include $31.94 \%$ of total sample. Respondents with income ranging from 1 million to 1.5 million reach $18.06 \%$ of total sample. In addition, those with income of 500 million- 1 million contribute $2.78 \%$ to the overall sample. The table of the characteristics of respondents based on the amount of income as follows.

Table 5. Respondent Category based on based on Income

\begin{tabular}{|l|c|c|}
\hline \multicolumn{1}{|c|}{ Income Category } & Frequency & Percentage \\
\hline Rp 500.000-Rp 1.000.000 & 2 & 2,777778 \\
\hline Rp 1.000.000-Rp 1.500.000 & 13 & 18,05556 \\
\hline Rp 1.500.000-Rp 2.000.000 & 23 & 31,94444 \\
\hline Over Rp 2.000.000 & 34 & 47,22222 \\
\hline Total & 72 & 100 \\
\hline
\end{tabular}

\section{Analysis and Results}

The analysis is divided into three parts. In the first and second parts, Lisrel statistical software is operative for the analysis. The first part measures the relationship between variables in the study. With the aim of knowing whether relationship exists between variables and how strong the relationship is between variables in eService. 
The second part measure the effects of each variable in eService. This is done to find out whether the relationship has a significant influence or not. In addition, it delves into whether the influence is negative or positive on eService. In the third part, modeling is conducted using Structural Equation Model (SEM).

\subsection{The Correlation among eService Dimensions and Variables}

Relationship investigation is done by connecting each dimension through a predetermined latent variable. A latent variable consists of quality service perspective, information service perspective and organization service perspective. Before testing the relationship between latent variables, the analysis investigates the relationship of each dimension is with each latent variable.

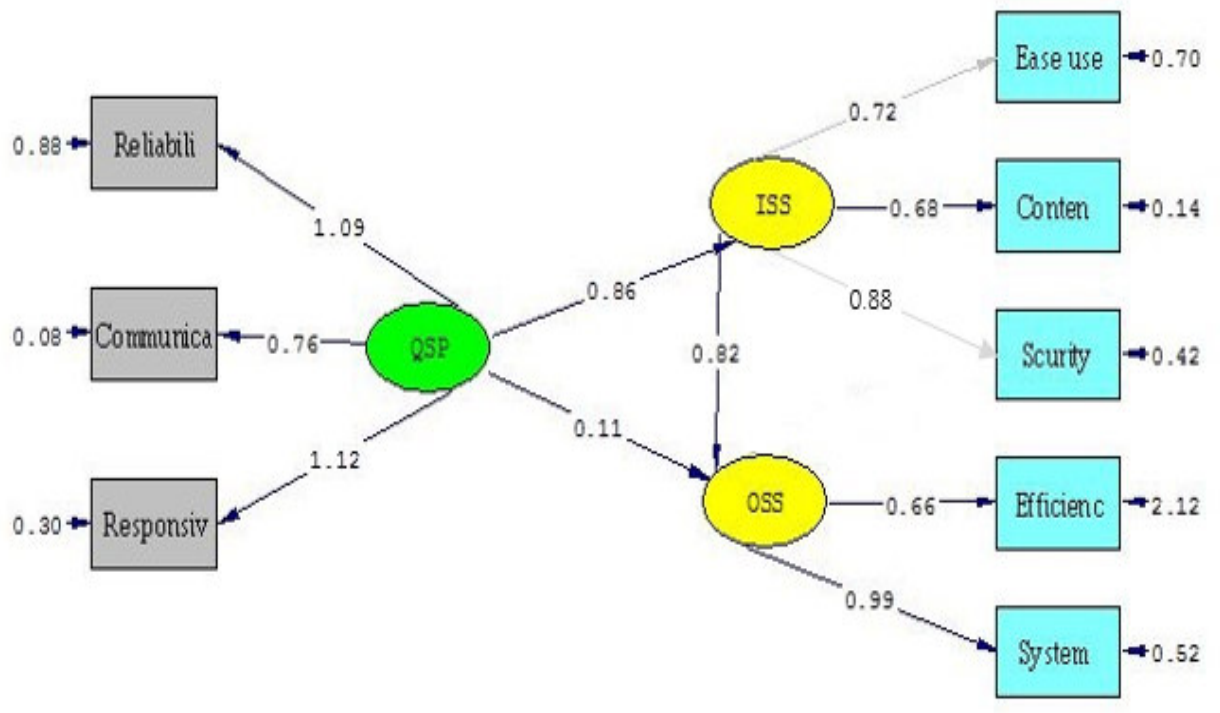

Chi-Square $=46.10, \mathrm{df}=17, \mathrm{P}-\mathrm{value}=0.00017, \mathrm{RMSEA}=0.155$

Figure 2. The Analysis Results on Correlation Test

The test results of the relationship among the dimensions with each latent variable indicate the following findings:

1. The relationship between reliability and other dimensions through latent quality service perspective variables indicates strong relationship.

2. The relationship between communication and other dimensions in the quality service perspective variable shows strong relationship.

3. The relationship between responsiveness and other dimensions in the quality service perspective variable shows a strong relationship.

4. The relationship between ease of use and other dimensions in information service perspective indicates weak relationship.

5. The relationship between content and other dimensions in information service perspective variables shows strong relationship.

6. The relationship between security and other dimensions in the organization service perspective variable indicates weak relationship.

7. The relationship between the efficiency dimension and other dimensions in the Organization service perspective variable shows a strong relationship.

8. The relationship of the system dimension with other dimensions in the organization service perspective variable shows strong relationship.

After testing the relationship of each dimension through latent variables, the relationship between each latent 
variable is tested. The test results are presented as follows.

1. The Relationship between Quality Service Perspective and Information Service Perspective

Based on the test results on the relationship between the Quality Service Perspective and the Information Service Perspective, strong relationship is evident between the two. This is indicated by the t-test value of 0.86 , which shows a strong relationship between quality service perspective and information service perspective.

2. The Relationship between Quality Service Perspective and Organization Service Perspective

The test results on the relationship between service quality perspective and organization service perspective reveal relationship between the two. However, the relationship between quality service perspective on organizational perspective is not significant, as this is indicated by the t-test value of 0.11 .

3. The Relationship between Information Service Relations Perspective and Service Perspective Organization

The test results on the relationship between information service perspective and organization service perspective indicate that there is a relationship. The t-test value of the information service perspective relationship with the organization service perspective is 0.82 . This shows that there is a significant relationship between informational service perspective and organization service perspective.

Based on the test results on the relationship among all dimensions and variables, not all dimensions pose strong influence on each variable and dimension. Ease of use and security dimensions do not have a strong relationship with other dimensions and variables. By contrast, the latent quality service perspective variable does not have a strong relationship with the organization service perspective.

\subsection{The Effect among eService dimensions and variables}

The correlation analysis conducted to see the influence of each variable. Relationship testing is done using Lisrel. The dimensions of each latent variable are tested for influence on each dimension through latent variables. The results of the relationship test between variables can be seen in the following figure:

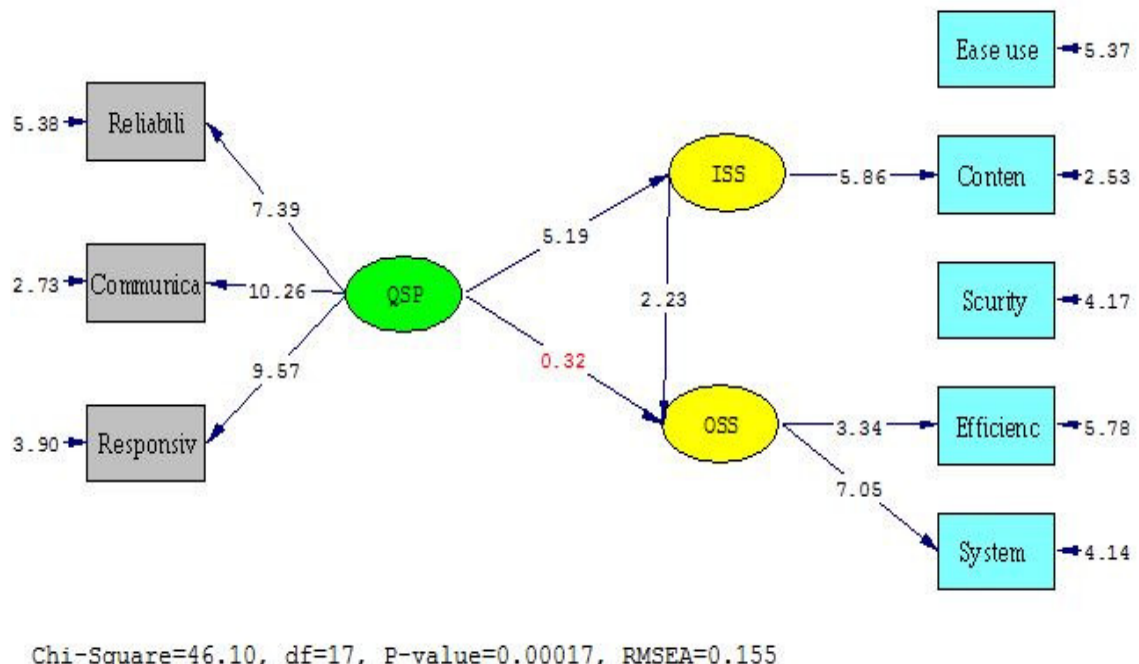

Figure 3. The Analysis Results on Correlation Test

Based on the results of the test of the relationship between dimensions through each latent variable, the researchers revealed the following findings. 
1. There is positive influence of reliability dimensions on other dimensions through latent quality service perspective variable. This influence is proven significant.

2. There is positive influence of communication dimension on other dimensions in quality service perspective variable. This influence is proven significant.

3. There is a positive influence on the dimensions of responsiveness with other dimensions in the variable quality service perspective. This influence is significant

1. There is no effect of the easy of use on other dimensions in Information service perspective variable.

2. There is a positive influence on the Content dimension with other dimensions in the Information service perspective variable. This influence is proven significant.

3. There is no influence of security on other dimensions in the Information service perspective variable.

4. There is positive influence of the efficiency on other dimensions in the Organization service perspective variable. This influence is proven significant.

5. There is positive influence of system on other dimensions in the Organization service perspective variable. This influence is proven significant.

To investigate the effect between each latent variable, the relationship between latent variables is put under analysis with the following results.

1. There is significant influence between quality service perspective variables and information service perspective as evinced by t-test value of 5.19 .

2. There is significant influence between information service perspective and organization service perspective variables as eivnced by t-test value of 2.23 .

3. There is significant influence between quality service and organizational service, as evinced by a t-test value of 0.32 . However, the influence of these two variables is not significant.

Based on the analysis results of all dimensions and variables in this study, there are several things the authors can draw. First, the dimensions of ease of use and security have no influence on other dimensions and variables. Second, quality service perspective does not have significant effect on the variable of organization service perspective. Thus, there are only two significant effects, that is the quality service perspective on the information system perspective and the information system perspective on the variable organization service perspective

\section{3. eService dimensions and variables Analyzing and Structural Equation Modeling}

In this section, a modeling analysis is performed using structural equation modeling using SMARTPLS. The results of the analysis using Structural Equation Modeling can be seen in the following figure.

The analysis results have found out the coefficient value of each dimension to other dimensions. Hereunder are some dimensions which have a high coefficient value.

1. The dimension of communication to reliability with a coefficient value of 0.557

2. The dimension of system reliability dimensions to stable system dimensions with coefficient value of 0.503

3. The dimension of stable system dimensions to efficiency dimension with a coefficient value of 0.506

4. The dimension of ease of use toward security and trust emission with coefficient value of 0.410 .

The analysis performed in the study has identified several relationship patterns and important dimensions as well as variables in the public service of online licensing in Banyuwangi regency, which encompasses the following.

1. Quality Service has a strong relationship and poses a significant influence on information servicer perspective. Thus, the quality service in online service conditions in Banyuwangi regency is deemed important in the provision of information service

2. Information service has strong relationship and poses significant influence on organizational service perspective. Therefore, information service toward online service conditions in Banyuwangi regency is considered important to provide an organization service.

3. Quality service perspective has weak relationship and does not have significant relationship with organization service. As such, quality service in online service conditions in Banyuwangi regency is considered inessential in providing organization service.

4. The dimension of ease of use and security as well as trust have weak relationship and no significant influence on all indicators and variables. As a corollary, in the online service conditions of Banywuangi ristrict, these dimensions do not have vital role in providing quality online services.

5. Dimensions of reliability, communication, responsiveness, content, efficiency and stable system in the online service conditions in Banyuwangi regency make very substantial contribution to the creation of 
online services in Banyuwangi regency. This is based on the test results related to the relationship and influence among dimensions, which indicates a strong relationship and significant influence.

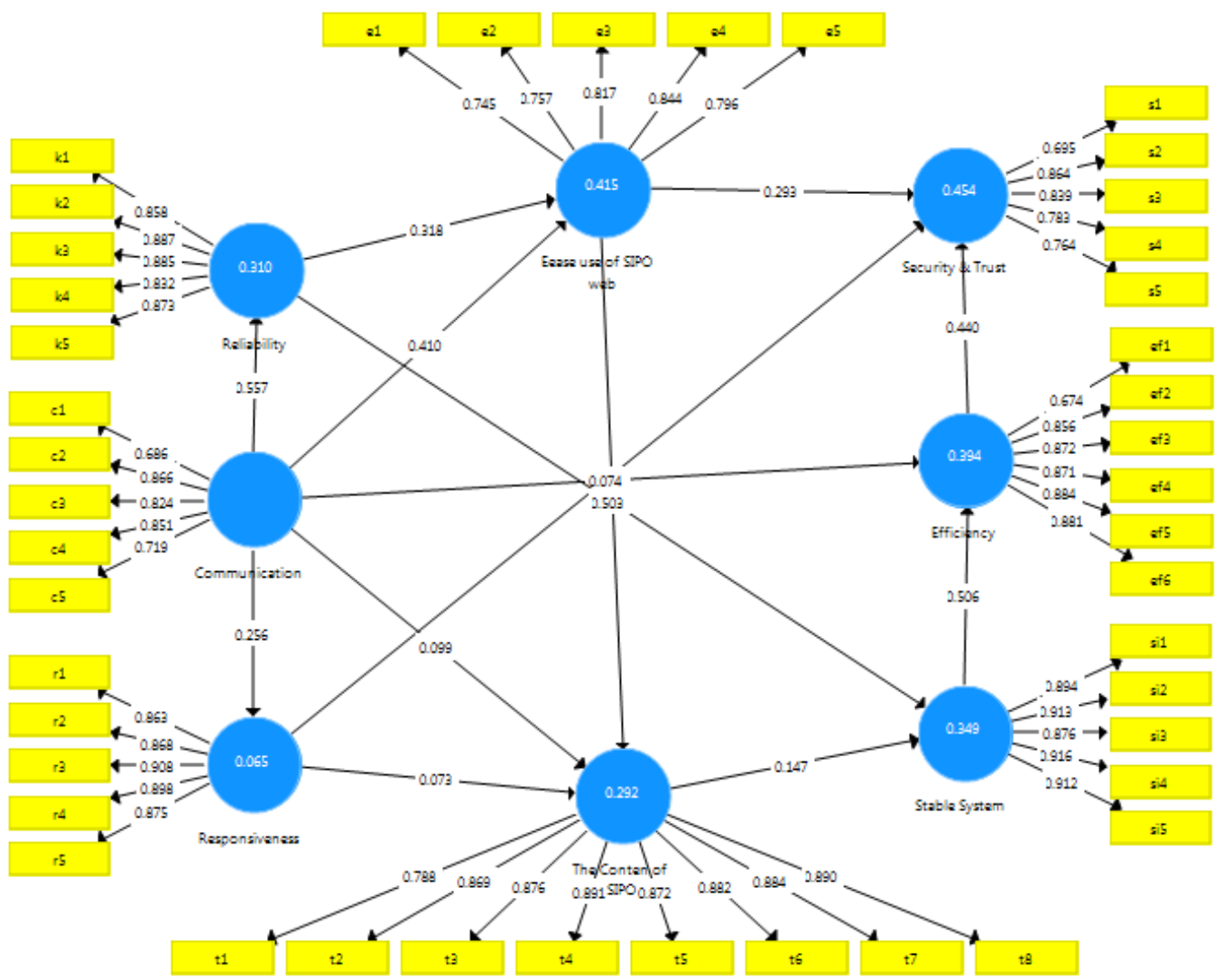

Figure 4. Modeling the eService Dimensions from Banyuwangi

\section{Conclusion and Implication: Alternative Model for assesing eService at local government level}

Subsequent to analyzing various variables in eService research of Banyuwangi regency, there are some interesting findings which worth careful discussion in this study are. This study has found that not all variables and dimensions hold strong relationship and pose significant influence on other dimensions and variables. From the results of the relationship analysis, quality service is proven to have weak relationship with organization service. This is corroborated by test results germane to the effect of quality service on the organization service perspective, which does not demonstrate significant relationship.

The relationship and the influence of quality service perspective on an organization service perspective can be interpreted in the results of research conducted on online services in Banyuwangi regency. The quality service perspective is considered inessential in actuating the organization service perspective framework. Therefore, the organizational process does not necessarily take into account the quality of service received by service users.

In addition to the relationships and influences between variables, the analysis on relationships and the influence of the dimensions in this study highlights some interesting results. The dimensions of ease of use and security and trust have weak relationship with other dimensions and variables, and nor do they pose influence on other dimensions and variables. Thus, these two dimensions are considered insignificant in the online service process of Banyuwangi regency.

The implementation of online services in Banyuwangi regency needs to ponder several things for service improvement. First, in the quality service perspective variable, each dimension needs to be given emphasis because the research results indicate that reliability, communication, and responsiveness as a whole have strong 
relationship and significant influence on the overall online service process in Banyuwangi regency.

Second, the information service perspective variable is only the dimension of the content that is considered to have a strong relationship and a significant influence on the overall service process. By contrast, the dimensions of easy use and security and trust do not have strong relationship and do not have influence on the overall online service process. Third, in the organization service perspective variable, the efficiency and system dimensions must be improved to improve the overall online service process.

From the modeling created based on eService in Banyuwangi regency, this research has identified several important dimensions and variables within the eGov platform. The following figure summarizes these variables and dimensions into a model that integrates eService-based eGov quality that is established by combining the dimensions of organizational quality and information quality in the eService mechanisms. On the service user side, this model identifies the importance of online service system reliability factors, effective communication and steady responsiveness from eService service personnels to be strategic in the eService-based eGov services.

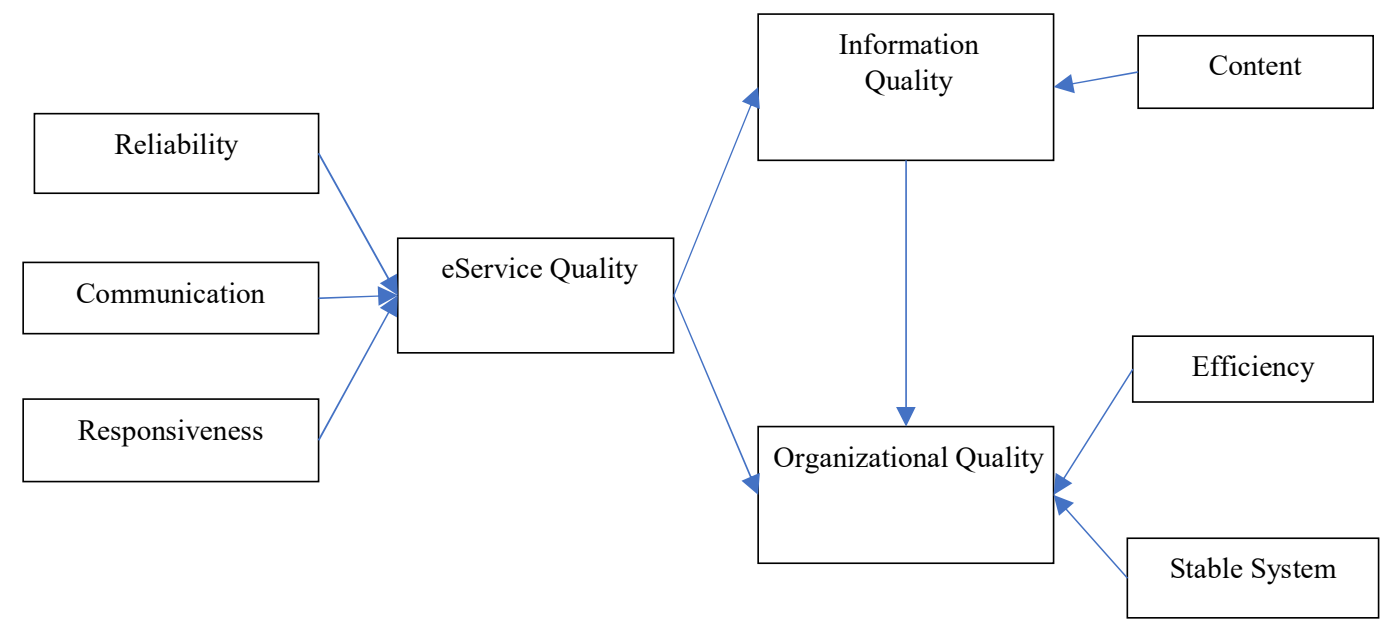

Figure 5. The Dimension for assesing eService at local government level

\section{Recommendation}

The research results on online licensing services in Banyuwangi regency have shed lights on the interaction, influence, and relationship of the dimensions pertinent to the quality of eService. This study also proposes an alternative model of eSevice assessment at the local government level that will run effectively by paying attention to several aspects for improvement, grounded within the experience of local governments in Indonesia, specifically Banyuwangi regency. Hereunder are important implications concerning strategic points garnered which are worth emphasis from the study.

1. Increasing the awareness of service providers about service users and providing accurate services

2. Improving communication media, clarity of content, and service information to ensure easy access for service users

3. Accruing the willingness and care of service personnel to provide assistance to service users in order to facilitate and accelerate services

\section{References}

Aladwani, A.M., Palvia, P.C., (2002) Developing and validating an instrument for measuring user-perceived web quality. Information and Management, 467-476.

Baker, D.L. (2009). Advancing e-Government performance in the United States through enhanced usability benchmarks. Government Information Quarterly, 26(1), 82-88.

Barnes, S.J., Vidgen, R.T., (2002) An integrative approach to the assessment of E-commerce quality. Journal of Electronic Commerce Research 114-127. 
Cai, S., Jun, M., (2003) Internet users' perceptions of online service quality: A comparison of online buyers and information searchers. Managing Service Quality 504-519.

Hidayat, R. (2017). Political Devolution: Lessons From a Decentralized Mode of Government in Indonesia. SAGE Open, 7(1), 2158244016686812.

Hiyen, Nguyen Manh, (2014) A Study on Evaluation of E-Government Service Quality, Journal of Humanities and Social Science, 16 - 19

Jun, M., Yang, Z., Kim, D.,. (2004) Customers' perceptions of online retailing service quality and their satisfaction. International Journal of Quality and Reliability Management, 817-840.

Li, Y.N., Tan, K.C., Xie, M., (2002) Measuring web-based service quality. Total Quality Management and Business Excellence 685-700.

Limi, H., \& Suomi, R. (2008). A Proposed Scale for Measuring E-service Quality. International Journal of eService, 1-10.

Loiacono, E.T., Watson, R.T., Hoodhue, (2002) D.L. WEBQUAL: measure of web site quality. Marketing Educators Conference: Marketing Theory and Applications 432-437.

Kim, DO Yeong, The Implicit Life Satisfaction Measure, Asian Journal of Social Psicology, 2004, $236-262$.

Ma, L., Chung, J., \& Thorson, S. (2005). E-government in China: Bringing economic development through administrative reform. Government Information Quarterly, 22(1), 20-37.

Meuter, M.L., Ostrom, A.L., Roundtree, R.I., and Bitner, M. J., (2000) "Self-Service Technologies: Understanding Customer Satisfaction with Technology-Based Service Encounters," Journal of Marketing, Vol.64, pp. 50-64.

Parasuraman, A., Grewal, D., (2000) The impact of technology on the quality-value-loyalty chain: a research agenda. Journal of the Academy of Marketing Science168-174.

Parasuraman, A., Zeithaml, V.A., Malhotra, A., (2005) E-S-Qual: A multiple-item scale for assessing electronic service quality. Journal of Service Research 213-233.

Piatkowski, M. (2003). Can Information and Communication Technologies Make A Difference in the Development of Transition Economics? Information Tecnologies and International Development, 39-53.

Sohn, C., Tadisina, S.K., (2008) Development of e-service quality measure for internet-based financial institutions. Total Quality Management and Business Excellence 903-918.

Yang, Z., Fang, X., (2004) Online service quality dimensions and their relationships with satisfaction: A content analysis of customer reviews of securities brokerage services. International Journal of Service Industry Management 302-326.

Wu, J., Liu, L., Wang, N., \& Wang, Z. (2013). Interorganizational IT capability in China: exploring the differences between state-owned and non-state-owned enterprises. Journal of System and Management Sciences, 3(3), 14-25. 


\title{
The Complexity of Coordination Among Indonesian State Intelligence Institutions
}

\author{
Sunarko*, Sumartono, M.R. Khairul Muluk, Bambang Santoso Haryono \\ Faculty of Administrative Science, Universitas Brawijaya \\ Jl. MT. Haryono 163, Malang 65145, Indonesia
}

\begin{abstract}
The reforms in Indonesia have given birth to innovations in institutional arrangement and has become one of the priorities for democracy that is still being fought for. The problem that arises after the reforms have taken place is not all state institutions are arranged and in accordance with the values and principles of democracy, including the arrangement of state intelligence institutions in Indonesia. The existing State Intelligence Institutions (besides Indonesian National Armed Forces (TNI) and Indonesian National Police (POLRI)) have Task Implementation Operational Standards (SOPT) which are based on the duties and capabilities possessed, but are not supported by adequate capacity building, so that these institutions are less able to carry out the mandate stated in Article 2 of Law No. 17 Year 2011. Not all existing National Intelligence Institutions' personnels (besides TNI and POLRI) have professional resource capabilities in the intelligence implementation as mentioned in Article 2 and Article 3 of Law No. 17 Year 2011. Almost most of the people or citizens in Indonesia assess intelligence as someone who is looking for information about crime and only in the scope of POLRI and TNI. The complexity of State Intelligence Institutions' Coordination in Indonesia is not something that needs to be made a scapegoat for the failure of intelligence's tasks. On the contrary, it must be seen as a source to achieve the success in carring out the tasks. Therefore the solution that can be done is by the Development of Capacity Building of the State Intelligence Institutions which is supported by the Network Type Command (NTC) coordination model, namely HTM, MTM and NTM model developments. The NTC model is a large coordination model with a broad network but still under one control or command, so that information processing can become increasingly faster and more accurate which in turn can increase high power in carrying out early detection and warning. This model is also able to make a more significant contribution in developing the operational plans and strategies of state intelligence institutions in order to achieve the role, purpose and function of state intelligence effectively.
\end{abstract}

Keywords: Complexity, Institution, Intelligence, The Republic of Indonesia

DOI: $10.7176 / \mathrm{PPAR} / 9-1-05$

\section{Introduction}

Regarding the intelligence implementation, various forms and sources of information in early detection are a first and fundamental step in administering intelligence operational strategies. Therefore, public administration science is expected to carry out the mandate in providing solutions to various problems, including intelligence institutions in Indonesia. As Frederickson thought that:

"The dynamism of state/public administration in an effort to provide its expediency for the sake of public service has given birth to several models, namely, originating from contemporary state administration, seen from the mindset of classical bureaucratic models that have two important components, namely the structure or framework of an organization and ways used to administer people and jobs within the framework of the organization. Whereas in the neo-bureaucracy model, the emphasis is on the decision making process in the organization. On the other hand, the institutional model emphasizes the discussion of the real pattern of organizational behavior. The human relations model emphasizes the pattern of group dynamics, sensitivity training and organizational development. The public choice model focuses more on promoting employee satisfaction, personal development, individual dignity and public choice, (Frederickson, 2010)".

Compared to other organizations in the security sector, intelligence agency indeed has a factor which is unique from the others, among them is to gather information maximally in order to achieve effective goals. Various problems that occur in the country that are related to intelligence problems are the scope of public administration study, various perspectives can be raised to find solutions to these problems. As Muluk stated that:

"The study and practice of public administration in various countries continues to grow, various changes occur along with the development of the complexity of the problems faced by public administrators. This complexity is responded to by theorists by continuing to develop public administration science. Denhardt \& Denhardt reveals that there are three perspectives in public administration, namely old public administration, new public management, and new public service, (Muluk, 2006)”.

The state intelligence institutions in Indonesia are not only limited to the State Intelligence Agency (BIN), or the Strategic Intelligence Agency (BAIS) which is owned by TNI Headquarters, or also the Security 
Intelligence (Intelkam) of POLRI Headquarters. There are quite a number of state intelligence institutions in Indonesia, as stated in Article 7 of Law No. 17 Year 2011 concerning State Intelligence that the scope of State intelligence includes: a). Domestic and foreign intelligence, b). Defense and/or military intelligence, c). Police intelligence, d). Law enforcement intelligence, and e). Ministerial/non-ministerial government institutions intelligence.

The general duties of the state intelligence institution as mentioned in Article 1 of Law No. 17 Year 2011 concerning State Intelligence are as follows:

1. "Intelligence is knowledge, organization, and activities related to the formulation of policies, national strategies, and decision making based on analysis of information and facts collected through work methods for early detection and warning in the context of prevention, deterrence, and overcoming any threats to national security.

2. State Intelligence is the organizer of intelligence which is an integral part of the national security system which has the authority to carry out the functions and activities of State Intelligence.

3. State Intelligence Personnels are Indonesian citizens who have special intelligence capabilities and are devoted to the State Intelligence service (Law No. 17 Year 2011)".

Based on consideration in point c of Law No. 17 Year 2011, it is stated that; "to conduct early detection and warning to prevent the occurrence of abrupt threats, strong and professional State Intelligence is required, in addition, State Intelligence is required to strengthen cooperation and coordination by respecting the law, democratic values and human rights as mandated in The 1945 Constitution of the Republic of Indonesia". Coordination is needed in order to achieve the objectives or tasks of the state intelligence institutions. Coordination mentioned here refers to a synchronous and orderly effort to provide the right amount and time, and direct the implementation to produce a uniform and harmonious action on the intended target. Coordination and cooperation between effective and efficient intelligence institutions in the Republic of Indonesia is needed in order to realize the integration of intelligence steps and results. Intelligence as a means of completing a government is an important issue. This issue becomes increasingly important when thinking more about the role of intelligence in the future and in global issues.

Based on the background of the problem described, the formulation of the problem in this research is:

1. How is the complexity of coordination among state intelligence institutions in Indonesia?

2. How are the SWOT (Strengths, Weaknesses, Opportunities and Threats) conditions of coordination among state intelligence institutions in Indonesia?

3. How is the reform of the coordination of state intelligence institutions in achieving the success of the intelligence task implementation?

4. How is the effective and efficient model of coordination among state intelligence institutions in Indonesia?

Based on the formulation of the problem above, the objectives in this research are to:

1. Describe and analyze the complexity of coordination among state intelligence institutions in Indonesia

2. Describe and analyze the SWOT (Strengths, Weaknesses, Opportunities and Threats) conditions of coordination among state intelligence institutions in Indonesia

3. Describe and analyze the reform of the coordination of state intelligence institutions in achieving the success of the intelligence task implementation

4. Find and develop effective and efficient model of coordination among state intelligence institutions in Indonesia

The results of this research are expected to provide the following contributions:

a. Contribute to the development of public administration science seen from the point of coordination in an institution (Scott, 2008). Coordination becomes the most important part so that the implementation of tasks can run well, it is necessary to carry out administrative functions, especially in the administrating organization so that the organization is able to carry out the activities that are its responsibility.

b. Can broaden the theoretical horizons of public administration in connection with institutional coordination (Scott, 2008) in the transformation and reform between state intelligence institutions. Because coordination problems still need to be solved, KIS (Coordination, Integration, and Synchronization) is provided as a guideline so that the implementation of the main tasks of the organization is successful. Therefore, integration needs to be carried out in unity of action. It is expected that the synchronization is harmonious, balanced, and consistent with each other.

c. As consideration and input for relevant parties, especially state intelligence institutions in Indonesia, namely in policies and efforts to take steps related to coordination policies in the transformation and reform of the State Intelligence Agency in the perspective of institutional theory.

d. As a recommendation material in activities and coordination policies in the transformation and reform of state intelligence institutions in Indonesia, so that they are more precise on the targets, methods and in accordance with their objectives.

e. As a reference for other researchers who have an interest in researching with the same scope and focus of 
research.

\section{Literature Review}

The New State Administration is a call that demands public administration's independence against political science domination and scientific attachment to political science. But unfortunately, the call failed in the intellectual development of the public administration science, but public administration was regarded as "the New Politics of Bureaucracy". The scientific journey of state administration finally returned to state administration again in the 1970s. Here comes the studies of state administrations which focus on "organizational theory and management science" and locus on "public interest and public affairs". According to Zauhar (2001: 57), there are 5 (five) reasons why public administration theory is important, the five reasons include:

a. Public administration theory states something meaningful, which can be applied to real life situations;

b. Administrative theory can present a perspective;

c. Administrative theory stimulates the birth of new ways in different things,

d. The existing administrative theory can be the basis for developing other administrative theories, and

e. Administrative theory helps its users to explain and predict the phenomena faced by them.

According to Sange (1987, in Anggoro, 2008: 42), he stated that coordination is "the process of integrating goals and activities in separate units (departments or functional fields) of an organization to achieve organizational goals efficiently". Coordination is one of the very important stages of work to be carried out in administering a system of administration. According to Khamdani (2014: 26), Coordination is: "Coordination as the achievement of orderly group efforts, and unity of action in the pursuit of common purpose". Verhoest and Bouckaert (2010: 40-49) stated that the coordination mechanism has three models as follows.

1. Coordination with Hierarchy Type Mechanism (HTM)
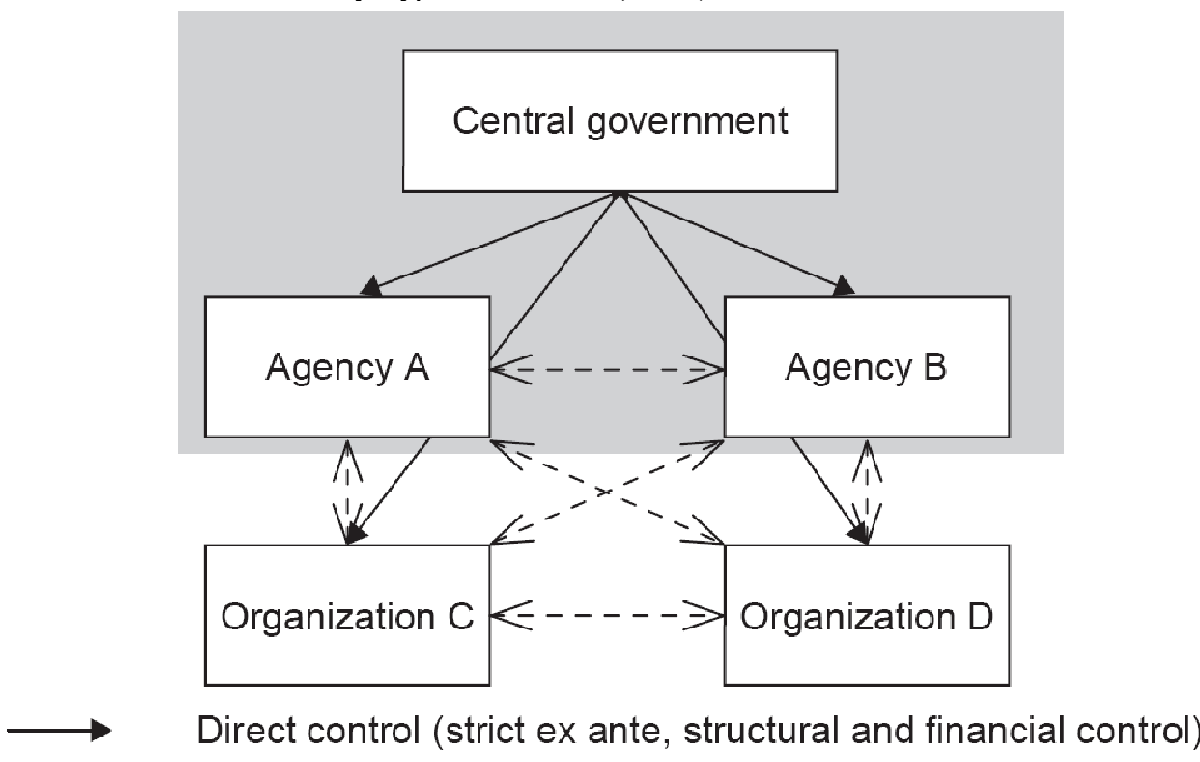

$\leftarrow->$ Quasi-automatic coordination between agencies and organizations

\section{Public sector}

Figure 1. Coordination with HTM Model

Source : Verhoest and Bouckaert (2010:40)

HTM refers to a set of coordination mechanisms that are based on authority and dominance. It involves setting goals and rules, assigning tasks and responsibilities and establishing lines of direct control and accountability. Both management instruments (such as procedures, top-down planning systems or financial management systems) and structural instruments (such as organizational mergers, coordination functions, direct lines of control and accountability) can be used. As stated by Verhoest and Bouckaert (2010: 39) that: "The feature common to all these expressions of the hierarchical coordination mechanism is that authority and power are used to make coordination more or less automatic among organizations and programmes, or at least are used to impose coordination on organizations and individuals. Public organizations' activities are coordinated by the direct control by the government of individual public organizations". 


\section{Coordination with Market Type Mechanism (MTM)}

MTM is based on competition and exchanges between actors, aiming to create incentives for performance. Although the market establishes 'spontaneous' coordination among market participants, the government can 'intentionally' encourage coordination with competition among organizations.

In this case, Verhoest and Bouckaert (2010: 39) stated that : (MTM) "shows the optimal operation of coordination through market-type mechanisms. The coordination of public organizations is mainly 'horizontal' self-coordination induced by the forces of price, competition, supply and demand. Relations between public organizations are mainly based on contractual exchange. The government mainly acts as a market creator and regulator. To the extent that government controls public providers, this control is mainly indirect and ex-post in nature".
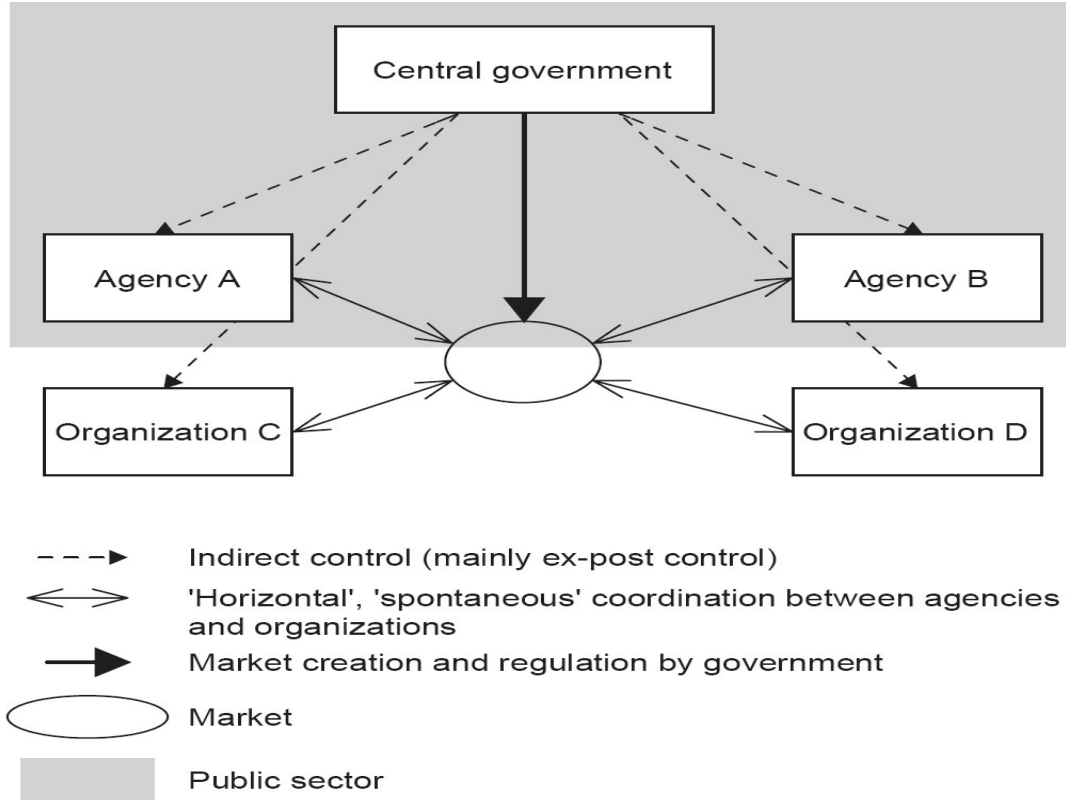

Figure 2. Coordination with MTM

Source : Verhoest and Bouckaert (2010:44)

3. Coordination with Network Type Mechanism (NTM)

NTM is based on mutual dependence and trust. The use of NTM is for the formation of general knowledge, general values and general strategies between coordination partners.

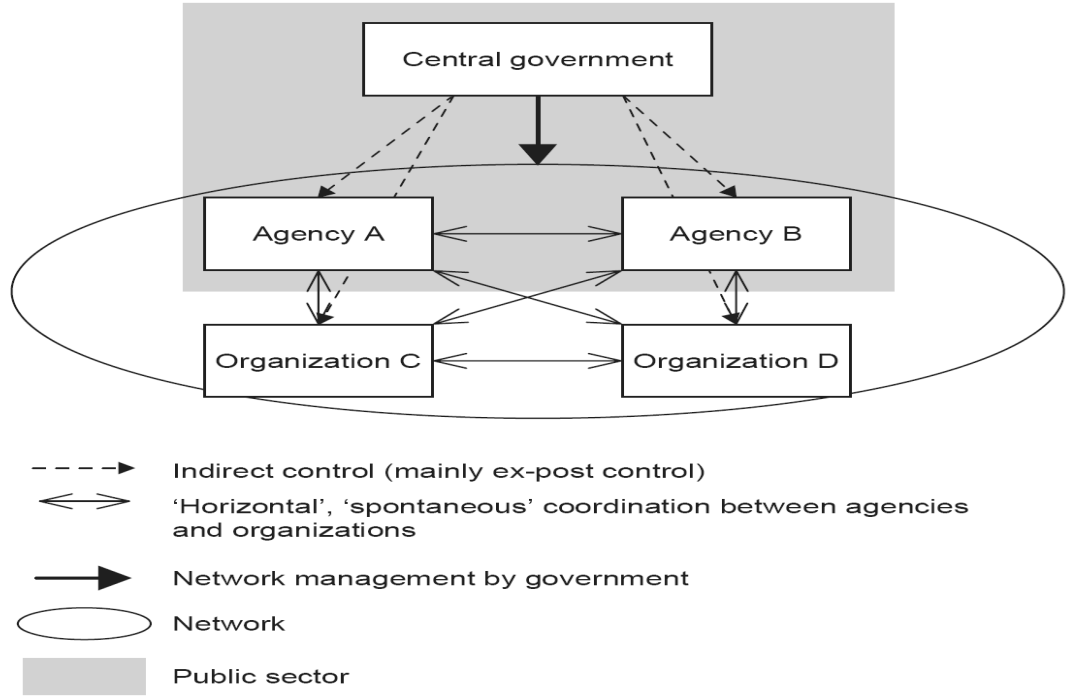

Figure 3. Coordination with NTM Model

Source : Verhoest and Bouckaert (2010:49)

While most coordination networks grow 'spontaneously' between the organizations involved, the 
government can create, take over and maintain a network structure between organizations, for example, with the creation of general information systems, connected structures, collective decision making, or even general organizational partnerships. Inter-organizational learning instruments such as cultural management can foster shared knowledge and values. The main element of coordination is the network, where coordination occurs horizontally between public sector organizations, with the main actor is the government as the network manager.

With this coordination, it is expected that harmony and consistency of all activities can achieve the expected goals, so that the burden of each part becomes harmonious, balanced and consistent. Based on previous research studies that have been presented and the thoughts of the experts presented in this chapter, the research on: "The Complexity of Coordination Among Indonesian State Intelligence Institutions" resulted in the following conceptual framework.

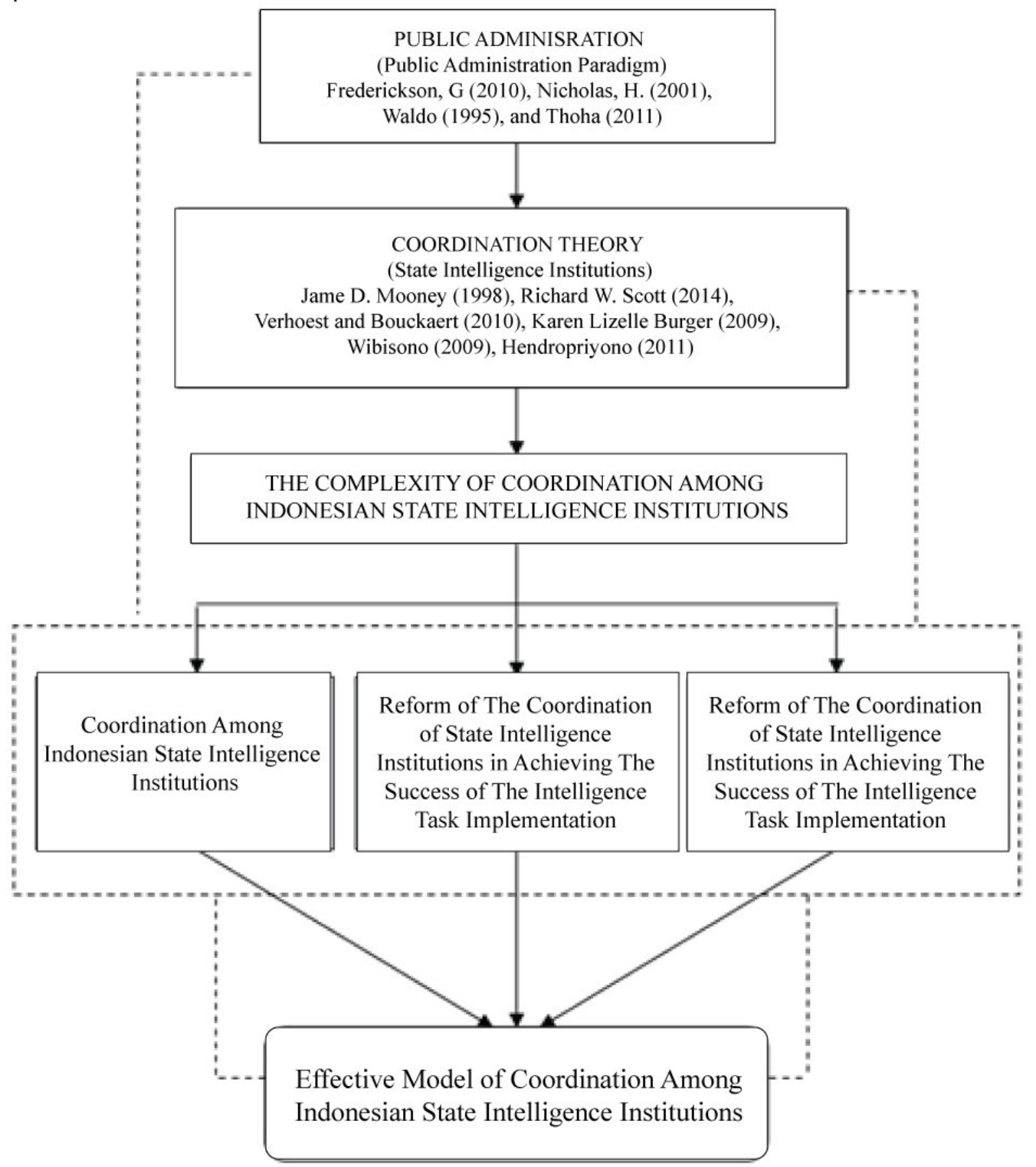

Figure 4. Conceptual Framework

\section{Method}

This research uses a type of qualitative research. According to Sinuff et al. (2007: 87) the purpose of qualitative research is to develop concepts that help to understand social phenomena in natural settings, emphasizing understanding, experience and seeing participants.

Primary data collection in this research uses interviews while secondary data collection uses documentation, then the data analysis of this research uses SWOT analysis and the qualitative research model of research is 
sharpened with the interactive data analysis model developed by Miles, Huberman and Saldana (2014), which is known as interactive models as presented in the following figure.

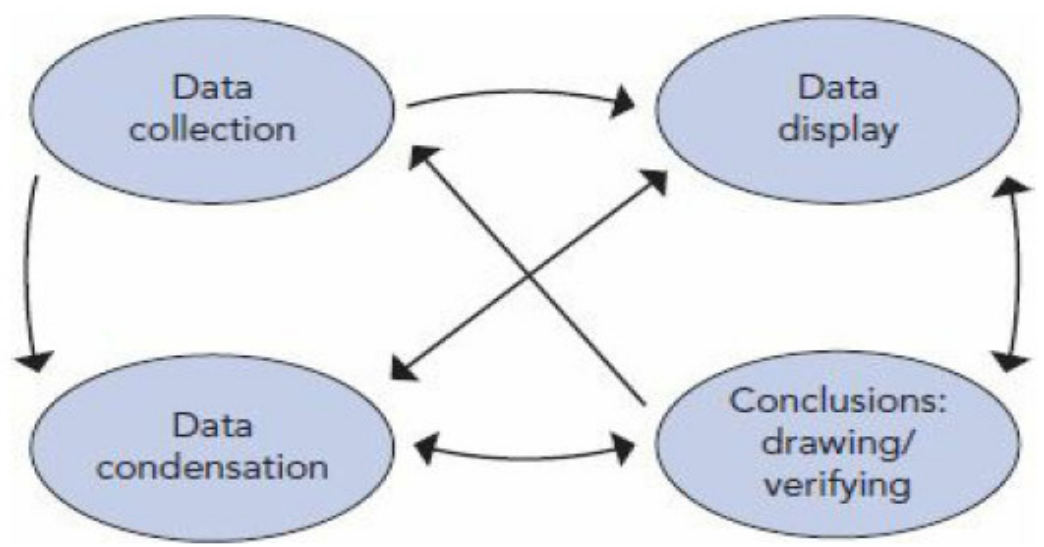

Figure 5. Components of Interactive Data Analysis

Source : Miles, Huberman dan Saldana (2014:33)

Data analysis supported by SWOT matrix analysis can illustrate clearly how the opportunities and threats faced and adapted to the existing strengths and weaknesses.

\begin{tabular}{|l|l|l|}
\hline EFAS & $\begin{array}{l}\text { STRENGTH (S) } \\
\text { Determine 5-10 internal } \\
\text { strength factors }\end{array}$ & $\begin{array}{l}\text { WEAKNESS (W) } \\
\text { Determine 5-10 internal } \\
\text { weakness factors }\end{array}$ \\
\hline $\begin{array}{l}\text { OPPORTUNITY (O) } \\
\text { Determine 5 - 10 external } \\
\text { opportunity factors }\end{array}$ & $\begin{array}{l}\text { STRATEGY S - O } \\
\text { Create a strategy that uses } \\
\text { strength to take advantage } \\
\text { of opportunities }\end{array}$ & $\begin{array}{l}\text { STRATEGY W - O } \\
\text { Create a strategy that } \\
\text { minimizes weaknesses to } \\
\text { take advantage of } \\
\text { opportunities }\end{array}$ \\
\hline $\begin{array}{l}\text { THREATS (T) } \\
\text { Determine 5-10 external threat } \\
\text { factors }\end{array}$ & $\begin{array}{l}\text { STRATEGY S - T } \\
\text { Create a strategy that uses } \\
\text { strength to overcome } \\
\text { threats }\end{array}$ & $\begin{array}{l}\text { STRATEGY W - T } \\
\text { Create a strategy that } \\
\text { minimizes weaknesses and } \\
\text { avoid threats }\end{array}$ \\
\hline
\end{tabular}

Figure 6. SWOT Analysis Matrix

Source : Yukl (2010)

\section{Findings and Discussion}

The legal basis for coordination among Intelligence institutions in Indonesia is in accordance with Article 28 paragraph (2) of Law No. 17 Year 2011 concerning State Intelligence, which stated that; "The State Intelligence Agency (BIN) administers the coordinating function of the State Intelligence". Furthermore, it is clarified in Chapter VII of Law No. 17 Year 2011. Then in further explanation, it is stated in Presidential Regulation No. 90 Year 2012 concerning the State Intelligence Agency. Based on the existing Laws and Regulations, the State Intelligence Agency is structurally the authorized body in the implementation of coordination among state intelligence institutions in Indonesia.

There is not yet a place that unites in the implementation of coordination among state intelligence institutions in Indonesia. So far, the coordination that often arises in state intelligence institutions is internal coordination, such as coordination between TNI intelligence leaders and their members, coordination between POLRI intelligence leaders and their members, or coordination between TNI and POLRI intelligence leaders and their members.

There are quite numerous intelligence institutions in Indonesia, but there is rarely coordination among these intelligence institutions. This is due to the strong ties and interdependence of the coordination among state intelligence institutions in Indonesia which causes more internal intelligence coordination among intelligence institutions, if BIN is considered as a body that has the coordination authority of state intelligence institutions as contained in Article 28 of Law No. 11 Year 2011 concerning BIN. However, the Deputy of Intelligence Coordination or Intelligence Coordination Expert Staff have not yet been listed in BIN's structure. Nevertheless, there is no part that has full duty and responsibility to strengthen and bind the implementation of coordination among state intelligence institutions until today. Therefore, it can be said that intelligence presents in various institutions and departments runs on its own.

There is an understanding from the legal basis that the intended coordination is only limited to the 
coordination of state intelligence in the TNI and POLRI circles. Whereas, Indonesia has quite a lot of intelligence, which maybe even more than some other countries in the world, including TNI, POLRI, Attorney, Judiciary, Customs, Department of Home Affairs, Department of Foreign Affairs, including a low level intellogence in communities such as Civil Defense (Hansip) and People Security Force (Kamra).

Based on the description that has been mentioned above, the state intelligence institutions must be supported by various resources and aspects in carrying out their duties, one of the elements that are considered important in ensuring the operational and smooth functioning of state intelligence is coordination. As mentioned earlier that coordination is important for the organization. According to Terry (1968), "coordination is a business that is synchronous and orderly to provide the right amount and time and direct implementation to produce a uniform and harmonious actions at predetermined goals". In view of this opinion, coordination among state intelligence institutions is a business that is synchronous and regulated based on a legal force (Laws and Regulations) to provide the right amount and time that is useful in directing actions to produce uniform and harmonious activities at the targets set in achieving the aim of state intelligence institutions to protect the interests of the security and integrity of the country.

Coordination among state intelligence institutions is one of the factors that contributes to achieving the objectives and tasks of intelligence institutions. Through effective coordination, the state intelligence institutions are able to collect data and process information well, quickly and precisely. Some of the foreign intelligence institutions mentioned also involve civil society in operations and coordination, which is proven to be able to provide significant results in supporting the tasks and objectives of state intelligence institutions. In accordance with the results of the research presented, a following model of coordination among Indonesian State Intelligence Institutions can be made.

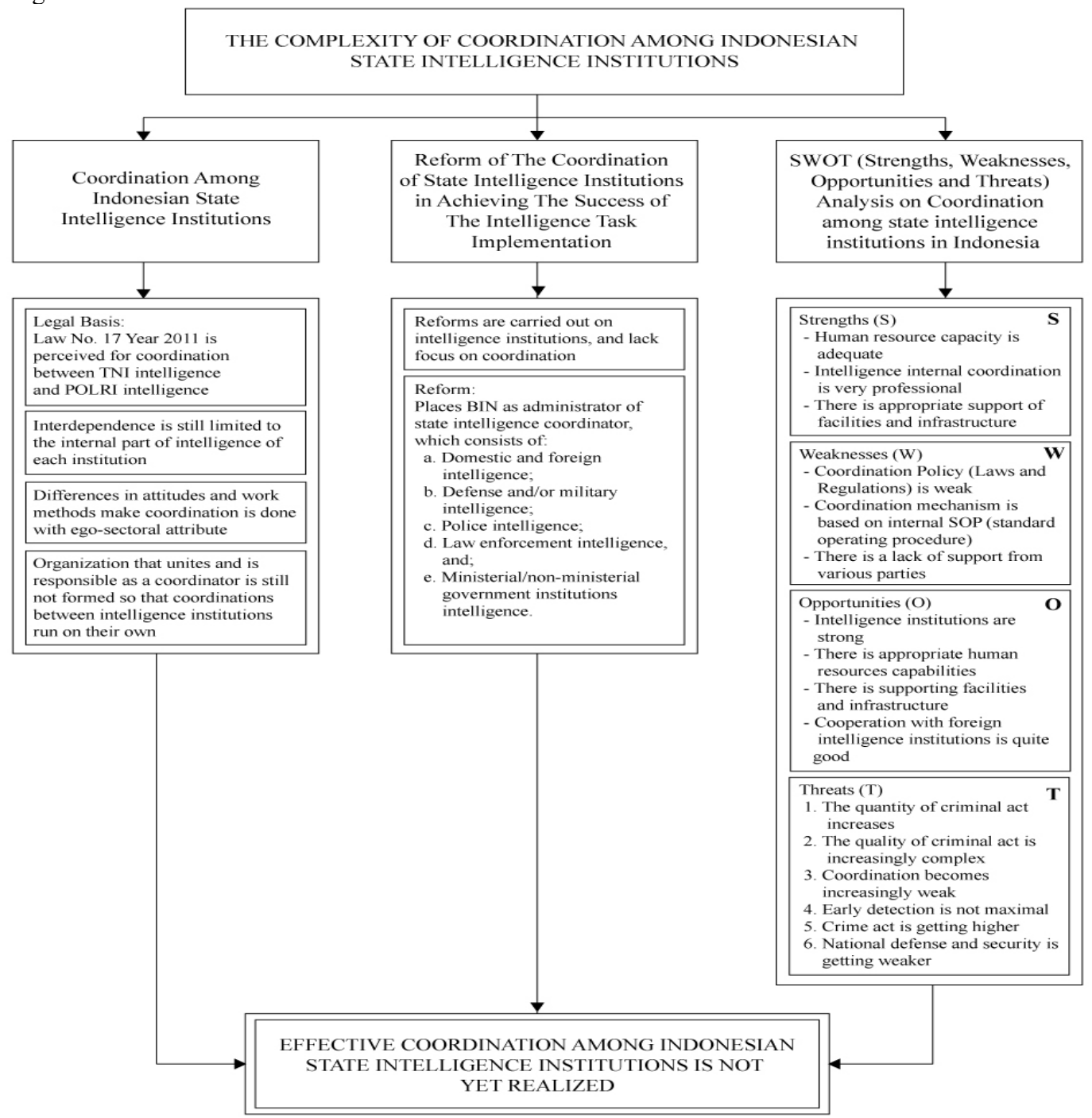

Figure 7.Existing Model: The Complexity of Coordination Among Indonesian State Intelligence Institutions 
SWOT Analysis (Strengths - Weaknesses - Opportunities - Threats) of Coordination among state intelligence institutions.

\section{Strengths}

Based on the focus of this research, our country's intelligence is getting better and it also has sufficient human resource capabilities as well as facilities and infrastructure. Even our state intelligence can be developed more professionally and steadily in the future due to the existence of State Intelligence Academy (STIN). The focus of this research found that:

a) The existing state intelligence, especially the TNI, is very capable of supporting the realization of the country's national goals to protect the entire Indonesian nation and the entire land of Indonesia.

b) The existing state intelligence, especially the TNI, is capable of early detection and warning to prevent the occurrence of abrupt threats which require strong and professional State Intelligence, in addition, State Intelligence is required to strengthen cooperation and coordination by respecting the law, democratic values and human rights as mandated in The 1945 Constitution of the Republic of Indonesia;

c) The existing state intelligence, especially the TNI, is able to anticipate the development of the situation, and strategic environmental conditions, the need to conduct early detection and warning of various forms and characteristics of threats, both from domestic and abroad that are complex and have a very broad spectrum;

d) The fundamental problem that still shows is that there is a lack of coordination among the existing state intelligence institutions in Indonesia so that the existing state intelligence institutions seem to run individually based on the Standard Operating Procedure (SOP) set by each intelligence institution.

\section{Weaknesses}

Based on the focus of this research with regard to weaknesses in coordination, there are some fundamental problems with regard to coordination among state intelligence institutions, namely;

1). The legal basis for coordination is still weak

The intelligence Law No. 17 Year 2011 is still vague so that there has not been a specific explanation for coordination. In addition, the Presidential Decree No. 90 Year 2012 concerning the state intelligence agency has not clearly elaborated the implementation of coordination of our country's intelligence institutions.

2). BIN's organizational structure is still not supportive

When viewed from the Organizational Structure of the State Intelligence Agency, configuration of state intelligence coordination has not yet been made in the structure.

3). Ambiguous coordination standards

Every intelligence institution in our country has its own standards so that BIN as an intelligence coordinator has not been able to reach out to the coordination of all existing intelligence institutions.

4). Separate coordination

The separation of the TNI and POLRI for internal security has been taken by POLRI makes the coordination has also become fragmented, especially with other intelligence institutions. Whereas the TNI, POLRI and other intelligence institutions must cooperate for domestic and foreign security.

\section{Opportunities}

The need for strategic information is delegated in the form of institutional authority manifested in an intelligence infrastructure consisting of the determination of intelligence functions. In connection with the focus of opportunities, there are two main aspects obtained from this research, namely;

a). Internal Opportunities

Internal coordination among state intelligence institutions is the coordination that is carried out between state intelligence institutions such as between TNI intelligence and Ministry of Defense, or Intelkam intelligence with POLRI and other intelligence with its services.

The coordination of intelligence institutions in Indonesia is actually an opportunity for intelligence coordination within the country that can be said as a form of internal opportunity, this opportunity is that our country's intelligence institutions have members (quantities) that are adequate with good quality support. There is an intelligence institution in every area of the Republic of Indonesia which is called as regional intelligence, in which this regional intelligence institution plays a role in detecting threats, maintaining the security and integrity of the Republic of Indonesia.

Another internal opportunity is the ability of the resources possessed by our country's intelligence institutions, namely infrastructure, technology and information that are sophisticated enough to support the implementation of coordination.

b). External Opportunities

External coordination among state intelligence institutions is the opportunity for coordination among state intelligence institutions and foreign countries, this opportunity, among others, with embassies outside the country, the cooperation of our state intelligence institutions with some intelligence in countries in the world. With the existence of this collaboration, it is very beneficial to achieve the main goal of our country's intelligence institutions, namely to detect threats and to maintain the security and integrity of the Republic of 
Indonesia.

\section{Threats}

Threats are things that can bring threats or losses originating from outside and influence the coordination activities between state intelligence institutions in Indonesia. The task of state intelligence institutions cannot be separated from national security and defense. The results of research related to threats in coordination among state intelligence institutions in Indonesia in this research have several findings, including;

a) There is a lack of attention and concern from political figures, bureaucratic figures, economic figures, public figures, academic figures and diplomatic figures in supporting the interests of coordinating our country's intelligence agencies.

b) The weakness of the laws and regulations on state intelligence if seen from the existing laws and regulations: coordination is still perceived only for TNI and POLRI.

c) The State Intelligence Agency (BIN) acts as the coordinator of state intelligence institutions in Indonesia. However, there is no configuration for the coordination section in the BIN's organizational structure. Therefore, it is unclear where the intelligence must coordinate.

d) There is a weak relations between intelligence and civilians, for example, civil society tends to close themselves if there is intelligence comes to their place, this is certainly affects intelligence's capabilities in early detection.

e) The budget for operating state intelligence is still inadequate so that it is difficult to routinely coordinate between state intelligence institutions

f) There is still a strong opinion about "black intelligence - intelligence is categorized as a bad activity" in the community that makes our state intelligence institutions are seen as if they were parasites for the community.

g) Legal umbrella for intelligence members in carrying out tasks is still not strong enough so that they are always haunted by "violations of human rights" in carrying out their duties.

\begin{tabular}{|c|c|c|}
\hline 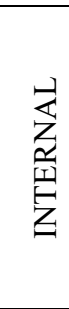 & $\begin{array}{l}\text { STRENGTHS } \\
\text { 1) Intelligence's loyalty on the Republic of } \\
\text { Indonesia } \\
\text { 2) HR capability is sufficient } \\
\text { 3) The existence of STIN } \\
\text { 4) There is regional intelligence } \\
\text { 5) There is a clear SOP } \\
\text { 6) Facilities and infrastructure are sufficient }\end{array}$ & $\begin{array}{l}\text { WEAKNESSES } \\
\text { 1. The legal umbrella is still weak } \\
\text { 2. Organizational arrangement is less } \\
\text { supportive } \\
\text { 3. The budget is still small } \\
\text { 4. Collaboration is less effective } \\
\text { 5. Lack of support from various parties } \\
\text { 6. Fear of Human Rights Violations }\end{array}$ \\
\hline 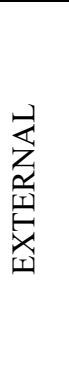 & $\begin{array}{ll}\text { Opportunities } \\
\text { 1. Development of intelligence's HR capacity } \\
\text { 2. Development of a more robust SOP } \\
\text { 3. Improvement of facilities and infrastructure } \\
\text { 4. Technology and Information Innovations } \\
\text { 5. Cooperation with better foreign State } \\
\text { Intelligence Institutions }\end{array}$ & $\begin{array}{l}\text { Threats } \\
\text { 1. The quantity of criminal act increases } \\
\text { 2. The quality of criminal act is increasingly } \\
\text { complex } \\
\text { 3. Coordination becomes increasingly weak } \\
\text { 4. Early detection has not been achieved } \\
\text { financially } \\
\text { 5. The crime act is getting higher } \\
\text { 6. National Defense and Security is getting } \\
\text { weaker }\end{array}$ \\
\hline
\end{tabular}

Figure 8. SWOT Analysis of Coordination Among State Intelligence Institutions

Source: Processed Research Results (2017)

The problem of coordination among state intelligence institutions is very important for state intelligence institutions in Indonesia. If the coordination between intelligence institutions is very strong, the cases I mentioned above may be detected early and the consequences may not be as severe as now. Even coordination reform is increasingly deemed necessary because of the increasingly sophisticated science and technology, which can pose a threat to the Country. Not much different from the information that the researchers got before, that according to the opinion of the resource person that has been presented by the researchers previusly, the problem of coordination of this state intelligence institutions indeed needss to be sharpened. What has been done so far is state intelligence reform, so that coordination reforms of state intelligence institutions need to be carried out. If reviewed from a legal basis that regulates the functions and roles of intelligence services that are currently in force, the law and regulations provide policies to BIN as the state intelligence coordinator in general. However, to achieve the task objectives of state intelligence, the existing laws and regulations have not been as specific as managing coordination among state intelligence institutions, so that misperceptions still occur in the implementation of tasks.

The sustainable principles of coordination among state intelligence institutions in Indonesia are a "package" of good coordination, which must be contained in environmental policies that are embodied in the instruments of 
environmental legislation. Harmonization of the principle of coordination among state intelligence institutions in Indonesia also has implications for:

1. The stronger drive towards coordination among state intelligence institutions in Indonesia (including the demands of the international community);

2. The society will be more open and democratic (democratic society and government) in assessing coordination among state intelligence institutions in Indonesia

3. The strengths of civil society as a support group need to be built effectively;

4. The Rule of Law is increasingly built in coordination among state intelligence institutions in Indonesia

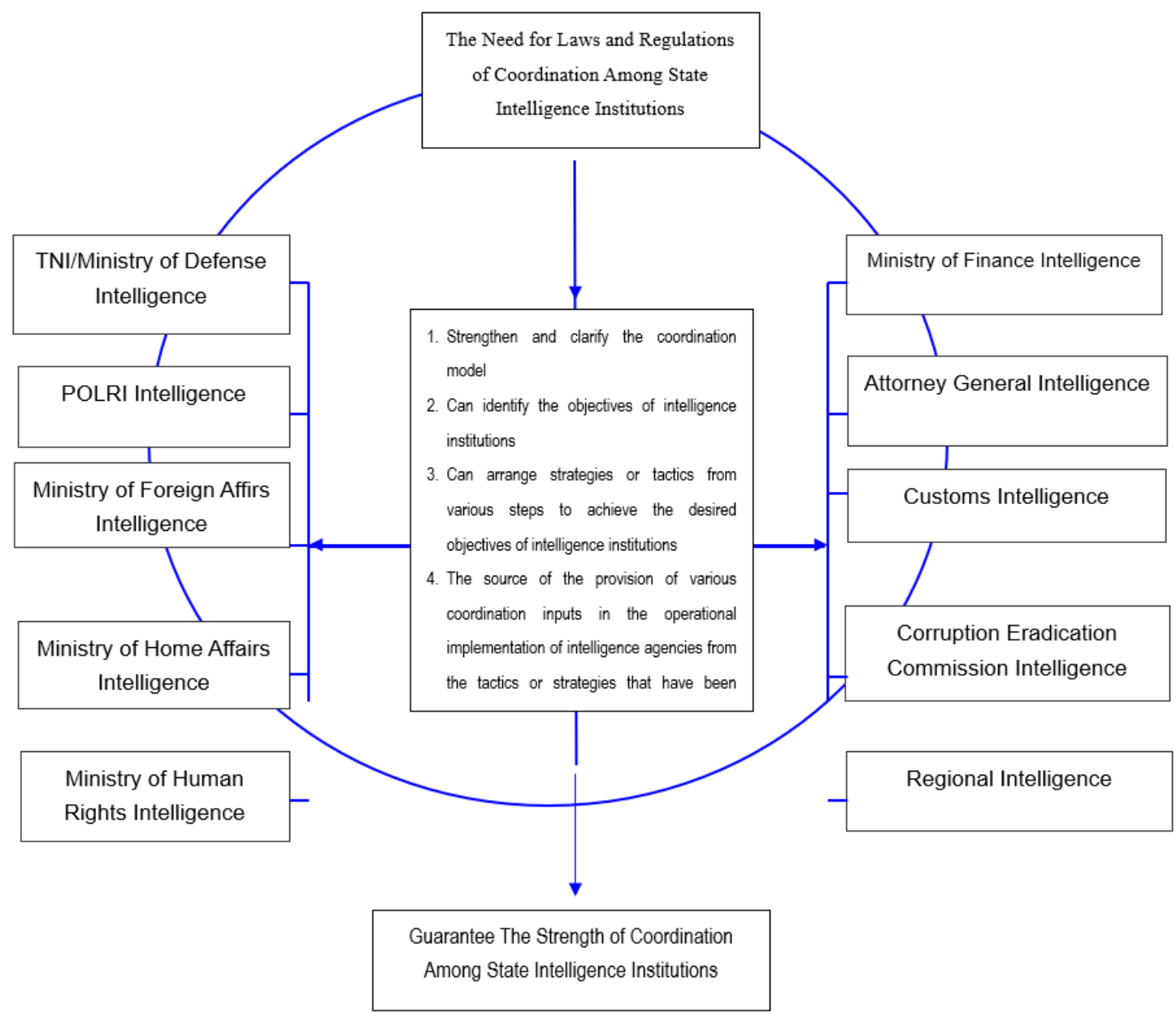

Figure 9. The Need for Laws and Regulations as Guarantor of Coordination Among the State Intelligence Institutions

Source : Processed Research Results (2017)

Coordination among state intelligence institutions can be carried out using a reciprocal adjustment coordination mechanism because relationships between individuals and units have reciprocal interdependence, whereas between sequential interdependent relationships the coordination mechanism is based on planning. Based on the thoughts that have been conveyed, the following model of interdependence in the coordination among state intelligence institutions in Indonesia can be made. 


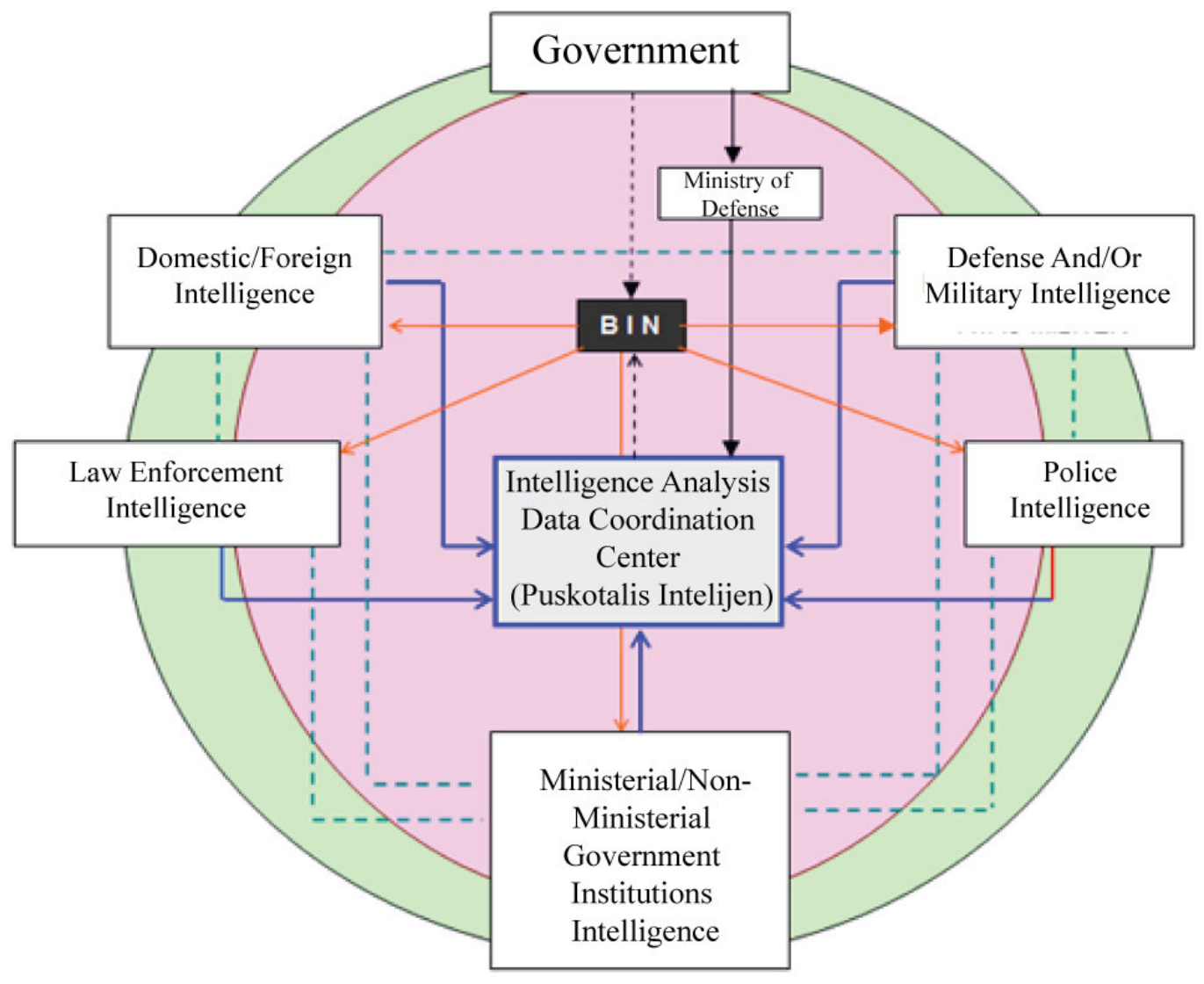

Figure 10. Proposed Model of Coordination Among Intelligence Institutions Using Network Type Command (NTC) Model

Source : Verhoest and Bouckaert (2010), processed by the researchers

Description :

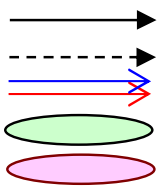

Direct control

Indirect control

Coordination

Internasional

REPUBLIC OF INDONESIA (Public, Politics, Private

Parties, and others)

The model presented is a Network Type Command model. This model is also in accordance with the Chart of the USA intelligence organization where there is a DNI which has the main authority in coordinating intelligence tasks and coordinating intelligence activities between departments and government. The proposed coordination can provide adjustments from each part, and efforts to move and operate parts at a suitable time (part in time), so that each part can make the most contribution to the overall results. The thought of coordination using Network Type Command (NTC) presented is also in line with the thoughts of Verhoest and Bouckaert (2010: 25) which mentioned that: "The logic of approaching coordination as a political rather than administrative activity is that the legitimacy and political power necessary to push and prod organizations out of their established patterns of delivering policies through 'silos' is vested largely in political leaders rather than in administrators. Producing effective, coordinated policy action requires making government go against many ingrained patterns of making decisions and managing programmes, and most administrative officials will have few incentives to engage in that type of battle. Therefore, political leaders may need to utilize their legitimate power in government to change such ingrained patterns".

The most important consideration is that any coordination problems faced by state intelligence institutions need to get full attention, so that the threat to national defense and security can be increased. Based on the results of the ideas that have been presented based on the latest research studies, the study of the theory of Wilson (1989), Mintzber (1996), Verhoest (2010), the ideas of Karen (2008), Jeffray (2016), and William (2017: 104), the recommended model of coordination among the State Intelligence Institutions that are effective in 
intelligence implementation in Indonesia can be seen below.

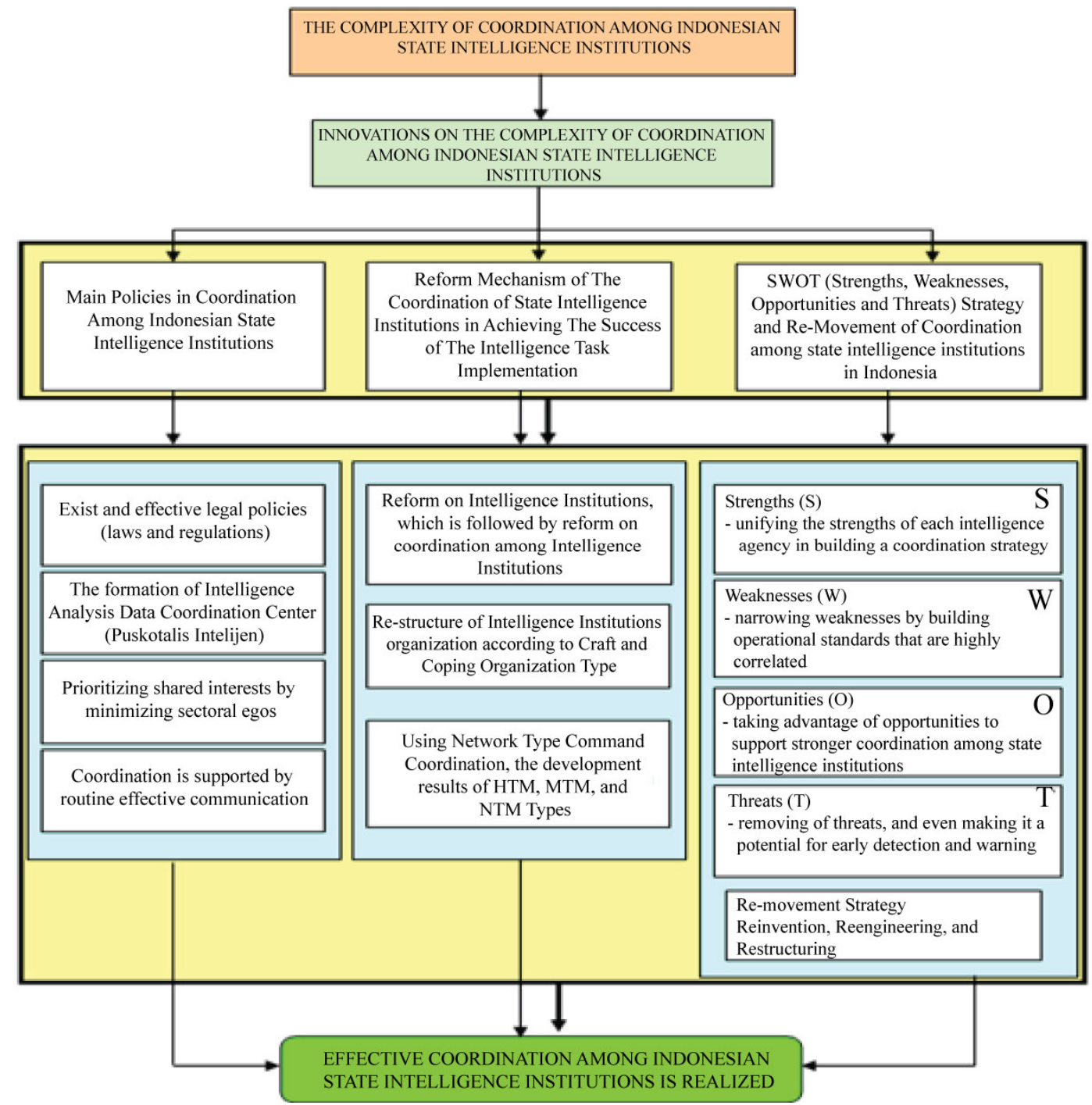

Figure 11. Recommended Model: Effective Coordination Among State Intelligence Institutions

\section{Conclusion}

In the closing section, four main conclusions are formulated which are arranged from the focus of the study, the presentation of the results of the research and the discussion so that it can provide answers to the problems and objectives of this research.

1. Complexity of coordination among state intelligence institutions in Indonesia, which consists of:

a. The legal basis for the policy of regulating the implementation of coordination among state intelligence institutions in Indonesia is Law No. 17 Year 2011 concerning State Intelligence. Explained in Article 28 that; "The State Intelligence Agency (BIN) administers the coordinating function of the State Intelligence". Article 7 states: "The scope of State intelligence includes: a). Domestic and foreign intelligence, b). Defense and/or military intelligence, c). Police intelligence, d). Law enforcement intelligence, and e). Ministerial/non-ministerial government institutions intelligence."

b. This research found a misperception of the legal basis of the implementation of coordination, which is perceived as an implementation of coordination of TNI and POLRI. Interdependence between the implementation of coordination among state intelligence institutions in Indonesia seemed weak, because coordination is more internal to intelligence institutions so that coordination implementation is carried out individually. So far, the coordination that often arises in state intelligence institutions is internal coordination, such as coordination between TNI intelligence leaders and their members, coordination between POLRI intelligence leaders and their members, or coordination between TNI and 
POLRI intelligence leaders and their members.

c. Regarding the differences in attitudes and ways of working in the implementation of coordination among state intelligence institutions in Indonesia, the results obtained prove that attitudes and ways of working are quite significant, given the different duties and authorities of state intelligence institutions. This condition has a quite complex impact on efforts to unite coordination among state intelligence institutions. However, it is also explained that differences in attitudes and ways of working in the implementation of coordination need not be questioned in depth. Important things that need to be considered are looking for solutions to coordinate accordingly to achieve intelligence roles, objectives and functions.

d. Regarding an organization that unites coordination among state intelligence institutions in Indonesia, the constitution of the organization formed is BIN, this is in accordance with Article 28 of Law No. 17 Year 2011 which states; "The State Intelligence Agency (BIN) administers the coordinating function of the State Intelligence". However, if viewed in the organizational structure of BIN, there is still no part and official that has full authority to be fully responsible for coordinating the state intelligence institutions.

2. SWOT (Strengths, Weaknesses, Opportunities and Threats) conditions of coordination among state intelligence institutions in Indonesia.

a. Strengths: the existing state intelligence institutions have a high loyalty to the country, have adequate resource capacity, are professional and can be developed. Operations have been supported by sophisticated technology and facilities, including the State Intelligence Academy (STIN) and the existence of good cooperation with foreign state intelligence institutions.

b. Weaknesses: the legal basis (Laws and Regulations) still do not provide a discourse that fits the needs of coordination among state intelligence institutions. The BIN organization as the organizer of the coordination function is less supportive, the different operational standards set by each intelligence institutions causes separate coordination. Therefore, BIN as the coordinator of the state intelligence institutions has not been able to carry out its function as the coordinator of all intelligence intitutions.

c. Opportunities are divided into two, namely;

1) Domestic opportunities

For domestic opportunities, it can be said as a form of internal opportunity. This opportunity is a state intelligence institutions that have members (quantity) that are adequate with the support of good quality. There is an intelligence institution in every area of the Republic of Indonesia which is called as regional intelligence, in which this regional intelligence institutions play a role in detecting threats as well as maintaining the security and integrity of the Republic of Indonesia. Other internal opportunities are the ability of resources possessed by state intelligence institutions, namely adequate facilities and infrastructure, sophisticated technological support so that they strongly support the implementation of coordination.

2) Foreign opportunities

For foreign opportunities, it can be said as a form of external opportunity. This opportunity is in the form of cooperation of state intelligence institutions with some foreign intelligence institutions in the world. With the existence of this collaboration, it is very beneficial to achieve the main objectives of the state intelligence institutions to detect threats early as well as to maintain the security and integrity of the Republic of Indonesia.

a. Threats in coordination are divided into two, namely;

1) Internal aspects

Internally, this threat is a threat to coordination originating from within the state intelligence institutions themselves, namely; the lack of clarity of the legal umbrella that forms the basis of coordination activities, the weakness of the organizational structure that handles coordination and the lack of attention of high-ranking state officials on the importance of coordination for state intelligence institutions. On the other hand, coordination activities between state intelligence institutions run on their own, so that the relationship between members of the state intelligence in intelligence institutions becomes less harmonious.

2) External aspects

Externally, this threat is in the form of small budget given to state intelligence institutions so that coordination activities between state intelligence institutions are rarely carried out. Negative opinions have been lied to by state intelligence institutions so that they are not supported by civil society.

3. Reform of the Coordination of State Intelligence Institutions in Achieving the Success of the Intelligence Task Implementation.

a) Intelligence institutional reform has been carried out, namely by placing the position of each 
intelligence institution in accordance with the roles, objectives and functions and scope of the intelligence institutions so that intelligence institutions are formed separately according to their capacity.

b) With conditions like this, coordination among state intelligence institutions runs on its own, where coordination is more focused on internal intelligence institutions.

Reforms in the implementation of coordination among state intelligence institutions have not been adequately covered. Threfore, uniting the implementation of coordination among state intelligence institutions is still an obstacle both technically and operationally in the implementation of coordination among intelligence agencies.

4. The focus of Model of Coordination between state intelligence institutions that are effective in intelligence implementation in Indonesia, concludes:

a. The existing legal basis, namely Law No. 17 Year 2011, is incidental so that it has not given full authority to state intelligence institutions in carrying out their duties and functions.

b. Effective coordination between intelligence institutions in Indonesia has still not been able to be achieved effectively, because the basic policy of implementing coordination (legal basis) is perceived to be limited to coordination for TNI and POLRI.

c. The coordination model used is the Hierarchy Type Mechanism (HTM), which is coordination that refers to a coordination mechanism based on authority and dominance, so that it is more concerned with the internal coordination of the intelligence institutions, bringing about the emergence of sectoral egos from each parties which asses that they are better than others.

Therefore, conclusions from the results of research that have been formulated are as follows.

1. The legal basis (Laws and Regulations) is a significant foundation in determining coordination among national intelligence institutions. Thus, there is a need on a legal policy that has an existence and responsiveness. Therefore, legal basis is a policy and order that contains various policies of coordination between intelligence institutions, which has several functions, namely;

a. Strengthen and clarify coordination mechanisms among state intelligence institutions

b. Can identify the objectives of intelligence institutions

c. Can arrange strategies or tactics from various steps to achieve the desired objectives of intelligence institutions

d. Act as a source of the provision of various coordination inputs in the operational implementation of intelligence agencies from the tactics or strategies that have been prepared

There is a need for a process of transformation of interdependence coordination among state intelligence institutions in Indonesia, which consists of;

a. Pooled interdependence, which is a coordination aimed at achieving the tasks of intelligence institutions in accordance with the applicable Laws and Regulations.

b. Sequential interdependence, which is routine coordination and requires rules and procedures as well as scheduling and planning.

c. Mutual reciprocal interdependence, which is a coordination to achieve common goals on the basis of regulations and procedures, through scheduling and reciprocal adjustment.

Differences in attitudes in coordination should be a strong correlation in achieving state intelligence goals. This difference can occur, but keep in mind that; "Coordination is a synchronous and orderly effort to provide the right amount and time and direct the implementation to produce a uniform and harmonious action on the targets set in achieving intelligence objectives". Therefore, differences in attitudes need to be integrated and harmonized. For example, if customs intelligence gets information that there will be smuggling of goods from abroad, and the information is obtained from clear parties or people, then this information must be submitted to TNI, POLRI, and other intelligence institutions that have close links with smuggling activities. So that differences in attitudes and ways of working in the implementation of coordination need not be questioned in depth, but what needs to be considered is good coordination to achieve the security, comfort and integrity of the Republic of Indonesia.

Reform requires a more robust organizational design so that the coordinator between state intelligence institutions is clearly visible in BIN as its coordinator. Thus, a solution that can be implemented is organizational restructuring. The structure is planned and is a deliberate attempt to establish a pattern of relations between various components, so that it can reach the target effectively. As a form of formalization (formal affirmation) to achieve coordination between the patterns of interaction that occur or happen among organizational personnel that unite the coordination among state intelligence institutions, an organization that is good at integrating coordination among state intelligence institutions in Indonesia will have positive impact on the performance of state intelligence institutions in Indonesia.

2. SWOT analysis of coordination among state intelligence institutions is one of the fundamentals of increasing the effectiveness of coordination; 
a. Strengths. The resources owned by each state intelligence institution, especially those owned by the TNI and POLRI, can be used as basic capital in improving coordination between the existing state intelligence institutions. So that other countries' intelligence institutions can use strategies that are collaborated from TNI and POLRI to support intelligence interests in carrying out their tasks.

b. Weaknesses. All forms of weakness that exist from each intelligence institution are immediately anticipated so that it does not become a bigger gap, which is increasingly difficult to coordinate between state intelligence institutions. Intelligence institutions that have advantage should make use of it as much as possible and wisely to overcome the weaknesses of other intelligence institutions.

c. Opportunities. The organization of intelligence institutions that have been formed is a great opportunity to unite the coordination mechanism in various intensity of operational intelligence institutions. Establishing harmonious communication is a requirement to achieve harmonious coordination among state intelligence institutions.

d. Threats. Every threat that exists in each intelligence institution must be mapped and minimized as small as possible, then making threats as an in-depth study so that they can bring benefits in formulating plans and policies to develop better coordination.

The strategy applied in this case is Weaknesses - Threats (WT), namely by minimizing weaknesses and distance challenges in coordination between the state intelligence institutions. Then a strategy to improve effective coordination is developed.

3. The reform of state intelligence institutions that have been carried out needs to be supported by coordination reforms between state intelligence institutions that are still untouched. Coordination reforms between state intelligence institutions are carried out by doing the Organizational Re-Structuring of Intelligence Institutions according to the Craft Organization Type and also Coping Organization Type, namely organizations that have clear and measurable characteristics of process performance, but the output is unclear and not measurable, but the results clear and measurable.

4. Innovation in coordination among state intelligence institutions needs to be carried out in order to realize effective coordination, namely by;

a. Forming Intelligence Analysis Data Coordination Center (Puskotalis Intelijen) as a coordinator in a structurally consisting of representatives from each state intelligence institution and led by an expert or intelligence expert who has high intelligence competency. This intelligence center can guarantee coordination among state intelligence institutions permanently among state intelligence institutions; Determining principles and mechanisms for coordinating implementation that are robust in identifying country threats, hazards and risks, so they can work together specifically; Providing recommendations to the president and ministers through the relevant BIN Head about the priority of gathering intelligence needed by the state, clear assignment assignments and missions among different intelligence institutions, and not overlapping each other; Achieving the goals of an organized national security system from each intelligence institution in accordance with the rights and obligations carried out by intelligence institutions.

b. Establishing a Strategy based on SWOT and Re-Movement, namely uniting the strengths possessed by intelligence institutions into implementing sources of coordination; covering and weaknesses with collaborative operational capabilities; developing all opportunities that exist; and eliminating threats and even making them potential early detection and warning. Strategies can also be arranged using the mapping of Reinvention, Reengineering, and Restructuring of intelligence so that it can support the overcoming of inaccuracy of organizational structure design in overcoming crucial problems.

c. Building a model of coordination between effective state intelligence institutions compiled in a unified Coordination System (Polled) with the support of Network Type Command (NTC), namely the development of HTM, MTM and NTM models. The NTC model is a large coordination model with a broad network but still under one control or command, so that information processing can become increasingly faster and more accurate which in turn can increase high power in carrying out early detection and warning. In addition, it is also able to make a more significant contribution in developing the operational plans and strategies of state intelligence institutions in order to achieve the role, purpose and function of state intelligence effectively.

5. The complexity of coordination among state intelligence institutions in Indonesia can also be supported by establishing a National Security Council so that military and non-military intelligence institutions can meet to coordinate, this is considered capable of making a positive contribution in realizing the same understanding so that the coordination mechanism among state intelligence institutions is increasingly more effective.

\section{References}

Anggoro, K. 2008. Mekanisme Koordinasi Dalam Organisasi. Universitas Gajah Mada Press. Yogyakarta. 
Frederickson, George. H. 2010. Social Equity and Public Administration. Origins, Developments and Applications. M.E. Sharpe, Inc. Business Park Drive, Armonk, New York 10504.

Jeffray, T. R. 2016. The U.S. Intelligence Community. Seventh Edition. Published by Westview Press, 2465 Central Avenue, Boulder. CO. 80301

Karen, Lize Burger. 2008. A Comparative Analysis Of Intelligence Coordination After The 9/11 Attack And The Second Gulf War : Selected Case Studies. University of Pretoria.

Khamdani, Muh. 2014. Koordinasi Dalam Pencapaian Kerja Organisasi. Jurnal BPSDM Hukum dan HAM, published on February $24^{\text {th }}, 2014$.

Miles, M.B., Huberman, A.M., Saldana, J. 2014. Qualitative Data Analysis: A Methods Sourcebook (Third Edition). USA: Sage Publications. Translated by T.R. Rohidi. Jakarta: UI-Press.

Mintzberg, Henry. 1996. The Structuring of Organizations a Synthesis of the Research. Englewood Cliffs N.J.: Prentice-Hall, Inc.

Muluk, M.R.K 2006. Pengembangan Kelembagaan. Malang: Fakultas Ilmu Administrasi Universitas Brawijaya.

Scott, Richard W. 2008. Institutions and Organizations Foundations for Organizational Science: Foundations for Organizational Science. A Sage Publications Series. Sage Publications, Inc.

Sinuff, T., Cook, D., Giacomini, M., Heyland, D., Dodek, P. 2007. Facilitating clinician adherence to guidelines in the intensive care unit: A multicenter, qualitative study. Critical Care Medicine, 35(9):2083-9.

Terry, G.R. 1968. Principles of Management. IL: Richard D. Irwin Inc.

Verhoest, K and Geert Bouckaert, B. 2010. The Coordination Of Public Sector Organizations. Shifting Patterns of Public Management Basingstoke, Hampshire RG21 6XS, England

Wilson, James Q. 1989. Bureaucracy: What Government Agencies Do and Why They Do It. US: BasicBooks a Division of Harper Collins Publishers.

William, Samuel. S. 2017. British Security Coordination : The Secret History of British Intelligence in the Americas 1940 - 1945 ( 1999-06-01). The Washington, Post.

Yukl, Gary. 2010. Kepemimpinan Dalam Organisasi. Edisi kelima. Penerbit, PT Indeks. Jakarta.

Zauhar, Soesilo. 2001. Reformasi Administrasi. Konsep, Dimensi dan Strategi, Bumi Aksara, Jakarta. 


\title{
The Tribe in the Arab Political System (A Model of Democratic Constraints)
}

\author{
Ahmed Aref Al kafarneh ${ }^{1} \quad$ Mohammad Saleh Bani Issa ${ }^{2}$ \\ 1. School of Political Science, Balqa Applied University, Ajloun University College, postal code (26816), Ajloun, \\ Jordan. \\ 2. School of Political Science, Middle East University, PO box (383) Amman 11831 Jordan \\ * E-mail of the authors: dr.alkafarneh@yahoo.com, baniissa@yahoo.com
}

The research is financed by authors themselves.

\begin{abstract}
This study entitled The Tribe in the Arab Political System "A Model of Democratic Constraints" "aimed at studying and analyzing the reasons that stand behind not success and achieve real democratic transition in the Arab World. This study also analyzes and assesses how the tribe played a coral role in not realizing and achieving that.

The researchers reached into a point that there are many obstacles that prevented realize democratic transition in the Arab World.

The study reached into a point that if the Arab World needs a democratic transition, the Arab countries must first of all go for involving tribe in political participation and in political development as well, otherwise the Arab World will never reach into the democratic transition for more coming decades.

This study contains of abstract, introduction, accurate analytical for the importance, hypothesis, goals, methodology of the study, as well as subtitles such as democratic transition in the Arab World, tribalism and democracy conflict, tribe and the difficulty of democratization in the Arab world, and conclusion and references.
\end{abstract}

Keywords: Structure, Civil State, Democratic Transition, Ruling Elites.

DOI: $10.7176 / \mathrm{PPAR} / 9-1-06$

\section{Introduction}

There has been divergent views on the optimal criteria on which to determine the means necessary to preserve the rights of citizens within and outside society, and the scientific and political debate took a lot of space in the debate and theoretical diagnosis, found that the old political thought has discussed the question of the State of the system that can last, and continue to be appropriate to the members of the community, until the consensus ended that democracy is the most appropriate way to the legitimacy of the system in the state, it is that preserves the rights and duties and freedoms of all without distinction.

The democratic concept of egos (direct, semi-direct, and representative democracy) cannot live without a culture and awareness based on the sovereignty of the individual, which is community and society. In his book "The Horizons of Democracy" in 1871, Walt Whitman discussed the culture of democracy as the necessary soil for the various spheres of mobility among society and the law individuals, which that reveal their talents and promote and develop them (Michel,2000:180).

Furthermore, Democracy became as popular demand among Arab countries, where Individuals, groups and all civil society organizations use a more courageous and powerful approach to authoritarian regimes, believing that democracy is the right path to modernization, reform and development to emerge from the era of backwardness with all of its types with a view to achieving sustainable and comprehensive development of hope.

The currents in the Arab world have started from the concept of renewing solidarity and social cohesion, and change is the responsibility of individuals and groups alike. Also, any dialogue with current systems should begin with confidence in the proposition, presentation and thus commitment to its content. In other words, the political culture of the Arab citizen is based on knowledge of the role of the political summit in reaching that the individual in society is an influential factor which has the right and the value of the ability to change, meaning effective participation in changing economic and social conditions, not the individual ruler or the ruling minority 
in the state (Massoud, 1999).

The tribe is a social organization based on the inclusion of individuals of common origins, namely, the extended intention. The effect of the state on the tribe identifies in two-way; from first way, the tribe is weakened when the state provides protection to individuals and their needs are met or co- exist with them when the government fails to deal with limited members who are accountable to individuals.

Despite the conflict between the tribe as a political unit and the concept of a national and democratic state, the tribe still plays an influential role in political life in the Arab world. In that matter, it specifies members of parliament or a number of members of the government. Consequently, the tribe is one of the constructional and structural obstacles in achieving political reform or democratic transition (Lavy, 2000, p.118).

The re-production of the modern civil state needs to be changed and developed from within. As well as reproduction new concepts and practices such as democracy, the rule of law, transparency and factionalism in closed societies such as Arab society.

In this study, it was pointed out explicitly that the most important obstacles to democratic transition in the Arab world are tribalism. So, The decision- making institution and the civil society institutions, including the political parties, must be united in order to contribute to the creation of political awareness among the citizens and to rehabilitate the concept of the civil state framework and to contribute to the departure of the ruling institution gradually from tribal logic.

\subsection{The importance of the study:}

The importance of the study stems from the fact that the issue of democracy in the Arab world is one of the most important national demands and the most urgent in activating throughout the contemporary history of the Arab countries because the age of participation and the subject of political pluralism are directly related to comprehensive development. International phenomenon towards the Arab region by countries in general. Given that a democratic society contributes to regional and global stability and thus leads to social change facing extremism and terrorism.

Depending on the importance of the research topic, it will deal with an important element in democratic transition, namely tribalism. The research will examine the nature of the tribe from within and the concept of democratic transition and its impact on democratic transition in the Arab world.

\subsection{The hypothesis of the study:}

Democratic experiences in the Arab world do not reflect a state of political maturity in order to create necessary and appropriate reviews for a gradual facilitating to find and build an effective and balanced democratic state that achieves qualitative stability in the transfer of power and governance because of tribalism.

\subsection{The goals of the study:}

The study aims to:

- Identify the most important obstacles and difficulties of democratization in the Arab World.

- Know how the political system (for the accuracy of governance) and the nature of dealing with democratic terms.

- Presenting a vision of building the state away from tribal mentality and conditions and using electoral means to establish democracy and move to the building of societies and the civil state.

\subsection{The methodology of the study:}

The study used historical and descriptive analytical methods.

\section{Democratic Transition in the Arab World:}

Meanwhile the current transitions at the international environment, western democratic model had been circulated broadly as a tool for integration into the international system. Also, discourse in political systems trends into the need of appropriate systems to ensure a more democratic political practice, responding to overlapping special circumstances which our societies have experienced (Michel, 2000:181).

Political experience in Arab countries indicates to raise views about political powers in its societies in an 
unprecedented manner at political gatherings, cultural and social forums, independent and partisan, and even official newspapers and publications on Internet sites at the media in light of the technological revolution and the information society. Meaning that the widening of the social protest on negative phenomena which firmly established in political, economic, social, cultural Arab structure. Becoming not acceptable to Arab masses regarding its negative noticeable effects on the performance of the Arab institutions. It is worth to note that democratic transition in Arab countries shows indicators of success as well as the manifestations of defaulting according to the internal, regional and international determinants (Lavy, 2000, p.127).

The reasons for the change and the motives of reform in the Arab World stands as a result of a group of changes and latest developments relating to internal, social interactions. Furthermore, relating to regional and international transitions which helped discussing the tools of modernization through political reform.

From this point of view, democratic becomes a contemporary issue over the Arab countries. In that, democratic becomes the measure of the current and

future political systems. The implication of the democratic system means stop raising slogans without the essence content. On the other hand, the constitution and the legal rules relating to the concepts of democracy and the rights and protection of human rights are the basic reference that must be considered as pillars to ensure the movement towards the desired political reform (Addi, 1998).

The theoretical models of democracy, such as mechanisms, institutions and interaction, are among the most important contents of studies in political science and the most extensive, directly linked to the state, which is the essence of every theory in political science and its relations with the philosophy of the state itself, that constitute political power and the division of society between ruler and ruled. Although the global stereotypes in democratic formalism; for instance, elections at various levels, political institutions (executive and representative), international covenants, constitutions and domestic laws, the most difference is the activation of political rights followed with their economic, cultural and social rights beside political consolidation. This difference implies that fault does not relate to formalities as much as it's relation to level of an important analysis in political science is the individual / citizen (Ali, 1999, p.62).

Democratic transition success in most of Arab and western countries is connected to the departure of the ruling elites on the system of monopoly power, and on non-recruitment of multiple political forces and intellectual orientations in order to delay or postpone democratic choice.

Moreover, democratic transition is linked to the importance of the full preparation toward reform at the institution of political system its internal and external equipment by a comprehensive review of the way organizations operate. From this perspective, we should identify to democratic conception before moving to democratic transition conception (Lavy, 2000, p.20).

\subsection{Conception of Democracy:}

Democracy Term conception considered one of conceptions that still the focus of preoccupation, thinking and point of contention many researchers. The term is unclear, it is composed of several things that are difficult to understand and explain. It still has meanings that are chosen even the difference of place and time.

There isn't a comprehensive definition of democracy nor one applied form that used by all democratic governance systems over the world. Hence, if there is one comprehensive, fixed ideological definition of democracy, democratic governance systems aren't able to spread over continents (Samuel, 1993, p.3).

Although of the agreement on the Greek origin of the word "democracy" which is compound of two parts; firstly: Demo stands to "people", secondly: Kratos stands for "authority and power". It means "the people themselves judged themselves", that is the classical definition of democracy and the same one that "Abraham Lincoln" who defined democracy "the people themselves judged themselves and it may appropriate in limited period with Latin society in which he was born, historical developments and knowledge transition stand as the reason for the current conception's marginalization.

\subsection{Conception of Democratic Transition:}

Democratic transition conception indicates to the change at the political systems from non-democratic formula into another more democratic formula. Democratic transitions considered a gradual process of transition of international communities by modify their political institutions and platforms through a variety of procedures linked to the nature of the parties (Ikram, 1998). 
The process of transition at the policy of the legislative authority and the prevailing political culture and the legitimacy of political authority is the first level to transition toward democratic system: "It is a transition period between a former phase of delegation of authority and establishment of a subsequent political system. Under these transitions, the authoritarian system is destroyed or another alternative is found.

These transitions may result in a strange system descend completely into chaos by democratic transition. Also, decline in systems of authoritarian rule in all its forms and types, replaced by other systems characterized by real popular choice, legitimate institutions and transparent elections which stand as a mean of circulation or access to the authority instead of Individual rule and violation of laws and the constitution (Lavy, 2000, p.26).

The democratic transition involves the system transfer from political situation which is an old authoritarian system to another new system that supports democratic trends by means of bargaining between active and politically active elements. Creating an appropriate climate for transition process that contributes not to return the system again authoritarian rule (Addi, 1998).

The transition process has occurred due to several factors; internal and external. These factors vary according to its impact. The nature of both factors and its power often identify the transition method or transition way. It is known, the difficulty in classifying ways of transition to a democratic system due to its multiplicity and interference.

Regarding the countries that experienced democratic transition, there are four main ways with different names: firstly, move from above; led by the ruling authority or reformist leadership. Secondly: move down, led by opposition forces after the collapse of the ruling regime or its removal an uprising or popular revolution by the people. Thirdly: move through the negotiation and bargain between the authority and opposition forces. Finally: move caused by external military intervention (Kassem, 2000, p.78).

Free and fair elections are considered one major tool for democratic system. However, it is alone are not sufficient for real democracy, it entails the availability of many foundations and elements such as: political pluralism, peaceful transfer of power, separation of powers and balance based on clear and stable constitutional reference.

Moreover, the ability of the elected government and the practice of power and governance, the rule of law, the effectiveness of institutions and procedures for transparency and accountability, an effective and independent civil society, to ensure political rights and civil freedoms for all citizens regarding the equal citizenship, the multiplicity of information with free access to it (Hilal, 2002, p.186).

After addressing democracy conception as well as democratic transition. Also, democracy and democratic transition designed to the retreat of authoritarian systems at all of its forms and types, replaced by other systems characterized by real popular choice, legitimate institutions and transparent elections which stand as a mean of circulation or access to the authority instead of Individual rule and violation of laws and the constitution.

Furthermore, considering Constitution and law rules relating to democracy and human rights as basic reference toward political reform to ensure the freedoms and rights of citizens who constitute the state and who choose the best for a decent life, it's supposed to show an important element which has its democratic impact in the Arab world that is " The Tribe".

\subsection{Concept of a Tribe:}

The most effective and obvious in any country.Their members, traditions, customs and values seem to be the most important authority compared with institutions and laws of the State itself. It is "Individuals who were governed by the Director or the chairman of the board of directors of the Tribe. He usually is re-selected in a semi-automatic manner" (Gabi, 1998). Among most Arab countries, the tribe is still the most prominent factors that affect the political life formation throughout its history.

In most Arab countries, the tribes and their leaders to lead the struggle against any threat it poses. It is the source of state power towards success. The tribes' leaders held several meetings as representatives of the people in the Arab countries to reach a constitution for the country eestablish constitutional monarchy, that lead to the enactment of a constitution constitutes basic rules for the preservation of the rights of public and private individuals (Abu Taleb, 2005).

\subsection{The Tribe and Democratic Transition in the Arab World:}

When we talk about modern development at the political structure in the Arab society, we note that the parties 
and organizations of civil society have taken a fixed value in this structure. However, the parties and organizations in Arab countries get into a trouble, the management of its affairs, it circulate democracy.

But the basic structure depends on the rule of certain individuals governed by a director or board of directors who have been chosen by periodic method to keep the institution or party linked to it. Deriving their influence and power from that person. And this is the state in most of basic structure that in relation to democratic conception without a real practice.

Talk about the relationship between the tribe and the state among the Arab countries shows that tribes in their ideal sense becomes debatable. Because of the mating in last period and cultural, economic and social changes that experienced in Arab societies.

Hence, that indicates a high proportion of citizens in the Middle East of Bedouin origin as well as a very small number of citizens can be regarded as tribes men in the old concept. Also, the self-rule assumed by total loyalty to the tribe contradicts with the principle of monopoly of the center by using power with the material and moral oppression (Abu Ghanem, 1999, p.225).

\section{Tribalism and Democracy Conflict:}

The tribes with its wide background affect the democratic transition's phases; in that, the political life is quite controlled by the tribe, which disappeared behind the systems and institutions of the modern state.

However, it still effective in some Arab societies. There are two main notions relating the tribal factor in the political map generally and in the democratic transition in particular (Hilal, 2002, p.186).

The first one: it ensures the positive impact of tribal in the democratic transition among Arab countries. Where the tribe fill the gap that left by the state's absence throughout the most historical periods by developing rules

and regulations that define the aspects that must govern the relations of society and regulate its movement. Further, the tribe performs some posts of civil society, that making it similar to civil society organizations.

The Second one: it ensures the negative impact of tribal in the democratic transition among most of Arab countries. Subsequently, it effect the political map constitute of the country too. Justifying that tribes have their origins and special beliefs, it is coherent often biased to what seemed to be appropriate to achieve their interests only or to achieve the individuals and groups' interests without doubt that public interest is the most important one and it's the people interest.

Parliamentary elections are evidence of tribal political participation in Arab World; general elections are not limited to the procedures and laws governing them, but it is a social, political and cultural process affected by general community framework and then the tribes' participation in the successive parliamentary elections according to its political culture and common tribal traditions (Michel, 2000:182).

Although the high illiteracy rate, some individuals participation in elections and their different forms are in favor of the tribe. The closer the candidate gets from his tribe and its interests, the greater the majority of its votes.

The tribes contribute to political mobilization for its members in order to participate in various elections; parliamentary and local without having the awareness of the so-called freedom of election and every citizen has the right to express his opinion and his selection to an appropriated person who represents him in parliament. The tribe canceled this right and a force the individuals adhere to the tribes' rules; to elect the person that seemed to be suitable for the head of the tribe.

\section{The Tribe and the Difficulty of Democratization in the Arab world:}

Most of Arab countries think that they are able to transition to democratic, or become closer to democracy and its effects, repercussions and entitlements. Unless they are taken into account that the majority of societies in Arab World believe with the tribe as the basic factor to manage the internal affairs.

So, is able to say that democracy as practical concept is a successful tool to manage the society at various levels. Or it is an easy way to apply among the Arab countries which stands as great shock to the realities of the historical structure of Arab societies at different geographical distribution, population structure.

When we say generally that the majority of the Arab countries experiences in dealing with democracy as a 
comprehensive and developed concept in the format of the modern human civilization are unsuccessful experiences. It carries injustice but majority of Arab countries do not reflect the political or social maturity to create suitable references needed for gradually preparing for democratization that achieves the qualitative balance and stability in circulation rule and authority (Abu Taleb, 2005).

The connection between the individual and his tribe dominates the other concepts in the matter of decisionmaking which affect individuals and societies life in the Arab World. Small family with its internal decision often was taken in non-democratic way.

Similar to the bigger family, extended family or the tribe followed by its clans that concluded to decisive decision made by the head of the tribe. Noted that women and youth are absent at decision making, as parliamentary elections that represent the people (Gabi, 1998).

From the standpoint of the decline and restrict freedom, the authority of the tribal or family thinking and partisan are limited to the loyalties purchase and constitute it in a manner consistent with the thinking of the President of the party central committee or organization.

It is not strange to see the countries of the Arab nation are living a state of tension in the democratic act. With the theoretical promotion of democracy, attractive slogans install failure daily in the arenas of political action, the mechanisms for building and functioning of civil society, this is reason enough to prevent the transition to a democratic, equitable system (Abu Taleb, 2005).

In majority of Arab notions, the tribe affects democratization referring to its political role; gathered some of the characteristics of the political party. The main aim is to reach to the authority and participate in decision making directly.

The tribes' heads practice many political tasks; such as: their participation in the successive governments and parliamentary councils, and take some leadership positions within political parties. This in itself stands as an obstacle in the process of democratic transition. The tribe system is walking within one route and in one direction without causing any change to the public interest (Abu Ghanem, 1999).

Most of the Arab notions based on the tribe at their societies would be in the end of democratization. This due to the tribe system based on the choice way of the party or organization head who is elected by recommendation

throughout his life becomes a perpetual symbol in the party or organization. In that, it prevents any renewal process, making it almost impossible to call in any process of change and aimed at evaluation or renewal. That makes the party head as a new parental authority (Al-Fateh, 2000).

Criticism or disobedience it considered as a crime in two parts; a moral nature relating to the leader and his parental authority and political party related to the leader as symbol of glory, criticism and disobedience him leads to affect the party unit and its position in the social and political setting.

In most of Arab countries, parliaments and their elections are conducted according to small or extended tribal planning. It often represents a family transition inherited by grandparents, parents and their children.

Many of the parliamentary titles and their government profiles are confined to the same tribal thread for decades. And this is contrary to the concept of democracy, which seeks to protect the freedoms and rights of citizens and seeks to expand the scope of freedoms in the expression of opinion. As a result, this creates a climate of stress among the people; either choose his tribe or choose his own independent character in the expression of his most basic rights (Massoud, 1999).

So we find out that the democracy finishes when the exercise of voting at the ballot box finishes. Before that, there is a situation of accumulated arrogance that between Arab communities and democratic transition a severe antipathy and wide distances as much as the size of lost democratic education and the equivalent of the patriarchal authority that revolves around the Arab peoples (Abu Saleh, 2006, p.121).

Arab parties have not taken a different tack from what has been practiced and is still largely in the tribal structure and its branches, which dominated all affecting sectors at the community politically, socially and economically.

Taking into account some Arab countries and societies never know the parties or its derivation. Only at the label and format level, we find in the Arab region that the political party regains its political breath and decides its considerations on the divisions and influences of the family and geographical areas not linked to the ability and efficiency in any form (Abu Ghanem, 1999.p.225). 
Political parties with their democratic and progressive titles, also civil society organizations with all of human rights slogans. All are developed in a formal but retained tribal practice whenever it comes to making a decision or making it. Whenever it comes to building policies and strategies at different levels.

The head of the party becomes the developed alternative for the tribe's head or the family's dean. Those who elect them from the upper party leaders are subject to the leadership of the leader. They are elected because he supports them or strengthens them or shows satisfaction with them. Their praise does not make an option for others to run for leadership positions. Democratic options are theoretically available but virtually non-existent. Permanent displacement of family tribal practice and its transfer to political practice and party building have resulted in political freedoms in the killing and negatively affect the individuals' freedoms and their ability to political participation except from the parties or non-governmental organizations perspective (Lavy, 2000, pp118-127).

In that, it doesn't grant an acceptable amount of freedom to its members or employees, thereby reducing the size of the individual creative contribution to interaction with democracy and its instruments (Michel, 2000):

- The emergence of a new phenomenon in Arab societies, especially Gulf by the use of the oil wealth to prevent the transition of Arab societies in the east and west of the Arab world from an authoritarian to a democratic organization.

- The goal of the tribal elders is no longer a material and moral gain for the tribe.

- Despite the efforts of many countries and governments in the Arab world loyalty of the individual to the state instead of the tribe, but the tribalism still has an undisclosed presence in the political arena to influence and pressure the decision maker.

- The most important impediments to democratic work in the Arab world are tribalism. This is the inability to fully integrate into the structure of the functional state, and thus ends its usefulness of forming political parties or institutions of civil society.

- Most regimes in the Arab world have contributed to the consolidation and deepening of bilateral loyalty between the state and the tribal group through political employment and reliance on it.

\section{Conclusion:}

In the summary of the discussion on the subject of the research, the tribe and the difficulty of transition to the democratic system, I believe that democracy is a political system cannot be achieved without work, whatever the nature of the culture of societies and their share of modernity and tradition, and that this work cannot be successful and productive without the foundations of the mentality of a sound and consistent. This is the beginning of the road.

In another meaning; the democratic transition depends on the success of the responsibility on the shoulders of the peoples and leaders in the future phase out of the current reality, it is tribal system which is an obstacle to building a new reality in which the values of democracy are open to open the door to the desired justice in the Arab world as is the difference in the price paid by the masses in their revolutions with different types of regimes, the difference will be the great challenges to building democracy in these countries.

Firstly, they need to build up democratic system based on Constitution and democratic institutions; it is based on advanced theory in order to be an attraction and push forward for democratic processes to move towards development and over time with their performance.

According to the above, the study reached a number of conclusions and recommendations as follows:

\subsection{The conclusions:}

- The study revealed the emergence of a new phenomenon related to the use of petroleum residue to distort, complicate and disperse and prevent the movement of Arab societies in the east and west of the Arab world from the restricted situation to the democratic situation.

- The study shows that a large segment of Arab tribal sheikhs' no longer aim to achieve material moral gain for the tribe, their interest became how to work within and gain from the state. 
- The study showed that despite the efforts of the state and the government in the Arab world to transform the loyalty of the individual to the state rather than tribalism, the tribe still has an inadequate presence in the political arena to influence and pressure the decision maker.

- The study shows that the most important obstacles to democratic work in the Arab world are tribalism. This is the inability to fully integrate into the structure of the national state, thus eliminating any desired benefit from the formation of political parties or institutions of civil society.

- The study revealed that most of the political systems in the Arab world have contributed to the consolidation and deepening of bilateral loyalty between the state and the tribal group through political employment, and benefit from this component in times of need and reliance on it most of the time.

\subsection{The recommendations:}

- The study recommends that the civil state should fight the tribal culture, which is surrounded by religious and religious beliefs, according to the agenda of this culture because it intersects completely with the civil state and modernity.

- The study recommends that religion and tribalism should not be combined to fill the political vacuum, as happened in Algeria, Iraq, Sudan, Libya and Somalia.

- The study recommends that it is necessary to integrate the tribe fully into society by spreading the culture of education and political participation.

- The study recommends that it is necessary for the state to gain the allegiance of the tribesmen through the rule of law, which guarantees freedom, justice, integrity, transparency and equality of opportunity for all without distinction.

\section{References:}

Abu Ghanem, Fadel. (1999). Tribal and State in Yemen, Cairo, Dar Al- Manar, first edition.

Abu Saleh, Thaer. (2006). Democracy and its main obstacles in the Arab world, Arab Institute for Studies and Publications, Beirut, Lebanon.

Abu Taleb, Mohammed Najib. (2005). Political Dimensions of the Tribal Phenomenon in Arab Societies, Arab Institution for Studies and Publications, Beirut, Lebanon.

Addi, Hoary. (1998). Democratic: pouvoir et crise polities dams contemporariness. Paris: editions La decouverte. Ali Ahmed Issa. (1999). Arab Society and Democracy, Cairo, Dar Al Ma'arif, Egypt.

Al-Fateh, Congratulations (2002). Society and State in Arab Countries, Beirut, Center for Arab Unity Studies, Lebanon.

Anis, Kassem. (2000). Arab Political System and Democracy, Arab Institute for Studies and Publications, Beirut, Lebanon.

Badr al-Din, Ikram. (1998). The Concept of Democracy and Liberalism in Ali Eddin Hilal (ed.), Democratic Development in Egypt, Issues and Discussions, Cairo, Nahdet Al Sharq Library, Egypt.

Dahir, Massoud. (1999). Contemporary Arab Orient from Bedouin to Modern State, Institute of Arab Belief, Beirut, Lebanon.

Gabi, Abdel Nasser. (1998). Elections State and Society, Algeria, Dar Al Kasbah Publishing.

Hilal. Ali al-Din, and Massad Nevin. (2002). Arab Political Systems, Issues of Continuity and Change, II, Beirut, Center for Arab Unity Studies.

Lavy, Diamond, (2000). Democracy in developing countries, Rienner publishers, Inc, Boulder, Colorado, public policy.

Michel, Grozier (2000). L”Acteur Et Le systeme, Paris, editions du seui, I.

Samuel p. Huntington, (1993). The third wave, democratization in the late twentieth century, (London: university of Oklahoma press. 